\title{
CRYOPRECIPITATE TRANSFUSION: ASSESSING APPROPRIATENESS AND DOSING IN TRAUMA
}

by

\author{
Bartolomeu Nascimento Jr.
}

A thesis submitted in conformity with the requirements for the degree of Master of Science

Institute of Medical Sciences

University of Toronto

(C) Copyright by Bartolomeu Nascimento Jr. 2012 


\title{
Cryoprecipitate Transfusion: Assessing Appropriateness and Dosing in Trauma
}

\author{
Bartolomeu Nascimento Jr. \\ Master of Science \\ Institute of Medical Sciences \\ University of Toronto
}

2012

\section{Abstract}

Cryoprecipitate is commonly used outside guidelines. In trauma, the appropriate cryoprecipitate dose and its impact on plasma fibrinogen levels are unclear.

This retrospective study aims to evaluate: (1) the appropriateness of cryoprecipitate transfusion in trauma; and (2) the plasma fibrinogen response to cryoprecipitate transfusion during massive transfusion in trauma.

Fibrinogen levels of $<1.0 \mathrm{~g} / \mathrm{L}$ within 2 and 6 hours of cryoprecipitate transfusion were used for assessing appropriateness. Out of 394 events, 238 (60\%) and 259 (66\%) were considered appropriate using 2 and 6 hour criteria, respectively. A dose of $8.7( \pm 1.7)$ units caused a mean increase in fibrinogen levels of $0.55( \pm 0.24) \mathrm{g} / \mathrm{L}$, or $0.06 \mathrm{~g} / \mathrm{L}$ per unit.

In our hospital, where transfusion guidelines and policies for rapid blood product and laboratory turnaround times exist, it is possible to achieve high rates of appropriateness for cryoprecipitate transfusion in trauma. The current recommended dose causes a modest increase in fibrinogen levels. 


\section{Acknowledgments}

This thesis is dedicated to my son Victor Nascimento; my infinite source of motivation to overcome challenges and endure hardship in life.

I would like to express my gratitude to my supervisors Dr. Sandro Rizoli and Dr. Jeannie Callum for the crucial support and guidance. I would also like to extend my thanks to the members of my thesis committee Dr. Gordon Rubenfeld, Dr. Najma Ahmed, Dr. Avery Nathens, Dr. Jamie Hutchison, Dr. Dietmar Fries and Dr. John Marshall.

I acknowledge Dr. Roberto Fukushima, Melissa Lio, Parminder Hans and Eric Rizoli for the excellent help with data collection and entry. I also thank Elena Brnjac (senior technologist) for the Hemostasis laboratory support; Cyndy Rogers and Connie Colavecchia for their contribution in providing trauma registry and blood bank data. 


\section{Table of Contents}

Page

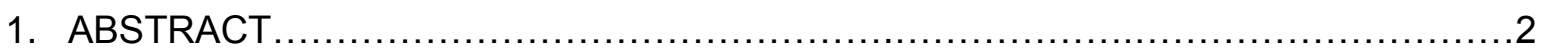

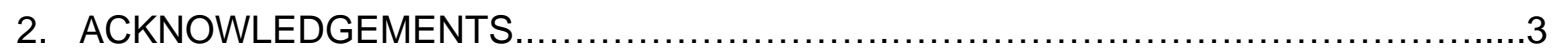

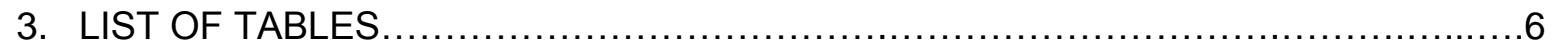

4. LIST OF FIGURES $\ldots \ldots \ldots \ldots \ldots \ldots \ldots \ldots \ldots \ldots \ldots \ldots \ldots \ldots \ldots \ldots \ldots \ldots \ldots \ldots \ldots \ldots \ldots \ldots . .8$

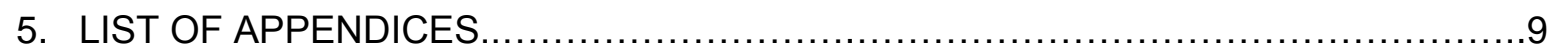

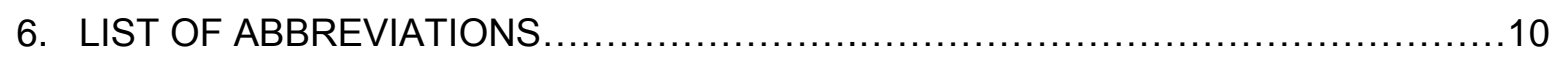

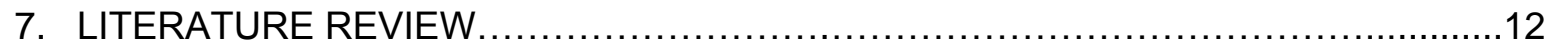

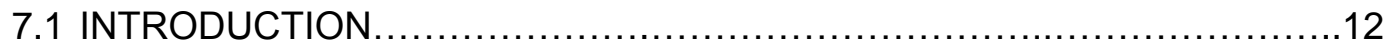

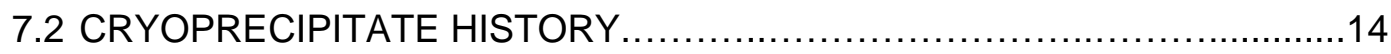

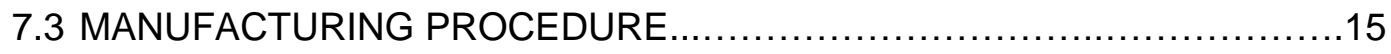

7.4 CRYOPRECITATE CONTENT AND PHYSIOLOGY.......................17

7.5 PRE-TRANSFUSION COMPATIBILITY TESTING $\ldots \ldots \ldots \ldots \ldots \ldots \ldots \ldots \ldots . \ldots \ldots$

7.6 PRE-TRANSFUSION PREPARATION...................................24

7.7 STANDARDS FOR THE USE OF CRYOPRECIPIATE $\ldots \ldots \ldots \ldots \ldots \ldots \ldots \ldots . \ldots \ldots$

7.8 CLINICAL GUIDELINES FOR CRYOPRECIPITATE USE..................26

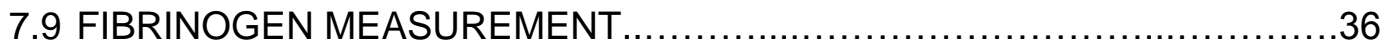

7.10DOSAGE RECOMMENDATIONS FOR CRYOPRECIPITATE

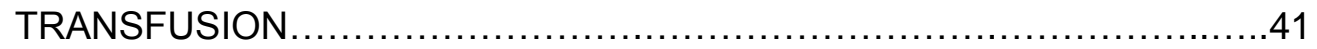

7.11THE TRAUMA-ASSOCIATED COAGULOPATHY ........................43

7.12THE ROLE OF FIBRINOGEN IN TRAUMA-ASSOCIATED

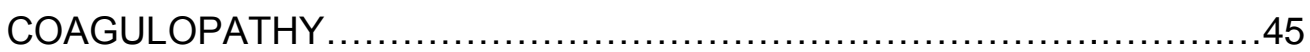

7.13 APPROPRIATENESS OF USE OF CRYOPRECIPITATE IN

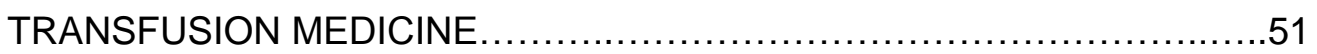

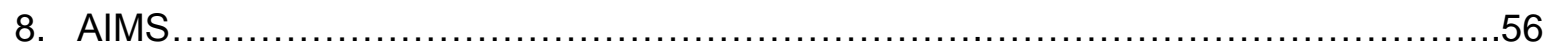




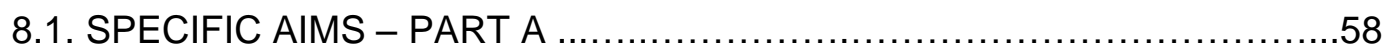

8.2. SPECIFIC AIMS - PART B............................................ 58

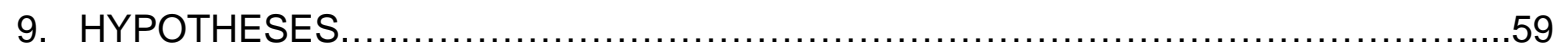

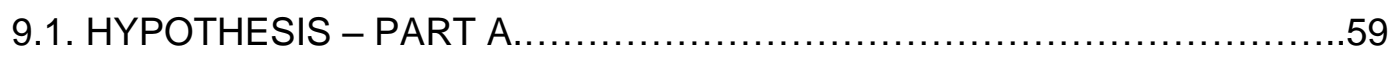

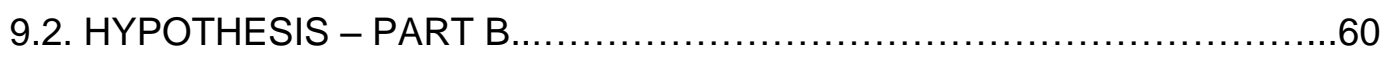

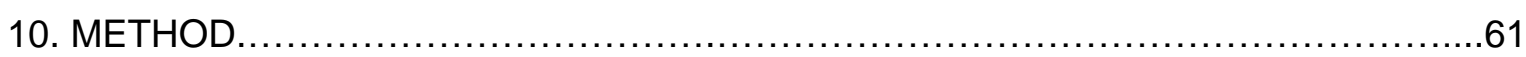

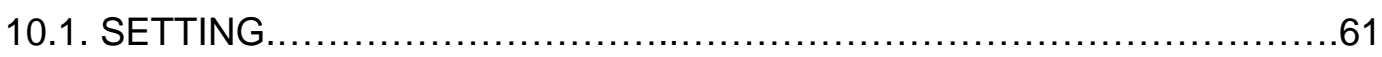

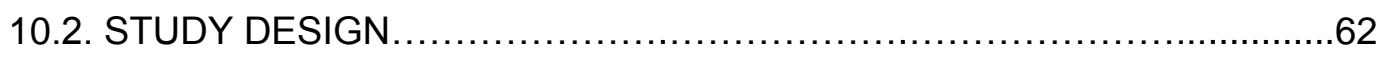

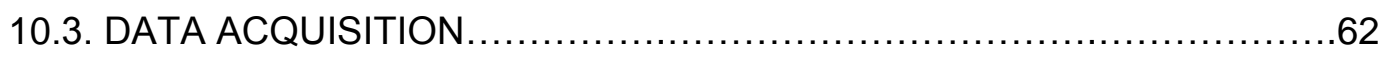

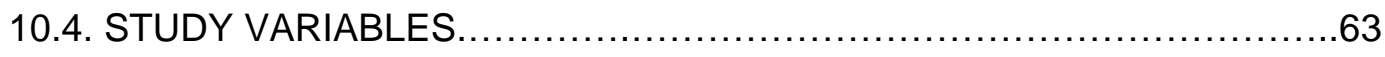

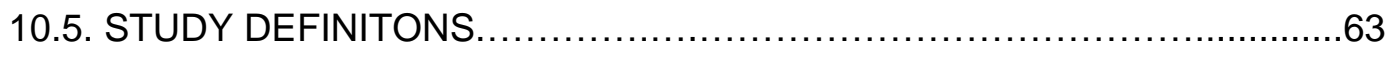

10.6. SUNNYBROOK HOSPITAL TRANSFUSION PROTOCOL.......................65

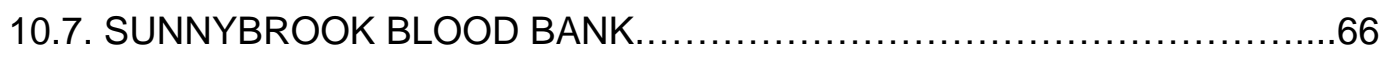

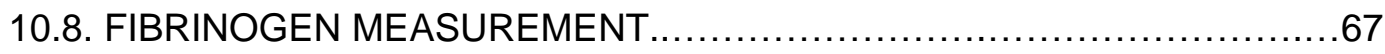

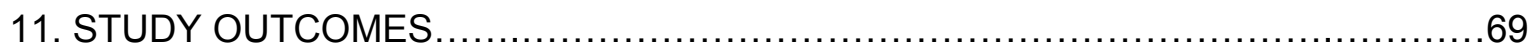

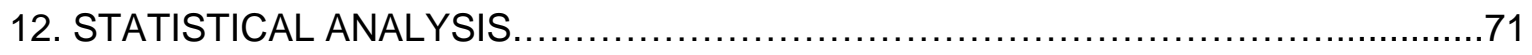

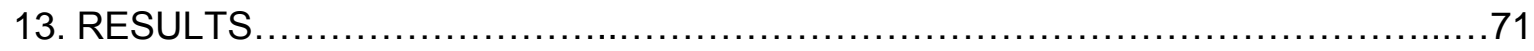

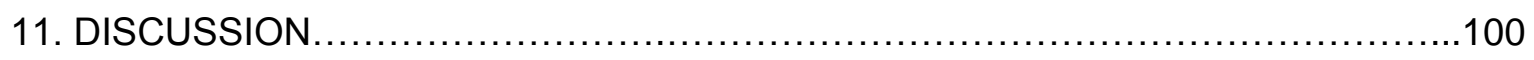

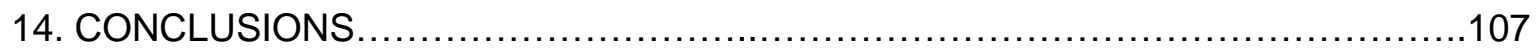

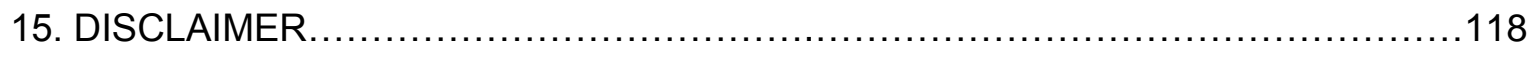

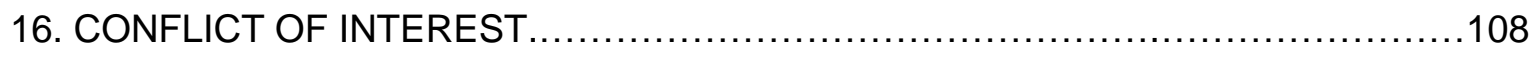

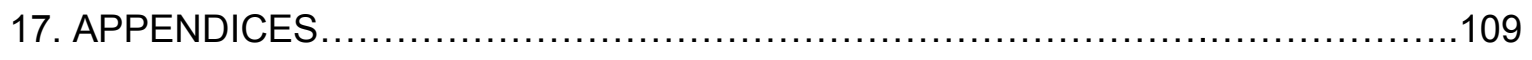

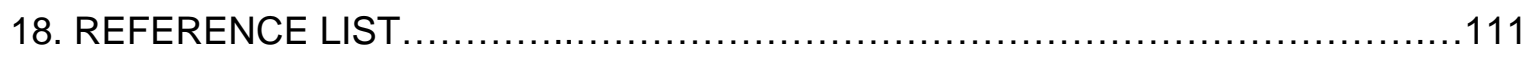




\section{List of Tables}

Page

Table 1. Dosage Recommendations for Cryoprecipitate Transfusion.

Table 2. The Abbreviated Injury Scale Rating System....

Table 3. Cryoprecipitate Transfusion at Sunnybrook (1998-2008).

Table 4. Dose of Cryoprecipitate at Sunnybrook Hospital (1998 - 2008)

Table 5. Comparison of Baseline Characteristics for Patients with Appropriate and Outside Guidelines Cryoprecipitate Transfusion Events in Trauma Patients.

Table 6. Comparison of Transfusion Data for Patients with Appropriate and Outside Guidelines Cryoprecipitate Transfusion Events.

Table 7. Subgroup Comparison of Demographics and Baseline Characteristics for Patients with Appropriate and Outside guidelines (without Fibrinogen Levels) Cryoprecipitate Transfusion Events.

Table 8. Subgroup Comparison of Transfusion Data for Patients with Appropriate and Outside guidelines (without Fibrinogen Levels) Cryoprecipitate Transfusion Events

Table 9. Subgroup Comparison of Demographics and Baseline Characteristics for 2001 (year) patients and non-2001 patients with Outside Guidelines Cryoprecipitate Transfusion Events.

Table 10. Subgroup Comparison of Transfusion Data for 2001 (year) patients and non-2001 patients with Outside Guidelines Cryoprecipitate Transfusion Events

Table 11. Subgroup Comparison of Demographics and Baseline Characteristics for CRYO events with and without fibrinogen measured within $1 \mathrm{hr}$ before Cryoprecipitate transfusion.

Table 12. Subgroup Comparison of Transfusion Data for CRYO events with and without fibrinogen measured within $1 \mathrm{hr}$ before Cryoprecipitate transfusion...... 


\section{List of Tables, cont.}

Table 13. Plasma Fibrinogen Response to Cryoprecipitate Transfusion during Massive Transfusion in Trauma.

Table 14. Plasma Fibrinogen Response to Cryoprecipitate Transfusion for Events with Fibrinogen $<1.0 \mathrm{~g} / \mathrm{L}$ before Administration of Cryoprecipitate during Massive Transfusion in

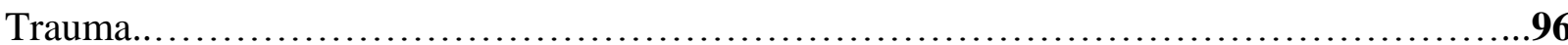

Table 15. Plasma Fibrinogen Response to Cryoprecipitate Transfusion for Events with Fibrinogen $\geq 1.0 \mathrm{~g} / \mathrm{L}$ before Administration of Cryoprecipitate during Massive Transfusion in

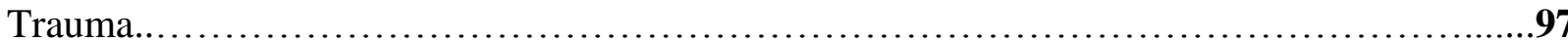

Table 16. Subgroup Comparison of Demographics and Baseline Characteristics for patients with fibrinogen $<1.0 \mathrm{~g} / \mathrm{L}$ and with fibrinogen $\geq 1.0 \mathrm{~g} / \mathrm{L}$ within $1 \mathrm{hr}$ before Cryoprecipitate

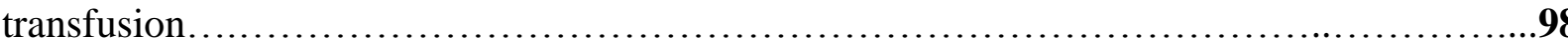

Table 17. Subgroup Comparison of Transfusion Data for patients with fibrinogen $<1.0 \mathrm{~g} / \mathrm{L}$ and with fibrinogen $\geq 1.0 \mathrm{~g} / \mathrm{L}$ within $1 \mathrm{hr}$ before Cryoprecipitate transfusion. 


\section{List of Figures}

Figure 1. Fibrinogen Cleavage by Thrombin and Formation of Fibrin....

Figure 2. Study Flow Diagram - Part A

Figure 3. Cryoprecipitate Use according to Clinical Settings over Study Period....

Figure 4. Number of Cryoprecipitate Transfusion Events and Patients Receiving Cryoprecipitate in Cardio-vascular Surgery over Study Period.

Figure 5. Number of Cryoprecipitate Transfusion Events and Patients Receiving Cryoprecipitate in Trauma over Study Period..........................................78

Figure 6. Study Flow Diagram - Part B...............................................

Figure 7. Sunnybrook Rates of Appropriateness for Cryoprecipitate Transfusions in Trauma Using Strict and Lenient Criteria...

Figure 8. Hourly Rates of Fibrinogen Measurement before and after Cryoprecipitate Transfusion

Figure 9. Hourly Fibrinogen Measurements and Fibrinogen Levels $<1.0 \mathrm{~g} / \mathrm{L}$ within 6 hours before Cryoprecipitate Transfusion for 394 Transfusion Events in Trauma

Figure 10. Hourly Fibrinogen Measurements and Fibrinogen Levels $\leq 1.5 \mathrm{~g} / \mathrm{L}$ within 6 hours after Cryoprecipitate Transfusion for 394 Transfusion Events in Trauma

Figure 11. Appropriate Cryoprecipitate Transfusions in Trauma over Study Period 


\section{List of Appendices}

Pages

Appendix 1. Sunnybrook Massive Transfusion Guidelines............................109

Appendix 2. Handling and Processing of Coagulation Specimens at Sunnybrook Campus

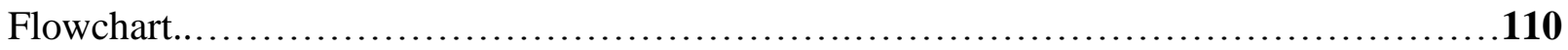




\section{List of Abbreviations}

CRYO, cryoprecipitate

vWD, von Willebrand's disease

UK, United of Kingdom

US, United States

HIV, human immunodeficiency virus

HBV, human B hepatitis virus

HCV, human C hepatitis virus

FFP, fresh frozen plasma

FP, frozen plasma

ADP, adenosine diphosphate

$\mathbf{T x} \mathbf{A}_{2}$, thromboxane $\mathrm{A}_{2}$

ESR, erythrocyte sedimentation rate

SHSC, Sunnybrook Health Sciences Centre

DDAVP, desmopressin

DIC, disseminated intravascular coagulation

PPV, positive predictive value

RBC, red blood cells

AAGBI, Association of Anaesthetists of Great Britain and Ireland

FDP, fibrin degradation products

PT, prothrombin time

RID, radial immunodifusion

ELISA, enzyme-linked immunoaborbent 


\section{List of Abbreviations, cont.}

TBI, traumatic brain injury

DCR, damage control surgery

HES, hydroxyethyl starch

PAI-1, plasminogen activator inhibitor - type 1

TRALI, transfusion-related acute lung injury

TACO, transfusion-associated circulatory overload

TEG, thromboelastography

ROTEM, rotational thromboelastometry

INR, international normalized index

PTT, partial thromboplastin time

ISS, injury severity score

AIS, abbreviated injury scale 


\section{Cryoprecipitate Transfusion: Assessing Appropriateness and Dosing in Trauma}

\section{Literature Review}

\subsection{Introduction}

The indications for cryoprecipitate (CRYO) use have changed considerably since its development many decades ago. Pool's cryoprecipitate was originally developed to provide factor VIII for patients with Congenital Factor VIII Deficiency in the mid-1960's (Pool, 1964; Pool et al., 1965). The use was subsequently expanded to the treatment of patients with von Willebrand's disease (vWD) and hypofibrinogenemia with some benefit (Bennet \& Dormandy, 1966). Nowadays, the most common indication of the product is for the replacement of low serum fibrinogen levels in patients with acquired hypofibrinogenemia and hemorrhage (O’Shaughnessy et al., 2004). However, the fibrinogen content of a unit of CRYO may vary widely (range, 120 - 796mg) (Callum et al., 2009), with each unit containing $30-50 \%$ of the original fibrinogen in the source plasma (Klein \& Anstee, 2005). Factor VIII and von Willebrand factor correspond to approximately $5 \%$ of the total pool of proteins in this concentrate (Allain, 1984). Other components of CRYO include fibronectin, factor XIII, immunoglobulins (IgG and IgM), albumin and platelet microparticles (Callum et al., 2009). In some European countries, the use of CRYO solely for fibrinogen replacement has been recently challenged and increasingly substituted by the use of virally inactivated fibrinogen concentrate, which has a more standardized concentration of fibrinogen and safer profile (decreased risk of pathogen transmission and immune-mediated complications) (Fenger-Eriksen et al., 2008; Bundesaertzekammer, 2009; Sorensen \& Bevan, 2010). Fibrinogen concentrate is currently 
licensed for use in congenital bleeding throughout Europe, USA, China and Japan, and for use in acquired bleeding in over 15 countries globally.

Major guidelines on blood component therapy in the United Kingdom (UK), United States (US) and Canada, where fibrinogen concentrates are not available, suggest transfusion of CRYO when plasma fibrinogen level is $<1.0 \mathrm{~g} / \mathrm{L}$ in the context of bleeding and/or disseminated intravascular coagulation (American Society of Anesthesiologists, 1996; O’Shaughnessy et al., 2004; Droubatchevskaia et al., 2007; Levi et al., 2009). Typically, an adult dose of 8 - 12 units (one unit per 5 - $10 \mathrm{~kg}$ of body weight) is administered (Canadian Blood Services, 2006; Ketchum et al., 2006).These recommendations are extrapolated from limited scientific evidence. In 1987, Ciavarella et al. reviewed 36 massively transfused patients and observed that microvascular bleeding occurred in all 4 patients whose fibrinogen levels were below 0.5 $\mathrm{g} / \mathrm{L}$ and only occurred in 2 out of 10 patients with fibrinogen levels $0.5-1.0 \mathrm{~g} / \mathrm{L}$ of whom both were severely thrombocytopenic (Ciavarella et al., 1987). The authors suggested a threshold of $1.0 \mathrm{~g} / \mathrm{L}$ as a trigger for CRYO transfusion. Lately, this "historical” $1.0 \mathrm{~g} / \mathrm{L}$ threshold was considered inadequate, being associated with excessive blood loss during cardiac surgery and severe postpartum bleeding (Charbit et al., 2007; Karlsson et al., 2008). In trauma, a recently formed European multidisciplinary Task Force for Advanced Bleeding Care in Trauma (Rossaint et al., 2010), recognizing the pivotal role of fibrinogen in the trauma-induced coagulopathy, recommends the replacement of fibrinogen (using fibrinogen concentrate or CRYO) for plasma fibrinogen level of less than 1.5 - $2.0 \mathrm{~g} / \mathrm{L}$ (Rossaint et al., 2010). This guideline also suggests increased doses of CRYO (15 -20 units in a $70 \mathrm{Kg}$ adult). However, the impact of CRYO transfusion on plasma fibrinogen levels, particularly in the context of major blood loss, is unclear and mostly based on limited evidence (Faringer et al., 1993) and expert opinion (Callum et al., 2009). Furthermore, the risk of bleeding when fibrinogen level is $<1.0$ $\mathrm{g} / \mathrm{L}$ in trauma patients is unclear (Callum et al., 2009). Durante the acute resuscitation of a 
trauma patient, fibrinogen is most commonly replaced by plasma transfusion. The content of a standard dose of CRYO is equivalent to the amount of fibrinogen found in an average adult dose of FFP (4 units), where each unit of FFP contains $0.5 \mathrm{~g}$ of fibrinogen (Callum et al., 2011; Nascimento et al., 2010). There is little published literature in trauma patients to guide when CRYO is required and what the effective dose may be.

Notwithstanding the lack of randomized control trials demonstrating its efficacy, CRYO is largely used for the management of acquired hypofibrinogenemia following hemorrhage. Rates of CRYO transfusion in the UK and Canada have been estimated to be 1.7 and 1.5 units per 1000 people annually, respectively (Callum et al., 2009). A recent Canadian audit observed that the commonest indication for CRYO transfusion was for the treatment of bleeding after cardiac, noncardiac surgery and trauma (Alport et al., 2008). Despite this widespread practice, previous audits have documented a wide variation in clinical practice, with rates of inappropriateness, as defined by expert opinion, ranging from 24 to 62\% (Schofield et al., 2003; Pantanowitz et al., 2003; Alport et al., 2008).

This study reviews the practice of CRYO transfusion at large academic hospital during a period of 10 years, with the aim to assess the appropriateness of and the plasma fibrinogen response to CRYO transfusion in trauma patients. This review will provide further information to assist in determining the appropriate dose for the use of CRYO in the context of major blood loss.

\subsection{Cryoprecipitate History}

The first description of CRYO preparation dates back in 1964. In that year, Judith Graham Pool (1919-1975), working at Stanford University, prepared the first unit of CRYO (Pool et al., 1964; Pool \& Hink, 1964). The method described the thawing of frozen plasma 
over a period of 18 to 24 hours to temperatures of $4^{\circ} \mathrm{C}-0^{\circ} \mathrm{C}$. This was followed by a centrifugation step when the product was placed in a refrigerated centrifuge set at $2{ }^{\circ} \mathrm{C}$ and at 2,000 x $g$ for twenty minutes (Pool, 1965). Then, gravity drainage was used to remove the supernatant plasma (named “exhausted” plasma), leaving only 10-15 mL of plasma in the preparation. Finally, the product underwent a re-freezing process to temperatures around $20^{\circ} \mathrm{C}$.

The first reported clinical use of the product happened one year after the development of the product. In October of 1966, three patients with vWD were reported to have successfully received CRYO (Bennett \& Dormandy, 1966). In the same year, Bennett and Dormandy reported on the successful use of “exhausted” plasma for a patient with factor XI deficiency (Bennett \& Dormandy, 1966). Subsequently to the first positive experiences with the product, in January of 1967, Barrett and colleagues reported on the successful use of cryoprecipitate for hemophilia in 7 patients (Barrett et al., 1967). CRYO thus gained popularity for the management of hemophilia. The product had great impact on the quality of life of patients with hemophilia. However, some significant risks of infectious disease transmission were associated with the introduction of this pooled blood product and many recipients of CRYO transfusion were exposed to Human immunodeficiency virus (HIV), hepatitis B virus (HBV), and hepatitis $\mathrm{C}$ virus (HCV).

\subsection{Manufacturing Procedure}

The process of manufacturing CRYO remains essentially unchanged since its original description many decades ago (Pool et al., 1964) and only minor variations may be encountered in different jurisdictions. CRYO can be considered a sub-product of fresh frozen plasma (FFP) or frozen plasma (FP). The latter two blood components differ only with respect to the time to 
freezing after collection and consequently to the content of clotting factors recovered in each unit. While FFP is frozen within 8 hours from collection, the time from drawing to freezing in FP can reach up to 24 hours (Callum \& Pinkerton, 2005). Due to the longer time to freezing, FP contains 15-20\% lower factor VIII levels than FFP (O'Neill et al., 1999; Smith et al., 2000)

FP or FFP is thawed at 1 to $6^{\circ} \mathrm{C}$ for the preparation of CRYO (Brecher, 2005). After thawing, the product is centrifuged at 5,000 $\mathrm{x} g$ for about 6 minutes and then the supernatant is removed. The original bag is left with only 5-15 mL of plasma and the cold insoluble precipitate. This residual material, the cryoprecipitate, is re-frozen within one hour of thawing and stored at $-18^{\circ} \mathrm{C}$ or colder. Under ideal storage conditions, the final product has a shelf-life of 12 months.

It has been estimated that each unit of CRYO contains approximately 100-250 mg of fibrinogen (Poon, 1993). However, recent fibrinogen testing reveals concentrations of fibrinogen in current preparations of cryoprecipitate higher than previously reported, with a median value of 388 mg per bag (range 120-796 mg) (Robert Romans. Canadian Blood Services. Personal communication). The American Association of Blood Banks standards for fibrinogen content in CRYO, requires a minimum of 150 mg per bag (American Association for Blood Banks Standards for Blood Bank and Transfusion Services, 2008). Each unit contains $30-50 \%$ of the original fibrinogen in the source plasma (Klein \& Anstee, 2005).

In the final CRYO preparation, factor VIII and von Willebrand factor represents only $5 \%$ of its total protein content, which corresponds to about $40-70 \%$ of the original factor VIII/vWF that was present in the original plasma (Allain, 1984). The in vivo recovery of factor VIII can be improved by a series of measures during the manufacturing process: continuous mixing of blood during collection; minimizing the time from donation of plasma to freezing; rapid re-freezing of CRYO on dry-ice; and limiting the duration of CRYO storage 
(Kasper et al., 1975). Higher donor baseline levels of factor VIII are also associated with improved in vivo recovery (Kasper et al., 1975). Despite increased levels of factor VIII in exercised donors, this recommendation failed to translate into superior post-infusion in vivo recovery of factor VIII due to the rapid clearance of the "exercise” factor VIII (van Gastel et al., 1973).

CRYO is considered a potential rich source of fibronectin, which represents $20-25 \%$ of the total protein in the product (Allain, 1984; Reilly et al., 1983). It also contains several other proteins as follow: albumin (5-8\%), IgG (5-8\%), IgM (1-2\%) (Allain, 1984).

\subsection{Cryoprecipitate Content \& Physiology}

\section{Fibrinogen}

Fibrinogen is a major soluble plasma glycoprotein of 340,000-Da containing three pairs of protein chains that are interconnected by disulfide bonds (Hantgan et al., 2006). Its concentration in the plasma, when measured as a clottable protein varies from $1.5-4.5 \mathrm{~g} / \mathrm{L}$. This glycoprotein is synthesized by the hepatocytes and has a long half-life in the plasma of approximately 4 days (Kreuz et al., 2005). Due to the fibrinogen's diffusion phase half-life of 12 hours, it is recommended that CRYO infusions be administered every 12 hours for patients with congenital fibrinogen deficiency where fibrinogen concentrates are not available. As oppose to the reduced factor VIII recovery, fibrinogen activity remains stable with $87 \%$ of the original content at time of thawing of fibrinogen recovered at 24 hours of liquid storage (Saxena et al., 1990).

Fibrinogen plays a critical role in hemostasis and thrombosis. It is the precursor of fibrin and promotes platelet aggregation (Hantgan et al., 2006). Thrombin cleaves the polypeptide chains $(\mathrm{A} \alpha$ and $\mathrm{B} \beta$ ) of the fibrinogen molecule, releasing fibrinopeptides $\mathrm{A}$ and $\mathrm{B}$ 
from the amino-terminal ends (Fig 1). The cleavage of fibrinogen results in the formation of fibrin monomers, which subsequently undergo polymerization to form an insoluble fibrin clot (Fig 1). The formation of fibrin is regulated by the endogenous fibrinolytic system (Hantgan et al., 2006). Fibrin is lysed by the activity of plasmin and then fibrin degradation products are formed (Fig 1). Besides being a substrate for fibrin formation, fibrinogen works on platelet aggregation by linking activated platelets (Colman et al., 2006). Activated platelets express on their surface the glycoprotein receptor GP IIb/IIIa, which binds fibrinogen (either plasma fibrinogen or fibrinogen that is secreted from intraplatelet granules following platelet activation) and link platelets together. 
Fig 1. Fibrinogen Cleavage by Thrombin and Formation of Fibrin

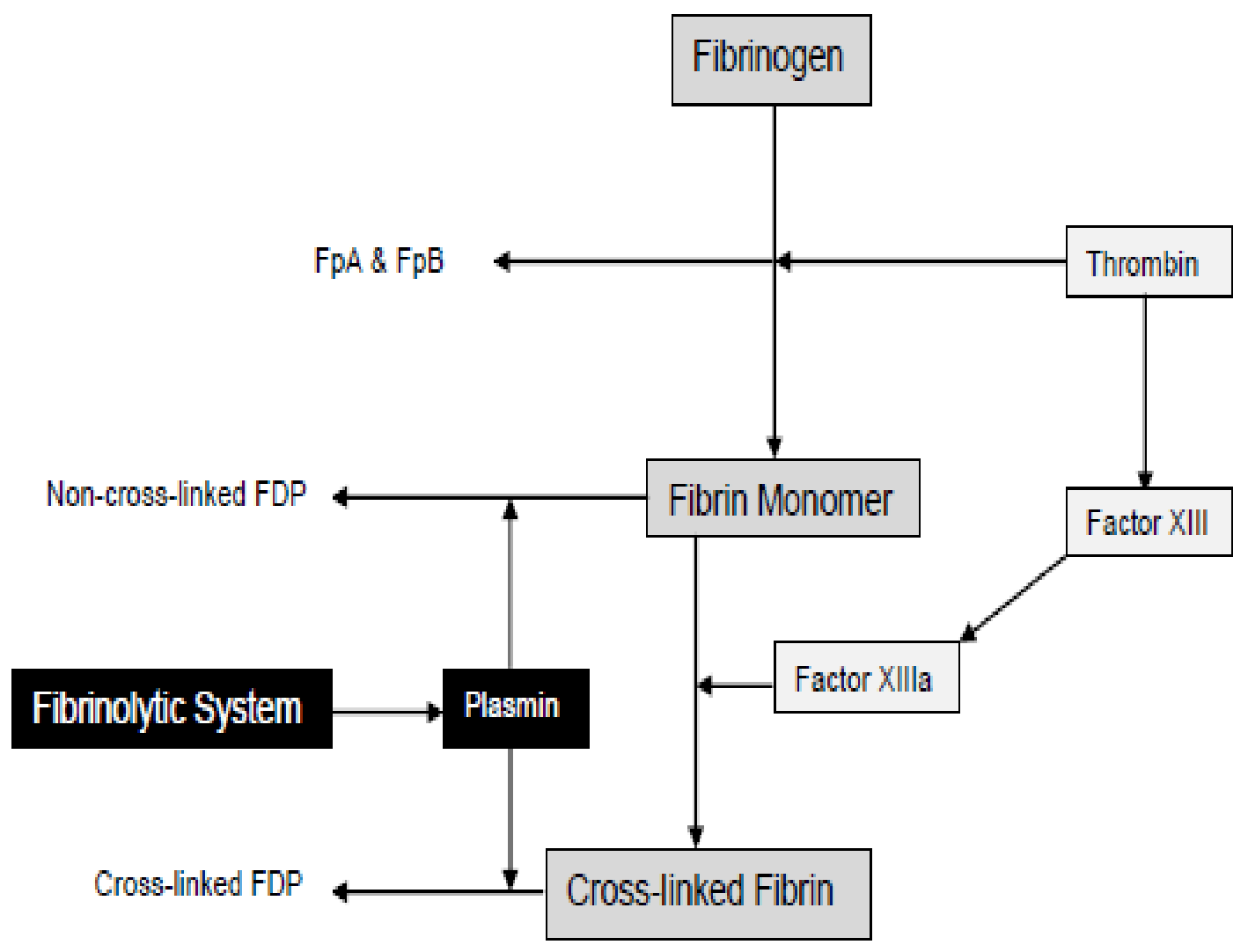

FpA, Fibrinopeptide A; FpB, Fibrinopeptide B; FDP, fibrin degradation products. 
Hemostasis is a physiologic mechanism where a well-balanced and complex response to bleeding is expected. Shortly, blood vessel wall, platelets, coagulation and fibrinolysis interact in order to stop bleeding while preserving vessel patency. Circulating platelets are activated by thrombin and subendothelial collagen after vessel wall injury. Once activated, platelets, in a positive feed-back, produce and secrete other stimulants of platelet aggregation, such as adenosine diphosphate (ADP), thromboxane $\mathrm{A}_{2}\left(\mathrm{TxA}_{2}\right)$ and serotonin. In the initial step to secure hemostasis (primary hemostasis), platelets adhere (platelet adhesion) to injured vessel walls and to other platelets (platelet aggregation), forming a plug at the site of bleeding (Colman et al., 2006). Fibrinogen and von Willebrand Factor can bind to exposed membrane glycoproteins IIb and IIIa on activated platelets, acting as a ligant between platelets for primary hemostasis (Colman et al., 2006). The initial platelet-rich plug is considered friable and is stabilized by the secondary hemostasis process, which is characterized by a subsequent formation of fibrin. Finally, the activity of endogenous fibrinolytic enzymes such as plasmin and neutrophil elastase, associated with other processes of tissue repair, is responsible for the digestion of the fibrin plug over a period of several days (Colman et al., 2006).

Fibrinogen is also a positive acute-phase reactant protein, which is elevated in response to a variety of acute clinical conditions, including injury (Lowe et al., 2004). Normally, plasma fibrinogen is synthesized in the liver, with a steady-state rate of $1.7-5.0$ g per day. However, in patients with peripheral consumption of fibrinogen, the production rates of fibrinogen can reach up to 20-fold increase from baseline rates (Colman et al., 2006). Its elevation in acute phase response might affect plasma viscosity and the erythrocyte sedimentation rate (ESR) (Lowe, 1987). Fibrinogen, plasma viscosity and ESR have been shown to be independent predictors of coronary heart disease events (Danesh et al., 1998; Lowe \& Rumley, 1999; Danesh et al., 2000). 


\section{Factor VIII and von Willebrand factor (vWF)}

Factor VIII is present in plasma mostly as a noncovalent complex with vWF and its coagulation role is to hasten factor IXa conversion of factor X to Xa. vWF has important participation in primary hemostasis. It promotes the adhesion of platelets to exposed subendothelium and also stabilizes coagulation factor VIII in the plasma. Factor VIII and vWF correspond to approximately 5\% of the total protein in CRYO (Allain, 1984). The final CRYO preparation retains $40 \%-70 \%$ of the original VIII/vWF that was present in the original plasma (Allain, 1984).

\section{Factor XIII}

Factor XIII is present in the blood as a tetramer composed of 2 A subunits (enzymatic portion) and 2 B subunits (carrier portion). When activated, Factor XIII loses its 2 B carrier proteins (Board et al., 1993). It plays a pivotal role in promoting clot stability. Factor XIII improves the mechanical strength of the fibrin clot and protect it from proteolytic degradation by forming covalent bonds between fibrin monomers and by cross-linking alpha-2 antiplasmin, fibrinogen, fibronectin, collagen, and other proteins (Lovejoy et al., 2006). Approximately 2030\% of factor XIII in the original plasma remains in CRYO (Klein \& Anstee, 2005).

\section{Fibronectin}

Fibronectin is a high molecular weight (440-530 kD) adhesive glycoprotein, which contains two almost identical subunits disulfide-bridged close to their C-terminal ends (Mitrovic S et al., 1995). It is present as a soluble glycoprotein in plasma and as an insoluble protein in the extracellular matrix of many tissues (Lucena et al., 2007). In human plasma, it is present at a concentration of $300 \mathrm{ug} / \mathrm{mL}$ (Mosher, 1984) and is involved in mechanisms of immune defense, immune surveillance and hemostasis. Among many biological roles, fibronectin is believed to have opsonic activity, which assists with the phagocytosis of 
particulate debris by the reticuloendothelial system (Saba \& Jaffe, 1980). CRYO is an important source of fibrionectin, containing approximately $1500 \mathrm{ug} / \mathrm{mL}$ (Reilly et al., 1983). Human derived factor VIII concentrates (excluding the high purity preparations), which are considered rich potential sources of fibronectin; contain 2100-3600 ug/mL (Reilly et al., 1983).

\section{Platelet Microparticles}

Microparticles can be defined as phospolipid microvesicles with size that usually range from less than $100 \mathrm{~nm}$ derived from blood cells, platelets, endothelial cells, and several other types of cells (Horstman \& Ahn, 1999; Freyssinet, 2003; Simak \& Gelderman, 2006) . These microvesicles contain certain receptors and other proteins innate of their parental cells. The identification of cell-specific antigens allows inferences about their origin. Microparticles are present in circulating blood and in plasma and cellular blood products; and possess a wide spectrum of biological activities. They may facilitate the interactions between cells, promote cell signaling and transfer of functional receptors between different types of cells (Mack et al., 2000; Simak \& Gelderman, 2006). It has been suggested that microparticles can play active roles in various tissue defense physiological processes and has also been implicated in the pathophysiology of thrombosis, inflammation, vascular reactivity, cancer metastasis and response to pathogens (Simak \& Gelderman, 2006; Ardoin et al., 2007).

The first official description of platelet microparticles dates back in 1967, when Wolf (Wolf, 1967) demonstrated that activated platelets released membrane fragment which he called platelet dust. However, the search for platelet microparticles in CRYO did not start until the detection of anti-platelet antibodies in hemophilia patients after the exposure to CRYO more than a decade later (McVerry \& Machin, 1979). The content of platelet microparticle in plasma and CRYO are measured using an antibody to the platelet membrane receptor glycoprotein IIb (George et al., 1986). Due to freezing and thawing, plasma used in the 
process of preparing CRYO further concentrates the platelet membrane microparticle content. Plasma processed to produce frozen plasma and CRYO contains a high number of platelets and elevated concentration of platelet membrane microparticles is particularly found in CRYO. It is estimated that each dose of CRYO (10 units) contains approximately $4 \times 10^{9}$ platelets in microparticle form. The concentration of platelet membrane microparticles in CRYO is many folds greater than the cryosupernant plasma and the original plasma (Callum et al., 2009). It has been shown that the microparticle content of plasma prepared from platelet-rich plasma was greater than that of plasma prepared directly from whole blood. However, it is unknown whether the platelet membrane microparticles retain hemostatic capacity after processing and freezing. Further understanding about the role of platelet microparticles in hemostasis, the content of these biologically active particles in CRYO and their potential participation in thrombosis and transfusion reactions (alloimmunization) is greatly required.

\subsection{Pre-transfusion Compatibility Testing}

Due to the small volume of plasma transfused, ABO-compatible CRYO is not required, although this may be significant in patients receiving large volumes of cryoprecipitate relative to their red blood cell mass (Brecher, 2005). In neonates, where the volume of plasma transfused via CRYO can be proportionally large, ABO-compatible CRYO is recommended by some (Klein \& Anstee, 2005).

In patients receiving non-ABO compatible CRYO, a positive direct antiglobulin test and hemolysis have only rarely been reported (Burman et al., 1973). The selection of this product for transfusion usually does not require consideration of Rh compatibility.

At Sunnybrook Health Sciences Centre (SHSC), no compatibility test for CRYO transfusion is required according to current hospital transfusion guidelines. 


\subsection{Pre-transfusion Preparation}

\section{Thawing}

There are two approved methods for thawing of frozen CRYO bags. In an approved temperature-controlled water bath, the product should be thawed in a plastic 'over bag' at 30 to $37^{\circ} \mathrm{C}$ for no more than 15 minutes. Alternatively, the product can be thawed with an approved microwave device. The water bath method is currently the only thawing technique used at SHSC.

\section{Use and Storage after Thawing}

After the thawing, CRYO should be infused immediately. In case the product is not used immediately, it should be stored at $20-24^{\circ} \mathrm{C}$ and, varying according to local regulations in different jurisdictions, the product must be used within 4-6 hours (American Association of Blood Banks, 2002; Canadian Blood Services, 2005). In Canada, if the indication is for fibrinogen replacement and the processing closed system is used, the Canadian Standards allow for storage for up to 24 hours at $20-24^{\circ} \mathrm{C}$ (Canadian Standards Association, 2004). The product cannot be re-frozen.

\section{Pooling}

Currently, pooling of CRYO is not a routine practice in many transfusion services. Pooling of CRYO within the transfusion laboratory is estimated to happen only in approximately 20\% of laboratories in the United Kingdom (UK Blood Transfusion \& Tissue Transplantation Services, 2004). The rate of pooling in other jurisdictions is unknown. In the European Union, all transfusion services must be licensed under the European Union Blood Directive to pool CRYO. These services are also subject to regular inspections. In addition, a unique identifier must be assigned to pools of CRYO, allowing tracing to the original donor 
unit numbers. These requirements lead many facilities in Europe to abandon the practice of pooling CRYO (Salter \& Lloyd, 2005).

In order to maintain sterility throughout the pooling process, approved biosafety cabinets are recommended. Furthermore, in high volume hospitals where CRYO is used usually in the context of emergent bleeding for cardiac and trauma patients (Alport et al., 2008), pooling within the blood transfusion service can ensure the product is available in an expedited fashion. On the other hand, pooling at the bedside may cause delays in infusing the product. Pooling involves opening of multiple single bags, diluting the bags with saline, mixing the fluid and then serially infusing the final product.

During pooling, each bag of CRYO should be mixed with $10-15 \mathrm{~mL}$ of $0.9 \%$ Sodium Chloride solution to ensure complete removal of all the material from the bag. After pooling, CRYO must be used within 4 hours. As mentioned previously, the product cannot be refrozen.

At SHSC, the preparation of a CRYO dose is performed at the blood bank by qualified blood bank technologists.

\subsection{Standards for Cryoprecipitate Use}

Major recommendations from regulatory agencies are in place with respect to processing, compatibility and the content of fibrinogen in CRYO. The American Association of Blood Banks Standards affirm that CRYO shall be prepared by a method known to separate the cold insoluble portion from FFP and result in a minimum of $150 \mathrm{mg}$ of fibrinogen and $80 \mathrm{IU}$ of coagulation factor VIII (American Association of Blood Banks, 2008).

The Canadian Standards for Transfusion Medicine recommend the use of ABOcompatible CRYO, with a policy required for situations where ABO-compatible CRYO is not 
available (Canadian Society of Transfusion Medicine, 2007). Additionally, in keeping with recommendations from the American Association of Blood Banks, the Canadian Society of Transfusion Medicine recommends that product should be thawed in a protective overbag at $30-37^{\circ} \mathrm{C}$ in an approved warming device.

The Council of Europe Recommendation requires that a unit of cryoprecipitate contain a minimum of $140 \mathrm{mg}$ of fibrinogen and 70 IU of factor VIII (Council of Europe, 2006).

\subsection{Clinical Guidelines for the Use of Cryoprecipitate}

Clinical practice guidelines are important sources of information for health care providers and are increasingly common in medicine. The field of transfusion medicine is not different, with a series of guidelines addressing blood and blood product transfusion published in the last two decades (College of American Pathologists, 1994; American Society of Anesthesiologists, 1996; O’Shaughnessy et al., 2004; Stainsby et at., 2006; American Society of Anesthesiologists, 2006; Ketchum et al., 2006; Droubatchevskaia et al., 2007; Hedges et al., 2007; Spahn et al., 2007; Levi et al., 2009; Rossaint et al., 2010; Thomas et al., 2010). These guidelines compile the available evidence in the area of transfusion medicine, providing recommendations to help the provision of care for patients necessitating transfusion.

The major guidelines containing recommendations on CRYO transfusion are discussed individually below. Overall, these recommendations are derived from low-quality scientific evidence (observational studies or case series). There is a lack of randomized controlled trials in the area of CRYO transfusion. Most of these guidelines suggest a fibrinogen cut-off of 1.0 g/L as a trigger for CRYO transfusion with a couple of exceptions. This cut-off is likely based primarily on expert opinion, although a study by Ciavarella et al. in 1987 reviewed 36 massively transfused patients and observed that no microvascular bleeding occurred in patients 
with fibrinogen levels above $1.0 \mathrm{~g} / \mathrm{L}$ (Ciavarella et al., 1987). Typically, an adult dose of $8-12$ units (one unit per 5 - $10 \mathrm{~kg}$ of body weight) is administered. However, there is a growing body of evidence that supports a fibrinogen level above $1.5 \mathrm{~g} / \mathrm{L}$ and increased doses of CRYO or fibrinogen according to the most recent guidelines (Rossaint et al., 2010; Thomas et al., 2010). In Canada, the number of units of CRYO issued by the Canadian Blood Service increased 7.2\%, from approximately 41,000 in 2007/08 fiscal year to over 46,000 in 2010/11 fiscal year (Mr. David Howe, Canadian Blood Services, personal communication). Regarding the measurement of plasma fibrinogen, few guidelines recommend the Clauss assay as the method of choice. The impact of CRYO transfusion on plasma fibrinogen levels, particularly in the context of major blood loss, is unclear and based on expert opinion.

\section{The College of American Pathologists Guidelines - Practice Parameter}

\section{for the Use of Fresh-frozen Plasma, Cryoprecipitate and Platelets - 1994}

The College of American Pathologist guidelines, developed by a group of experts assessing the available evidence at the time, published recommendations on the use of CRYO. These guidelines recommended that the use of CRYO should be reserved for patients with clinical bleeding or planned invasive procedures in patients with a fibrinogen level less than 1.0 g/L (College of American Pathologists, 1994). They suggested that CRYO might be considered for vWD and Hemophilia A when factor concentrates are not available. The guidelines also suggested a dose of one unit of CRYO per $5 \mathrm{Kg}$ of body weight for hypofibrinogenemia, and one unit of CRYO per $10 \mathrm{Kg}$ of body weight in case of vWD. For Hemophilia patients, the number of bags of CRYO can be calculated according to the following formula: number of bags $=[($ plasma volume in $\mathrm{mL} \mathrm{x} \%$ increase in factor VIII needed $) / 100] / 80$. It states that the plasma recovery of transfused fibrinogen is approximately 50\%. No specific recommendations 
on time to fibrinogen measurement before administration of the product or specific assay for fibrinogen measurement were made in this document.

\section{The American Society of Anesthesiologists Practice Guidelines for}

\section{Blood Component Therapy - 1996}

The American Society of Anesthesiologists convened the Task Force on Blood Component Therapy to develop evidence-based guidelines on the proper indications for perioperative and peripartum administration of red blood cells, platelets, fresh-frozen plasma and cryoprecipitate (American Society of Anesthesiologists, 1996). The available evidence during the time was classified by study design category, using the grading of evidence proposed by the US Preventive Services Task Forces (US Preventive Services Task Forces, 1989) as follow (from the stronger to the weaker): I - randomized controlled trials; II -1 nonrandomized controlled trials; II-2 - controlled observational studies (e.g.: case-control, cohort studies); II-3 - uncontrolled observational studies; and III - descriptive studies and expert opinion. Based on the strength of evidence and expert opinion regarding effectiveness of the intervention, recommendations for indications were generated (category II-3 and expert opinion): CRYO is likely to be effective and is recommended for: (i) prophylaxis in nonbleeding perioperative or peripartum patients with congenital fibrinogen deficiencies or vWD unresponsive to desmopressin (DDAVP) (whenever possible, these decisions should be made in consultation with the patient's hematologist); (ii) bleeding patients with vWD; and (iii) correction of microvascular bleeding in massively transfused patients with fibrinogen concentrations levels less than $80-100 \mathrm{mg} / \mathrm{dL}$ (or when the fibrinogen levels cannot be measured in a timely fashion). No specific dose was recommended in these guidelines, but it was stated that one unit of CRYO per $10 \mathrm{Kg}$ body weight raises plasma fibrinogen by approximately $50 \mathrm{mg} / \mathrm{dL}$ in the absence of continued consumption or massive bleeding. 


\section{The British Committee for Standards in Haematology, Blood}

\section{Transfusion Task Force - Guidelines for the Use of Fresh-frozen Plasma, Cryoprecipitate and Cryosupernatant - 2004}

A blood transfusion task force from the British Committee for Standards in Haematology addressed the use of CRYO and published their recommendations (O’Shaughnessy et al., 2004). CRYO was considered appropriate to enhance fibrinogen levels in dysfibrinogenaemia and acquired hypofibrinogenaemia seen in the setting of severe bleeding and/or disseminated intravascular coagulation. The guidelines stated that treatment was usually indicated if plasma fibrinogen was less than $1.0 \mathrm{~g} / \mathrm{L}$, although there is no absolute threshold value for diagnosing clinically significant hypofibrinogenaemia. It was also stated that results of fibrinogen assays vary according to the method used; nevertheless no particular recommendations on fibrinogen assays and time to its measurement before CRYO transfusion were made. The guidelines did not address the dosage of CRYO to be utilized in those indications nor made any statement on the plasma recovery of fibrinogen following CRYO infusion.

\section{The British Committee for Standards in Haematology, Blood}

\section{Transfusion Task Force - 2006}

In 2006, the British Blood Transfusion Committee Task Force published guidelines on the management of massive blood loss, including recommendations on the use of CRYO (Stainsby et at., 2006). During massive blood loss - defined as the loss of one blood volume (Mollisson et al., 1997), or a 50\% blood volume loss within 3 hours or a rate of loss of 150 $\mathrm{ml} / \mathrm{min}$ (Fakhry \& Sheldon, 1994) - CRYO should be used to maintain fibrinogen $>1.0 \mathrm{~g} / \mathrm{l}$ if not corrected by fresh-frozen plasma. Two packs of pooled CRYO should be given for adults according to these guidelines. It was stated that $1 \mathrm{l}$ of fresh-frozen plasma might be expected to 
provide $2-5 \mathrm{~g}$ of fibrinogen, while two pools of CRYO provides $3.2-4 \mathrm{~g}$ of fibrinogen in a volume of 150 - $200 \mathrm{ml}$. They commented that fresh-frozen plasma alone, if given in sufficient quantity, will correct fibrinogen in most cases, thus CRYO is rarely needed in the context of massive blood loss except in the presence of disseminated intravascular coagulation. These guidelines also suggested that fibrinogen should be measured by the Clauss method. No reference was made to the plasma fibrinogen response to CRYO infusion.

\section{The American Society of Anesthesiologists Task Force on}

\section{Perioperative Blood Transfusion and Adjuvant Therapies - Practice}

\section{Guidelines for Perioperative Blood Transfusion and Adjuvant Therapies: An}

\section{Updated Report - 2006}

In these updated report from the American Society of Anesthesiologists Task Force, the same recommendations on CRYO use, made a decade before in their first statement on perioperative blood transfusion and adjuvant therapies (American Society of Anesthesiologists, 1996), were re-iterated (American Society of Anesthesiologists, 2006). CRYO is usually indicated: (i) when fibrinogen concentration is less than $80-100 \mathrm{mg} / \mathrm{dl}$ in the presence of excessive microvascular bleeding, (ii) to correct excessive microvascular bleeding in massively transfused patients when fibrinogen levels cannot be obtained in a timely fashion, (iii) for patients with congenital fibrinogen deficiencies and bleeding patients with vWD if concentrates are not available.

\section{Trauma Guidelines (Ketchum et al.) - 2006}

A review article by Ketchum et al. has recently addressed the indications for early FFP, CRYO and platelets transfusion in trauma (Ketchum et al., 2006). This review cautioned against the prophylactic administration of cryoprecipitate in trauma patients in the absence of hypofibrinogenemia. This document recognized the importance of FFP and platelets in 
preserving adequate coagulation. They argued that adequate FFP administration should be enough to ensure hemostatic concentrations of all coagulation factors and thus prevent severe hypofibrinogenemia. The review stated that one unit of FFP contains approximately $0.5 \mathrm{~g}$ of fibrinogen, while one unit of CRYO contains $0.25 \mathrm{~g}$. They observed that CRYO is usually given in 10 units, which contains $2.5 \mathrm{~g}$ of fibrinogen in only $100 \mathrm{ml}$ of plasma, rapidly raising the plasma concentration of fibrinogen. However, the benefits of higher than normal fibrinogen concentrations in trauma patients remain unknown. The review makes no recommendation on timing to fibrinogen measurement, type of fibrinogen assay, nor on specific triggers for CRYO transfusion.

\section{British Columbia Medical Journal Guidelines - 2007}

The Transfusion Medicine Advisory Group of British Columbia in Canada also developed evidence-based guidelines on the appropriate use of CRYO (Droubatchevskaia et al., 2007). The levels of evidence and grades of recommendations were based on standards developed by the US Agency for Healthcare Research and Quality - formerly the US Agency for Health Care Policy and Research (United States Department of Health and Human Services, 1993). Due to the weak level of evidence available (Level IV) on the clinical application of CRYO, all recommendations in these guidelines were rated as grade $\mathrm{C}$ recommendations (based on expert opinion). These guidelines indicated that CRYO is usually recommended if fibrinogen levels are less than $1.0 \mathrm{~g} / \mathrm{L}$ in the context of bleeding, albeit clinically significant bleeding can occur at higher levels. In the presence of DIC associated with bleeding and fibrinogen levels greater than $1.0 \mathrm{~g} / \mathrm{L}$, these guidelines advise on the use of FP instead of CRYO in order to replace multiple factor deficiencies seen in that condition. When small volume infusion is desirable for the replacement of fibrinogen, CRYO may be preferred over FP as suggested by these guidelines. This document also recommends the use of CRYO for 
hypodysfibrinogenemia when recombinant or virally-inactivated concentrates are not available for von Willebrand's disease, hemophilia A, factor XIII deficiency, and thrombolytic-related hemorrhage. No recommendations on timing to fibrinogen measurement and choice of fibrinogen assay to be used were made. Finally, this document considered the use of CRYO inappropriate for the preparation of fibrin glue and for the replacement of fibronectin in sepsis.

\section{Evidence-based Guideline on Uremic Bleeding - 2007}

These evidence-based guidelines included recommendations on the use of CRYO for the management of uremic bleeding in 2007 (Hedges et al., 2007). Despite acknowledging that the response to CRYO administration in uremic patients can be unpredictable, CRYO was considered a reasonable therapeutic option in uremic patients at high risk for bleeding or actively bleeding. Other therapeutic options recommended in this document included dialysis, erythropoietin, DDAVP, and conjugated estrogens.

\section{Management of Bleeding After Major Trauma: a European Guideline}

$-2007$

An international initiative, the Multidisciplinary European Task Force for Advanced Bleeding Care, developed comprehensive guidelines on multiples aspects of the management of bleeding following severe injury, including recommendations on the use of CRYO and fibrinogen concentrates (Spahn et al., 2007). According to the grading system utilized in these guidelines (Guyatt et al., 2006), the recommendations on CRYO use (grade 1 C) were derived from observational studies and case series, and graded as being low-quality evidence but where the benefits clearly outweighed the risks, thus being classified as strong recommendations. They recommended treatment with CRYO or fibrinogen concentrate if significant bleeding is accompanied by plasma fibrinogen levels of less than $1 \mathrm{~g} / \mathrm{L}$. An initial CRYO dose of approximately 15 to 20 units or $50 \mathrm{mg} / \mathrm{kg}$ or 3 to $4 \mathrm{~g}$ of fibrinogen concentrate was suggested. 
Repeat doses should be guided by laboratory values of fibrinogen. The document stated that although no optimal initial dose has been defined, their suggested dose raises plasma fibrinogen level above $1 \mathrm{~g} / \mathrm{L}$, which provides sufficient hemostasis. Similar to the majority of published guidelines, type of fibrinogen assay to be used and timing of fibrinogen measurement were not addressed.

\section{The British Committee for Standards in Haematology - Guidelines for the Diagnosis and Management of Disseminated Intravascular Coagulation - 2009}

These guidelines were developed by the British Committee for Standards in Haematology Taskforce in Hemostasis and Thrombosis and European experts to help hematologists in diagnosing and managing disseminated intravascular coagulation (DIC) (Levi et al., 2009). This document recommended the use of CRYO or fibrinogen concentrate for severe hypofibrinogenemia in the context of DIC that persists despite administration of FFP. A dose containing $3 \mathrm{~g}$ of fibrinogen should be expected to increase plasma fibrinogen levels by approximately $1 \mathrm{~g} / \mathrm{L}$, which can be provided by two pools of CRYO (10 donor units) or as $3 \mathrm{~g}$ of fibrinogen concentrate, according to these guidelines. They also advised that plasma fibrinogen levels should be interpreted with caution in the setting of DIC. Because fibrinogen is an acute-phase reactant protein, plasma levels can be within normal range for long period of time. These guidelines suggested that serial measurements of fibrinogen might be more helpful and that the Clauss method should be used. However, it should be kept in mind that the high levels of FDP might interfere with the measured fibrinogen by the Clauss assay. 


\section{Management of Bleeding Following Major Trauma: An Updated}

\section{European Guideline - 2010}

In 2010, the Multidisciplinary European Task Force for Advanced Bleeding Care published an updated version of their guidelines for the management of bleeding following major trauma (Rossaint et al., 2010). Two major changes were made to the original version with respect to CRYO use in trauma. First, they suggested fibrinogen concentrate and CRYO for fibrinogen replacement if plasma fibrinogen levels of less than $1.5-2.0 \mathrm{~g} / \mathrm{L}$ are found, a more liberal trigger for replacement than the $1.0 \mathrm{~g} / \mathrm{L}$ previously suggested. Also, it was incorporated a recommendation on the use of thrombelastometric monitoring, as a way to detect functional fibrinogen deficits. Those new recommendations were originated from a growing body of evidence on the pivotal role of fibrinogen in the trauma associated coagulopathy and observations of improved outcomes with a more aggressive approach in replacing fibrinogen in trauma (Rugeri et al., 2007; Hess et al., 2008; Stinger et al., 2008; Fries \& Martini, 2010; Tisherman, 2010) . A fibrinogen concentrate dose of $3-4 \mathrm{~g}$ or $50 \mathrm{mg} / \mathrm{Kg}$ of CRYO (15 - 20 units) for an average weight adult $(70 \mathrm{~kg})$ were recommended for fibrinogen < $1.5-2.0 \mathrm{~g} / \mathrm{L}$.

The document included the following statements supporting their new recommendations: (i) based on the thrombelastometry data on trauma patients, maximum clot firmness was associated with plasma fibrinogen levels of approximately $2 \mathrm{~g} / \mathrm{L}$ (Rugeri et al., 2007); (ii) during massive transfusion, fibrinogen may be the first clotting factor to drop to critical levels (Hippala et al., 1995); (iii) plasma fibrinogen concentration less than $2.0 \mathrm{~g} / \mathrm{L}$ was the only coagulation variable independently associated with the progression to severe bleeding in postpartum hemorrhage, with a 100\% positive predictive value (PPV) (Charbit et al., 2007); (iv) in coronary artery bypass graft surgery, preoperative plasma fibrinogen levels were 
inversely correlated to blood loss and transfusion requirements (Karlsson et al., 2008); (v) in major perioperative bleeding, replacement with a median of $2 \mathrm{~g}$ (range 1 to $5 \mathrm{~g}$ ) of fibrinogen increased plasma levels from $1.4 \mathrm{~g} / \mathrm{L}(\mathrm{IQR} 1.0,1.8)$ to 2.4 (IQR 2.1, 2.6), which was associated with decreased need for allogeneic blood product transfusion (Fenger-Eriksen et al., 2008); (vi) a retrospective observational review involving combat-related trauma suggested that high ratios of fibrinogen to red blood cells (RBC) improves survival rates (Stinger et al., 2008); (vii) postoperative blood transfusions was reduced by increasing fibrinogen from $1.7( \pm 0.3) \mathrm{g} / \mathrm{L}$ to $2.4( \pm 0.1) \mathrm{g} / \mathrm{L}$ in a randomized controlled trial involving patients undergoing radical cystectomy (Fenger-Eriksen et al., 2009); (viii) the Clauss method for plasma fibrinogen measurement overestimates the actual concentration of fibrinogen in the plasma (Hippala, 1995); (ix) fibrinogen levels are expected to rise regardless of its replacement after major surgery and trauma (Thompson et al., 2007; Wei et al., 1995), and the effect of fibrinogen replacement during surgery on postoperative levels remains unclear (Fenger-Eriksen et al., 2009; Karlsson et al., 2009); and (x) no thrombotic risk was found in patients with acquired hypofrinogenemia $(<1.5 \mathrm{~g} / \mathrm{L}$ ) treated with fibrinogen concentrate (Weinkove \& Rangarajan, 2008)

\section{Association of Anaesthetists of Great Britain and Ireland (AAGBI) -}

\section{Guidelines - Blood Transfusion and the Anaesthetist: Management of}

\section{Massive Haemorrhage - 2010}

A Working Party established by the AAGBI, with the contribution from the British Committee for Standards in Haematology Transfusion Task Force and the Appropriate Use of Blood Group, produced a consensus document containing guidelines on the management of massive haemorrhage (Thomas et al., 2010). This document stated that the replacement of fibrinogen can be achieved faster by the use of fibrinogen concentrate, as oppose to CRYO use 
that requires thawing and transportation and should be reserved if fibrinogen is not available.

They suggested a dose of 30 - $60 \mathrm{mg} / \mathrm{kg}$ for fibrinogen concentration and no dose regime for CRYO was recommended. According to these guidelines, emerging evidence suggests that fibrinogen levels higher than $1.5 \mathrm{~g} / \mathrm{L}$ should be the target. A plasma fibrinogen level of less than $1.0 \mathrm{~g} / \mathrm{L}$ in the context massive bleeding is indicative of haemostatic failure with impending microvascular bleeding. They also supported the use of the Clauss method for fibrinogen measurement and cautioned against total reliance on coagulation tests, which due to activation of anticoagulant pathways in massive trauma, may be within normal ranges despite hemostatic compromise (Wolberg et al., 2004).

\subsection{Fibrinogen Measurement}

There are currently several laboratory methods available for the measurement of plasma fibrinogen (Nieuwenhuizen et al., 1995; Mackie et al., 2003; Lowe et al., 2004; Verhovsek et al., 2008). The assays differ with respect to their precision of fibrinogen levels determination in different clinical settings; ability to detect total fibrinogen concentrations versus functional fibrinogen levels; degrees of expertise; and time and equipment required. Four main types of assay are used to determine plasma fibrinogen: clotting rate (von Clauss method), total clottable fibrinogen, prothrombin -time derived and immunological (radial immunodifusion, enzymelinked immunoabsorbent or nephelometric) assays (Nieuwenhuizen et al.,1995; Mackie et al., 2003; Lowe et al.,2004; Verhovsek et al., 2008).

In general, clotting rate assays, which use clotting time of plasma dilutions for the determination of functional plasma fibrinogen levels, remain the routine assay of choice for the diagnosis of hypofibrinogenemia in the context of bleeding (Mackie et al., 2003). Total clottable protein assays have high accuracy and are used as reference method for plasma 
fibrinogen measurement (Mackie et al., 2003). However, these assays are technically difficult and time-consuming to perform; thus rarely required in clinical practice (Lowe et al., 2004). Prothrombin time-derived assays, which estimate fibrinogen concentrations based on optical density or light scatter in automated coagulometers, are easy and cheap to perform (Lowe et al., 2004). Nevertheless, their results show wide variability depending on the reagents and analysers used and give higher values than von Clauss assays (Palateri et al., 1991; Chitolie et al., 1994; Chantarangkul et al., 1994; Kitchen et al., 1995; Chitolie et al., 1998; De Cristofaro et al., 1998; Lawrie et al., 1998; Medical Devices Agency, 2000). Immunological assays, which measure total fibrinogen (clottable or not), are useful to differentiate afibrinogenemias or hypofibrinogenemias from dysfibrinogenemia (Lowe et al., 2004; Verhovsek et al., 2008).

Traditionally, plasma fibrinogen assays have been performed for the investigation, monitoring and management of hemorrhagic risks associated with low congenital or acquired fibrinogen levels. In acute bleeding situations, a simple and fast method to determine plasma concentration of clottable fibrinogen is desirable. In addition, the management of acute bleeding disorders (such as in trauma, in the perioperative period, in obstetric complications and in disseminated intravascular coagulation), requires multiple and frequent measurements. Due to its pivotal role in primary and secondary hemostasis, circulating clottable fibrinogen is considered clinically the most relevant measure. Of note, circulating plasma fibrinogen can present significant heterogeneity in structure and function due to genetic individual differences and degradation by enzymes such as thrombin, plasmin and neutrophil elastase (Nieuwenhuizen et al., 1995). This heterogeneity might render some plasma fibrinogen nonclottable, explaining differences in results between clottable assays and other methods. Currently, automated hemostasis analysers use mainly two different technologies to assess fibrin clot end-points. The use of mechanical end-point technology is based on the tensile strength of the clot in a magnetic field. Despite being sensitive at low fibrinogen 
concentrations, this technique is specially affected by heparin therapy, which can be overcome with in vitro heparin neutralization and re-running of the sample (Mackie et al., 2003). Photooptical systems are also used and measure the changes in light scatter through $90^{\circ}$ or light transmission as a result of fibrin formation. Therefore, this derived fibrinogen assay is based on the changes in optical density, which are proportional to the concentration of fibrinogen. The von Clauss method is the standard assay used at SHSC for fibrinogen measurement.

\section{Clotting Rate Assay (von Clauss Method)}

A standardized high concentration of thrombin (varying from 35 to $200 \mathrm{U} / \mathrm{ml}$, but usually about $100 \mathrm{U} / \mathrm{ml}$ ) is added to diluted test plasma and the clotting time is recorded (Clauss, 1957). The test result is derived by comparison with calibration curves, which are generated by clotting a series of dilutions of a reference plasma sample of known clottable fibrinogen concentration, and is expressed in g/L (SI units). Different analysers can use mechanical end-point or photo-optical systems and a multiplicity of commercial reagents are now available (Medical Devices Agency, 2000; Mackie et al., 2002). Significant differences (approximately $0.1 \mathrm{~g} / \mathrm{L}$ ) in fibrinogen estimations were found when different analysers are utilized, but they are unlike to be of any clinical relevance (Medical Devices Agency, 2000). It is estimated that reasonable degree of precision is documented in coagulometers with normal plasma: the coefficient of variation (CV) is characteristically $3-7 \%$ by optical methods and 6 - 9\% by mechanical methods (Marbet \& Duckert, 1992; Mackie et al., 2002). Manual techniques are less precise than other methods (CV 10\% or above) (Lowe et al.,2004).

\section{Total Clottable Fibrinogen Assay}


These assays are performed in the absence of $\mathrm{Ca}^{2+}$ in citrate plasma by adding thrombin, which converts fibrinogen to fibrin clot during prolonged incubation. Epsilon aminocaproic acid is added to prevent degradation of the clot by plasmin. Soluble proteins in the clot are then washed and dissolved in alkaline urea or other reagents (Ratnoff \& Menzie, 1951; Jacobsson, 1955; Blomback \& Blomback, 1956; Swain \& Feders, 1967; Gaffney \& Wong, 1992). Most of the protein in the clot will be fibrin, which will be the equivalent to the fibrinogen concentration. Different from the Clauss assay (Clauss, 1957), where fibrin degradation products (FDPs) inhibits the conversion rate of fibrinogen to fibrin, in clottable assays FDPs may form the clot and increase the assay value. The fibrinogen concentration can be measured by measuring light absorbance at 282nm (Blomback \& Blomback, 1956) or by determination of tyrosine in the washed clot (Lowe et al., 2004). Despite being very accurate and used as reference assays for fibrinogen, clottable protein assays are time consuming and technically difficult to perform, limiting their use as routine method in clinical coagulation laboratories (Mackie et al., 2003).

\section{Prothrombin -time Derived Test}

This technique is not a direct determination of plasma fibrinogen but an estimation of the concentration of fibrinogen during the clotting process of the prothrombin time (PT) on automated photo-optical coagulometers. In this method, absorbance changes at $450 \mathrm{~nm}$ (delta OD) are used to determine the concentration of fibrinogen by analysers which are calibrated by performing PT on a plasma (or a series of plasma dilutions) of known fibrinogen concentration and then by plotting optical changes against fibrinogen concentration (Chitolie et al., 1994; Sobas et al., 2002).

Due to its ease to perform at "no additional costs", the method rapidly gained popularity among hemostasis laboratories (Chantarangkul et al., 1987; De Metz \& van Wersch, 1987; 
Hoffmann \& Verhappen, 1988; Rossi et al., 1988). However, there is controversy regarding the suitability of PT-derived assays for clinical use (Sobas et al., 2002; Cunningham et al., 2002). It has been showed to yield higher fibrinogen levels than the Clauss method, particularly in anticoagulated patients (Chitolie et al., 1994; Sobas et al., 2002).

\section{Immunological Fibrinogen Assays}

Several immunological assays are available for the determination of plasma fibrinogen: radial immunodifusion (RID), enzyme-linked immunoabsorbent (ELISA) or nephelometric. In immunonephelometric and radial immunodifusion techniques, polyclonal antibodies to fibrinogen are incubated with diluted plasma and immune complexes formed. The detection of theses immune complexes are performed by diffusion and precipitation in agarose gel in RID assays and by light-scattering in immunonephelometry. In ELISA techniques, specific antibodies on polystyrene surfaces capture the fibrinogen molecules from diluted plasma. The detection method uses a second enzyme-conjugated antibody to bind fibrinogen on microplates or tubes. All immunological assays measure protein concentration rather than functional activity. Degraded forms of fibrinogen are present and may produce "falsely elevated concentrations of functional fibrinogen”. This effect explains discrepancies between immunological and functional assays such as Clauss and Prothrombin-derived. Due to this limitation, immunological assays are indicated for conditions where normal or elevated fibrinogen levels are expected, such as studies assessing fibrinogen as a risk factor for cardiovascular disease (Cremer et al., 1994; Sweetman et al., 1996, 1998).

Recently, the issue of long turn-around time for lab tests was addressed in a study by Chandler el al (Chandler et al., 2010). The authors implemented a series of modifications to stat coagulation testing such that: i) the emergency hemorrhage panel was prioritized; and ii) speed in processing samples was improved at the expense of precision, but to still produce clinically 
relevant results (shortened centrifugation time [from 8 at $2000 \mathrm{~g}$ to $2 \mathrm{~min}$ at $4440 \mathrm{~g}$ instead]; elimination of checks for clots and hemolysis; and extension of fibrinogen calibration curve down to $0.53 \mathrm{mg} / \mathrm{dL}$ with repeated test, but results as $<0.53 \mathrm{mg} / \mathrm{dL}$ released). They were able to reduce their turn-around time from 34 to 13 minutes (Chandler et al., 2010).

\subsection{Dosage Recommendations for Cryoprecipitate}

\section{Transfusion}

Currently, due to its high content of fibrinogen, CRYO is used as a way to raise fibrinogen levels in the context of bleeding. One unit of CRYO contains $0.25 \mathrm{~g}$ of fibrinogen, thus an average dose of 8 units contains $2 \mathrm{~g}$ of fibrinogen. The content of a standard dose of CRYO is equivalent to the amount of fibrinogen found in an average adult dose of FFP (4 units), where each unit of FFP contains $0.5 \mathrm{~g}$ of fibrinogen (Callum et al., 2011; Nascimento et al., 2010). Of note, the total volume of a standard dose of CRYO is approximately $150 \mathrm{ml}$, while the total volume of a FFP dose is equivalent to $1000 \mathrm{ml}$.

As described previously, typically, an adult dose of 8 - 12 units (one unit per 5 - $10 \mathrm{~kg}$ of body weight) is recommended for plasma fibrinogen concentration $<1.0 \mathrm{~g} / \mathrm{L}$ in the presence of bleeding. However, there is preliminary evidence that challenges this target and recommends a higher target for fibrinogen levels (above $1.5 \mathrm{~g} / \mathrm{L}$ ) and increased doses of CRYO or fibrinogen according to the most recent guidelines (Rossaint et al., 2010; Thomas et al., 2010). A fibrinogen concentrate dose of $3-4 \mathrm{~g}$ or $50 \mathrm{mg} / \mathrm{Kg}$ of CRYO (15 - 20 units) for an average sized adult $(70 \mathrm{~kg}$ ) have recently been recommended for fibrinogen $<1.5-2.0 \mathrm{~g} / \mathrm{L}$ (Rossaint et al., 2010). 
A summary of dosage recommendations from major guidelines and their supporting evidence is displayed on table 1.

Table 1. Dosage Recommendations for Cryoprecipitate Transfusion

\begin{tabular}{|c|c|c|c|}
\hline Guidelines & CRYO Dosage & $\begin{array}{c}\text { Plasma Fibrinogen } \\
\text { Response }\end{array}$ & Reference \\
\hline \multicolumn{4}{|l|}{ College of American } \\
\hline Pathologists - 1994 & 1 unit/5-10kg & $50 \%$ increase & No \\
\hline \multicolumn{4}{|l|}{ American Association of } \\
\hline Anesthesiologists - 1996 & 1 unit/10kg & $50 \mathrm{mg} / \mathrm{dL}$ increase & No \\
\hline British Task Force - 2004 & No recommendation & Not stated & No \\
\hline British Task Force - 2006 & $\begin{array}{c}2 \text { packs of pooled CRYO } \\
\text { for an adult }\end{array}$ & Not stated & No \\
\hline \multicolumn{4}{|l|}{ American Association of } \\
\hline Anesthesiologists - 2006 & 1 unit/10kg & $50 \mathrm{mg} / \mathrm{dL}$ increase & No \\
\hline Trauma Guidelines - 2006 & 10 units & Not stated & No \\
\hline British Columbia - 2007 & No recommendation & Not stated & No \\
\hline European Guidelines -2007 & $\begin{array}{c}15-20 \text { units or } 50 \mathrm{mg} / \mathrm{kg} \\
\text { for } 70 \mathrm{~kg}\end{array}$ & Raised to $1.0 \mathrm{~g} / \mathrm{L}$ & No \\
\hline British Committee -2009 & 10 units & Raised to $1.0 \mathrm{~g} / \mathrm{L}$ & No \\
\hline European Guidelines - 2010 & $\begin{array}{c}15-20 \text { units or } 50 \mathrm{mg} / \mathrm{kg} \\
\text { for } 70 \mathrm{~kg}\end{array}$ & Not stated & No \\
\hline Great Britain and Ireland & & & \\
\hline Guidelines - 2010 & No recommendation & Not stated & No \\
\hline
\end{tabular}


The American Association of Blood Banks physician handbook states that 1 unit will increase the fibrinogen by 5 to $10 \mathrm{mg} / \mathrm{dl}(0.05-0.1 \mathrm{~g} / \mathrm{L})$ in an average sized adult (American Association of Blood Banks, 2002) . Also, the American Association of Blood banks technical manual (Brecher, 2005), recommends the use of the following calculation:

- $\quad$ Blood volume $=$ weight $(\mathrm{kg}) \times 70 \mathrm{~mL} / \mathrm{kg}$

- $\quad$ Plasma volume $=$ Blood volume $\mathrm{x}$ (1-hematocrit)

- $\quad$ mg of fibrinogen required = (desired fibrinogen-current fibrinogen in $\mathrm{mg} / \mathrm{dl}) \mathrm{x}$ plasma volume divided by $100 \mathrm{ml} / \mathrm{dL}$

- $\quad$ Bags of cryoprecipitate required $=$ mg of fibrinogen divided by $250 \mathrm{mg}$ This calculation assumes that $100 \%$ of the infused fibrinogen is measured as plasma fibrinogen concentration by standard fibrinogen assays. However, the content of fibrinogen in CRYO is variable (Callum et al., 2009), wide variation among different fibrinogen measurement methods exist (Nieuwenhuizen et al.,1995; Mackie et al, 2003; Lowe et al.,2004; Verhovsek et al., 2008), and the plasma fibrinogen response to CRYO administration is unclear but likely significant lower than 100\%. These recommendations are likely based on expert opinion only and their clinical utility are limited.

\subsection{The Trauma-associated Coagulopathy}

Approximately $40 \%$ of all in hospital trauma-related deaths are directly caused by hemorrhage (Sauaia et al., 1995; Kauvar et al., 2006) and many are regarded as being potentially preventable (Tien et al., 2007; Teixeira et al., 2007; Saltzheer et al., 2010; Tien et al., 2010; Sanddal et al., 2011). In massively hemorrhaging patients, current resuscitation protocols regularly fail to prevent the development of coagulopathy in a proportion of patients. It has been estimated that mortality rates can vary from 20 to $50 \%$ in trauma patients requiring 
massive transfusion, usually defined as the transfusion of 10 or more units of RBC within 24 hours of hospitalization (Malone et al., 2006; Huger-Wagner et al., 2007; Sauaia et al., 1995).

Large-volume crystalloid infusion, early aggressive transfusion of RBC and late replacement of clotting elements may cause dilution, which, associated with clotting factor consumption, hypothermia and acidosis are the multiple factors implicated in the development of the complex coagulopathy following major injury and bleeding (Cotton et al., 2006; Tieu et al., 2007). In 2003, Brohi and MacLeod separately described that trauma coagulopathy occurs early following injury and is present on hospital admission in $25 \%$ of all severely traumatized patients (Brohi et al., 2003; MacLeod et al., 2003). Of note, the studies used different cut-off values for PT and partial prothrombin time (PTT) (Brohi et al. used PT $>18$ and PTT $>60$ seconds and Macleod et al. defined as PT > 14 seconds and PTT > 34 seconds) Further studies suggest that early coagulopathy is associated with the presence of shock and the amount of tissue destruction, independent of clotting factors consumption or dilution, and is associated with a 3-fold increase in mortality increase (Brohi et al., 2003; MacLeod et al., 2003; Brohi et al., 2007; Hess et al., 2008). Furthermore, a unique coagulopathy in traumatic brain injury (TBI) has long been described, where the release of brain tissue factor causes systemic activation of coagulation (disseminated intravascular coagulation), exhaustion of clotting elements and hyperfibrinolysis (Gando, 2006; Gando et al., 1999). While coagulopathy is common and critically important in TBI, the controversial existing evidence suggests it may not differ from trauma coagulopathy in general (Gando, 2009; Gando et al., 211). The evidence of this early trauma-associated coagulopathy has led to a paradigm shift in the way massively bleeding trauma patients are currently resuscitated, prompting the majority of trauma hospitals to adopt a more aggressive and earlier use of plasma and clotting factors (Holcomb, 2010).

The early trauma-associated coagulopathy concept has challenged the current crystalloid-based resuscitation where coagulopathy is not addressed until late during trauma 
resuscitation. Recently, a more aggressive use of plasma and platelets with restriction of crystalloids has been suggested. This hemostatic resuscitation, commonly named “Damage Control Resuscitation” (DCR) or “ reconstituted whole blood resuscitation”, proposes early and aggressive FFP and platelets transfusion to treat or prevent early trauma-associated coagulopathy while providing volume replacement (Holcomb et al., 2007; Beekley, 2008).

\subsection{The Role of Fibrinogen in Trauma-associated}

\section{Coagulopathy}

Fibrinogen is essential in the coagulation process and clot stabilization in order to form a strong clot. It is cleaved by thrombin to form fibrin polymers, which are capable of binding factor XIII, with subsequent cross-linkage to produce a robust fibrin network (Velik-Salchner et al., 2007). Furthermore, fibrinogen plays an important role in platelet activation and aggregation by its binding to $\alpha_{2} \beta_{3}$ integrin glycoprotein (GP) IIb/IIIa fibrinogen receptors present on the surfaces of platelets, which are the main substrate for primary hemostasis. However, in trauma-associated coagulopathy multiple causal factors may directly affect fibrinogen polymeration and metabolism (Fries \& Martini, 2010).

\section{Dilutional Coagulopathy}

Traditional resuscitation strategies utilize crystalloid to correct shock in order to maintain euvolemia, blood pressure, cardiac output and thus adequate oxygen delivery to tissues. Aggressive initial fluid replacement causes dilution, which compromises coagulation and has been associated with worse outcomes in trauma. Despite being affected by direct dilution, fibrinogen metabolism is not directly disturbed by crystalloid use (Martini et al., 2006). 
Hydroxyethyl starch (HES) is also a solution used as fluid replacement in acute resuscitation in trauma. HES may have several deleterious effects on coagulation and has been associated with increased bleeding tendency. It induces a blockage of the fibrinogen receptor (GIIb/IIIa); interferes with fibrin polymerization; and causes platelet coating, hypocalcemia, and a vWB-like syndrome (Mittermayr et al., 2007). HES solutions are routinely used in resuscitation protocols in European countries, but no commonly employed in Canada.

Gelatin products may also cause dilution and impair fibrinogen polymerization (Mardel et al., 1998).

\section{Hyperfibrinolysis}

Fibrinolysis is a physiologic response to various insults such as trauma, surgery, infection and ischemia to maintain hemostasis (Levi et al., 1993). Normally, this initial fibrinolytic phase is followed by a suppression phase when anti-fibrinolytic systems are activated (Levi et al., 1993). Tissue and endothelial damage result in the release of tissue plasminogen activator (t-TPA), which causes fibrinolysis through the conversion of plasminogen to plasmin; and its antagonist, plasminogen activator inhibitor type 1 (PAI - 1), which regulates fibrinolysis by inhibiting the formation of plasmin (Cesarman-Maus \& Hajjar, 2005; Chandler, 1996; Medcalf, 2007). In trauma, hyperfibrinolysis (increased fibrinolysis) occurs due to the combined effects of both extensive tissue injury and shock (Hess et al., 2008). It is believed that this hyperfibrinolysis develops to limit the coagulation to the site of bleeding, but in the context of extensive tissue damage, this regulatory process may be imbalanced (Hess et al., 2008). This exacerbated fibrinolysis is considered to be an important contributor of hemorrhage and coagulopathy (Tanaka et al., 2009). It seems to be associated with the severity of trauma and specific tissue traumas, where the increased release of thrombloplastins are present, such as traumatic brain injury and long-bone fractures (Zehtabchi et al., 2008; Hulka et 
al., 1996; Stein \& Smith, 2004; Gando et al., 1999; Kushimoto et al., 2003; Kupe et al., 1971; Mellor \& Soni, 2001).

The bleeding tendency in hyperfibrinolysis can be treated by the use of antifibrinolytic drugs such as tranexamic acid and aprotinin. In fact, a recent randomized controlled trial evaluated an impressive 20,110 number of trauma patients at risk of significant hemorrhage who were treated with $2 \mathrm{~g}$ tranexamic acid or placebo, and showed reduced mortality rates in favor of the intervention for all-cause in-hospital mortality within 4 weeks (Shakur et al., 2010). Subsequent subgroup analysis of this trial demonstrated the importance of early (first 3 hours following injury) administration of tranexamic acid for its survival benefit (Roberts et al., 2011). Despite its antifibrinolytic action, no corresponding increase in thromboembolic events was observed. The efficacy of antifibrinolytic therapy has also been documented in liver transplant, cardiac and orthopedic surgery (Henry et al., 2007).

\section{Hypothermia}

In trauma, hypothermia is defined as core temperature of $34^{\circ} \mathrm{C}$ or lower and is commonly observed in trauma patients (Tsuei \& Kearney, 2004). The deleterious effect on coagulation are well described and include decrease in fibrinogen synthesis and in activity of the complex tissue factor-FVIIa, and inhibition of platelet function (Fries \& Martini, 2010; Reed et al.,1990; Wolberg et al., 2004; Meng et al., 2003) . Core temperatures below $32^{\circ} \mathrm{C}$ are associated with excessive mortality rates in trauma (Gentilello et al., 1997; Shafi et al., 2005).

\section{Acidosis}

Acidosis is frequently found in trauma patients usually due to the shock state and excessive administration of normal saline (ionic chloride) during acute resuscitation (Siegel et al., 1990; Rutherford et al., 1992). It is an independent predictor of coagulopathy in trauma patient and its severity is directly correlated with mortality rates (Siegel et al., 1990; Rutherford 
et al., 1992). Acidosis affects adversely coagulation by reducing protease activity and depleting fibrinogen and platelet counts. As oppose to hypothermia, acidosis did not affect fibrinogen synthesis but significantly increased fibrinogen degradation by an order of almost two in a recent animal study (Martini \& Holcomb, 2007).

\section{Evidence and Risks of Fibrinogen Replacement in Trauma-associated}

\section{Coagulopathy}

Fibrinogen was the first clotting factor to decrease to critical levels in coagulopathic patients who underwent major abdominal surgery with estimated blood loss of more than 200 \% of the patients’ calculated total volemia (Hiippala et al., 1995). Furthermore, compensatory mechanism of synthesis could not increase fibrinogen levels to overcome the increased breakdown in a porcine model of moderate dilutional coagulopathy, suggesting that hypofrinogenemia can not be entirely explained by blood loss and dilution (Martini et al., 2005). It has been shown that low preoperative levels of fibrinogen are associated with increased postoperative bleeding (Blome et al., 2005; Ucar et al., 2007b; Karlsson et al., 2008). In postpartum patients, low levels of fibrinogen had a PPV of 100\% for severe bleeding (Charbit et al., 2007). Finally, besides the importance of fibrinogen in fibrin formation and platelet function, the replacement of exogenous fibrinogen could theoretically bypass other missing components of the coagulation cascade.

Currently, fibrinogen can be provided through plasma, CRYO and fibrinogen concentrate. FFP and CRYO are human blood products that contain high concentrations of fibrinogen. One unit of CRYO contains $0.25 \mathrm{~g}$ of fibrinogen, thus an average dose of 8 units contains $2 \mathrm{~g}$ of fibrinogen. The content of a standard dose of CRYO is equivalent to the amount of fibrinogen found in an average adult dose of FFP (4 units), where each unit of FFP contains $0.5 \mathrm{~g}$ of fibrinogen (Callum et al., 2011; Nascimento et al., 2010). Of note, the total volume of 
a standard dose of CRYO is approximately $150 \mathrm{ml}$, while the total volume of a FFP dose is equivalent to $1000 \mathrm{ml}$.

However, the use of these two human blood products as a source of fibrinogen has important and practical limitations, such as extended turnaround time for thawing and pooling, transfusion-related risks and unproven efficacy (Stanworth et al., 2004; Stanworth, 2007). Of note, CRYO is not available in most European countries (Haas et al., 2008), but it still widely used in North America and the UK. For FFP transfusion, time permitting, blood group matching is required; and both FFP and CRYO are stored frozen, which require thawing before using. These factors contribute to long turnaround times (from the time products are requested to its completion of transfusion). Furthermore, FFP is not submitted to viral inactivation procedures in North America, carrying, although low, a risk of infectious disease transmission. Pathogen inactivation treatments can be used for FFP, but it can reduce the content of fibrinogen present in the product (Cardigan et al., 2009). These procedures cannot be employed for the CRYO product itself. Other potential complications of these products, particularly FFP, include transfusion-associated circulatory overload (TACO) and transfusion-related acute lung injury (TRALI) (Stanworth, 2007; Callum et al., 2009; O’Brien, 2007; Renaudier et al., 2009). TRALI is the commonest cause of transfusion-related mortality (Popovsky, 2006; Renaudier et al., 2009). Finally, the evidence on the clinical efficacy of FFP and CRYO for the replacement of fibrinogen is limited (Chowghury et al., 2004; Danes et al., 2008). A recent retrospective study by Stinger and colleagues, reviewing 252 massively transfused injured soldiers, found that the transfusion of an increased ratio of fibrinogen (given as combination of all blood and blood product administered) to RBC was independently associated with improved survival, mainly by reducing hemorrhagic deaths (Stinger et al., 2008). Of note, the vast majority of fibrinogen administered to these patients in this study was in the form of plasma, thus survival improvement could also be attributable to the infusion of other coagulation factors. 
As compared to FFP and CRYO, fibrinogen concentrate preparations are routinely subjected to pathogen reduction technologies treatment in their manufacturing process (Groner, 2008) and their content of fibrinogen are standardized (Fenger-Eriksen et al., 2009a). With fibrinogen concentrate, there is no thawing time and due to its small volume, the turnaround time and administration time is short. The infusion time for 100ml (approximately $2 \mathrm{~g}$ of fibrinogen) of reconstituted RiaSTAP $^{\circledR}$, a recently approved and commercially available human fibrinogen concentrate in the United States, is approximately $20 \mathrm{~min}$. It has been shown to be effective and well tolerated in a variety of congenital and acquired fibrinogen deficiency in medical and surgical clinical settings (Fenger-Eriksen et al., 2008; Fenger-Eriksen et al., 2009a,b; Rodriguez et al., 1988; Kreuz et al., 2005; Aygoren-Pursun et al., 2007; Heindl et al., 2005; Danes et al., 2008; Haas et al., 2008; Weinkove \& Rangarajan, 2008; Rahe-Meyer et al., 2009a,b). In animal models of dilutional coagulopathy, fibrinogen concentrate substitution prior to injury was associated with reduction in blood loss, improvement in coagulation parameters and increase in survival rates (Fries et al., 2005; Fries et al., 2006; Grottke et al., 2010). As a consequence of this, in Europe, a marked increase in the use of fibrinogen concentrates for the management of bleeding patients has been documented in the last few years (Meyer et al., 2011).

Despite the intense interest in this concentrate and growing use, there is a lack of studies demonstrating its efficacy in trauma. A comprehensive review on fibrinogen concentrates for bleeding trauma patients published early this year (Meyer et al., 2011), identified only four relevant studies. None of these studies were randomized controlled trials. One observational study, including 128 trauma patients (Schochl et al., 2010b) and three cases reports comprised this review (Schochl et al., 2010a,c; Brenni et al., 2010). The main finding of these studies was that the administration of fibrinogen concentrate sometimes associated with prothrombin complex concentrate, might be an alternative hemostatic strategy in trauma 
patients treated with synthetic colloids during resuscitation, as compared to the traditional plasma strategy. This review highlights the urgent need for higher quality study designs in order to address this question (Meyer et al., 2011). No published studies comparing the efficacy of CRYO with fibrinogen concentration are available to date.

\subsection{Appropriateness of Use of CRYO in Transfusion}

\section{Medicine}

\section{Assessing Appropriateness of Use}

The appropriateness of a medical or surgical procedure is evident when "the expected health benefit exceeds the expected negative consequences by a sufficiently wide margin that the procedure is worth doing, exclusive of cost” (Brook et al., 1986; Park et al., 1986). Physician and patients are daily faced with the challenge to make important decisions about diagnostics tests, surgical procedures and medical treatments, which require knowledge about the best evidence available and its application in an individual basis to minimize inappropriate risky and expensive medical interventions. Several methods have been developed to assess appropriateness of care that identifies the opinion of experts about an intervention (Fink et al., 1984). In general, they use a structured process for incorporating information from the scientific evidence with the expert judgment to generate explicit criteria in order to establish the appropriateness of particular procedures. It usually involves defined steps that include but is not limited to: (i) literature review; (ii) development of clinical scenarios to be assessed by a panel of experts; (iii) selection of experts; (iv) rating and discussion of scenarios; (v) obtain input from patients and other physicians when applicable; and (vi) update recommendations when necessary (Brook, 2009). 
Once a medical or surgical procedure is assessed and appropriateness criteria are agreed upon, basically two conditions are needed to evaluate if its use is appropriate in clinical practice: (i) guidelines for the intervention have to be in place and users (physicians) aware of its existence and (ii) enough information about the indication for the intervention from the responsible physician available for verification.

\section{Anticipated Challenges in Assessing Appropriateness of CRO}

\section{Transfusion in Trauma}

CRYO transfusion is considered an important strategy in the management of refractory hemorrhage in trauma patients. In the setting of massive hemorrhage in trauma, transfusion decisions are usually made according to physicians’ clinical judgment, available laboratory testing results and transfusion protocols where available, to provide some general guidelines, usually customized by the individual patient's needs.

\section{Patient's characteristics}

Massively bleeding patients are at great risk of coagulopathy and refractory shock, which occur soon after admission, leading to early in-hospital hemorrhagic deaths (Moore et al., 2008b). In fact, Acosta et al. reviewed autopsies and time to death of patients who died from trauma and described that $70 \%$ of all deaths occurred in the first 24 hours of hospitalization, with a significant number of these deaths (35\%) occurring within 15 min of hospital arrival (Acosta et al., 1998). Blood and blood product transfusion is essential part of the resuscitation of these patients and an estimated $80 \%$ of all RBC transfusions occur in the first 6 hours of admission (Moore et al., 2008a; Kashuk et al., 2008). This illustrates the urgent nature of transfusion in this population of massively bleeding trauma patients, which might affect compliance with transfusion guidelines, due to complete lack of laboratory test results in the first $30-60$ min of arrival. 


\section{Low Use of Guidelines}

The failure of many institutions to adopt published transfusion guidelines is an important consideration for the assessment of appropriateness of CRYO transfusion. A recent national survey conducted in the UK on the use of transfusion guidelines for major trauma documented that guidelines were infrequently utilized (Westerman et al., 2008). Out of 109 major emergency departments which responded to the questionnaire, only 17 (16\%) have transfusion guidelines in place to guide the transfusion management of trauma patients. Also, an international survey of clinical practice for the management of coagulopathy in patients with multiple injuries has recently been published. This survey involved 25 countries and reported that $45 \%$ of the respondents claimed to follow their institution's massive transfusion protocol, $19 \%$ reported having a protocol but with inconsistent use and 34\% do not have a protocol.

\section{Variability in Practice}

The lack of consensus on major aspects of massive transfusion is evident. A recent review on massive transfusion protocols, including 14 large medical academic centers, documented the presence of important variations in transfusion practice (Young et al., 2011).

Of 14 massive transfusion protocols, 5 (36\%) indicate CRYO use based on ratios of blood with blood products, 5 (36\%) use CRYO upon request and 4 (28\%) do not recommend its use. The lack of agreement on major aspects of prevention and treatment of coagulopathy in patients receiving massive transfusions was also evident in a recent international forum (Levi et al., 2011). This forum received 12 contributions from experts in the area, who had to compile their answers to five questions addressing 5 major aspects of massive transfusion, representing 8 different countries (Austria, Belgium, Canada, Denmark, France, Germany, Netherlands, Switzerland and USA). Interestingly, all 12 contributions used a different criteria or language to define massive transfusion. Other significant variations could be appreciated with respect to: 
(i) the utilization of a preset ratio of blood products and/or which ratio should be used if adopted; (ii) the use of standard coagulation tests (platelet count, International Normalized Ratio [INR], partial thromboplastin time [PTT], fibrinogen levels), viscoelastic coagulation testing (thromboelastography [TEG] or rotational thromboelastometry [ROTEM]), and no testing at all during massive transfusion; (iii) the use of adjuncts to hemostasis (antifibrinolytic drugs; fibrinogen concentrate; prothrombin complex concentrate, clotting factor XIII concentrate, etc.)

\section{Adequacy of Documentation}

Another potential challenge in assessing appropriateness in major trauma, particularly through retrospective audits of physician's orders, is the adequacy of physician and nursing documentation of transfusion. Due to urgent nature of CRYO transfusion in trauma, documentation is frequently regarded as secondary in face of other clinical priorities. Friedman \& Edrahim conducted a retrospective review of the adequacy of documentation for RBC transfusion in two New York acute care hospital facilities in the US (Friedman \& Edrahim, 2006). Transfusions of RBC were deemed justified or not by comparing with hospital transfusion guidelines. Events with suboptimal (intermediate and inadequate) documentation accounted for $49 \%$ of all medical record reviewed transfusion events and $62 \%$ could not be justified. The authors noted that there was a significant correlation between suboptimal documentation and failure to justify transfusion (Friedman \& Edrahim, 2006).

All of these might produce obstacles to assessing compliance with published guidelines in this patient population.

\section{Evidence on Appropriateness of CRO Transfusion in Trauma}

To date, no studies were performed assessing the appropriateness of CRYO transfusion exclusively in massively transfused trauma patients. Three studies evaluated the 
appropriateness of CRYO transfusion in a variety of clinical setting, including a small subpopulation of trauma patients (Schofield et al., 2003; Pantanowitz et al., 2003; Alport et al., 2008). These studies, one a prospective audit and two retrospective reviews of transfusion records, considered appropriate CRYO use according to published guidelines on plasma fibrinogen triggers and type of clinical settings. They did not explore physician’s clinical judgment and perceptions, neither specific patient's clinical characteristics, which might affect clinical decisions on laboratory monitoring and/or CRYO transfusion.

Alport et al. conducted a prospective audit involving 25 Canadian hospitals, involving 603 transfusion events, and reported an overall 24\% of appropriateness for CRYO use in different clinical settings (Alport et al., 2008). The authors categorized CRYO transfusions as likely appropriate if a fibrinogen level, taken within $6 \mathrm{hr}$ before or after transfusion was not more than $1.0 \mathrm{~g} / \mathrm{L}$. However, the authors did not report on individual appropriateness rates for the different clinical settings.

In 2003, an Australian study reviewed 64 CRYO transfusions and reported that only 38\% of CRYO transfusions were considered appropriate when the same fibrinogen level criteria were applied (Schofield et al., 2003). When a more relaxed fibrinogen level $(<1.5 \mathrm{~g} / \mathrm{L})$ was used, 57\% of CRYO transfusions were considered appropriate. However, the time to fibrinogen measurement in this report was not stated.

An audit from the United States also published in 2003, applying different criteria for appropriateness, reported that 76\% of CRYO transfusions were appropriate in 51 patients (Pantanowitz et al., 2003). In that report, CRYO transfusion was considered appropriate for a fibrinogen level less than $1.0 \mathrm{~g} / \mathrm{L}$ when bleeding, and in addition, for tissue plasminogen activator-related hemorrhage, transfusion of 10 or more PRBC units irrespective of fibrinogen level, uremic bleeding and von Willebrand's disease. The two latter indications are considered inappropriate by others due to the availability of desmopressin, virally inactivated human- 
derived factor VIII/von Willebrand factor concentrates and fibrin (Janson et al., 1980;

Maierhoter et al., 1981; Triulzi et al., 1990; Weigert et al., 1998; Mannucci, 2004).

\section{Appropriateness of Red Blood Cell and Plasma Transfusion}

Although guidelines for RBC and FFP have been published, adherence to these guidelines is frequently low. An international multidisciplinary panel of 15 expert reviewed all pertinent literature on RBC transfusion, and applying establish criteria for assessing appropriateness of a procedure (RAND/UCLA Appropriateness Method), determined the appropriateness of RBC transfusion (based on its expected impact on outcomes) in 450 typical inpatient medical, surgical, or trauma scenarios (Shander et al., 2011). Panelists rated RBC transfusion as appropriate in 53 of the scenarios (11.8\%), inappropriate in 267 (59.3\%), and uncertain in 130 (28.9\%). This observation indicates that the available evidence on RBC transfusion is limited and many areas of disagreement exist. It also supports a more judicious use of this product. In another UK-wide survey on FFP transfusion practices, including 4969 transfusions in 190 different hospitals, 43\% of all FFP transfusion in adults was not support by published recommendations (Stanworth et al., 2011). The appropriateness of FFP transfusion was recently evaluated in a Canadian intensive care unit (Lauzier et al., 2007). In this review, 47.6\% of the FFP were considered inappropriate according to national guidelines. An academic hospital prospective audit documented that $45 \%$ of FFP orders were inconsistent with national guidelines (Luke et al., 2002). Others have also found important inconsistencies between FFP use and accepted recommendations (Rao et al., 2002; Dara et al., 2005; Wallis \& Dzik, 2004).

\section{Aims}

This study reviews the practice of CRYO transfusion during a period of 10 years at a large tertiary care trauma hospital. It analyzes a cohort of massively transfused trauma patients where CRYO was used for the management of bleeding/coagulopathy following injury. It aims 
to assess the appropriateness and fibrinogen response to CRYO transfusion. The study is divided in two major parts:

\section{Part A (Appropriateness of CRYO transfusion)}

The study aims to assess appropriateness of CRYO transfusion in trauma by applying two different definitions:

(i) Strict definition: CRYO transfusion was considered appropriate if fibrinogen levels were $<1.0 \mathrm{~g} / \mathrm{L} 2$ hour before and/or $\leq 1.5 \mathrm{~g} / \mathrm{L}$ within 2 hour after CRYO transfusion. If no fibrinogen levels were measured within 2 hour of CRYO use the event was classified as outside guidelines. This definition was thought to be more appropriate by the authors in the setting of major trauma with high rates of bleeding and aggressive resuscitation.

(ii) Lenient definition: CRYO transfusion was considered appropriate if fibrinogen levels were $<1.0 \mathrm{~g} / \mathrm{L} 6$ hour before and/or $\leq 1.5 \mathrm{~g} / \mathrm{L}$ within 6 hour after CRYO transfusion. If no fibrinogen levels were measured within $6 \mathrm{hr}$ of CRYO use the event was classified as outside guidelines. This definition has been used previously by other studies to characterize appropriateness in a variety of clinical settings including trauma (Schofield et al., 2003; Pantanowitz et al., 2003; Alport et al., 2008).

\section{Part B (Fibrinogen Response to CRYO Transfusion)}

It analyzes a subgroup of trauma patients where fibrinogen levels were obtained within 1hr before and after CRYO transfusion, and with no transfusion of plasma and/or platelets within 2hr prior to the start of CRYO. This analysis aims to assess the plasma fibrinogen response to CRYO transfusion alone.

\subsection{Specific Aims - Part A}


A.1 - To determine the frequency of appropriate CRYO transfusion events in the setting of trauma. Appropriateness was defined based on published and our hospital guidelines.

A.2 - To assess the rate of appropriateness of CRYO use in trauma over time at a single institution;

A.3 - To assess patients factors associated with appropriateness; to compare demographics and baseline characteristics of patients in the group defined as appropriate to patients in the group outside guidelines; to compare transfusion practice for RBC, plasma and platelets between appropriate and outside guideline groups;

A.4 - To describe our hospital massive transfusion protocol;

A.5 - To describe our transfusion medicine program;

A.6 - To describe our hospital emergency laboratory protocol;

A.7 - To discuss system-related factors associated with appropriateness of CRYO transfusion at a single institution;

A.8 - To describe CRYO utilization according to the clinical setting at a large teaching hospital;

A.9 - To describe CRYO dosage in different clinical settings in a large teaching hospital.

\subsection{Specific Aims - Part B}

B.1 - To determine the incremental changes in plasma fibrinogen levels within $1 \mathrm{hr}$ of CRYO transfusion in trauma patients;

B.2 - To compare plasma fibrinogen response to CRYO transfusion between trauma patients with documented low and high fibrinogen levels before the administration of CRYO; 
B.3 - To explore patient factors associated with differences in fibrinogen response to CRYO transfusion; to compare demographics, baseline characteristics and transfusion data between patients with low and high fibrinogen levels before CRYO transfusion;

\section{Hypotheses}

\subsection{Hypothesis - Part A}

We hypothesize that our rates of appropriateness for CRYO precipitate transfusion in the context of trauma are higher than previous reported rates in mixed trauma, surgical and medical patients due to the presence of institutional guidelines, active involvement of transfusion medicine physicians in transfusion management, and adequate turnaround time for fibrinogen levels.

Previous audits documented rates of appropriateness in a variety of clinical indications ranging from 24 to 76\% (Schofield et al., 2003; Pantanowitz et al., 2003; Alport et al., 2008). This wide variability is mostly due to different definitions for appropriateness being used in different settings. In 2003, an audit from the United States (Pantanowitz et al.) reported high rates of appropriate use of CRYO utilizing a very inclusive definition. In this audit, in addition to the commonly accepted indication (fibrinogen level $<1.0 \mathrm{~g} / \mathrm{L}$ in the context of bleeding) for CRYO transfusion, its use was also considered appropriate for transfusion of 10 or more RBC units irrespective of fibrinogen level, for tissue plasminogen activator-related hemorrhage, and for uremic bleeding and vWD. The two latter indications are considered inappropriate by others due to the availability of desmopressin, virally inactivated human-derived factor VIII/von Willebrand factor concentrates and fibrin (Janson et al., 1980; Maierhoter et al., 1981; Triulzi et al., 1990; Weigert et al., 1998; Mannucci, 2004). Furthermore, the indication for CRYO based solely on the number of units of RBC transfused is not supported by most published 
guidelines (American Society of Anesthesiologists, 1996; O’Shaughnessy et al., 2004;

Droubatchevskaia et al., 2007; Levi et al., 2009). Therefore, the rate of 76\% appropriate CRYO transfusion reported by Pantanowitz et al. is inappropriately high.

We believe with an organized system where a transfusion protocol is in place and monitored by transfusion medicine specialist and blood bank technologists, despite the challenges and limitations of trauma resuscitation, over $50 \%$ of the transfusion events in trauma will be considered appropriate (transfusion of CRYO will be accompanied by fibrinogen levels below $1.0 \mathrm{~g} / \mathrm{L}$ preceding the transfusion and/or $<1.5 \mathrm{~g} / \mathrm{L}$ after transfusion).

\subsection{Hypothesis - Part B}

The American Society of Anesthesiology, in their guidelines for blood component therapy, states that an average dose of 1 unit of CRYO per 10kg of body weight raises plasma fibrinogen by approximately $0.5 \mathrm{~g} / \mathrm{L}$ in the absence of continued consumption or massive bleeding (American Society of Anesthesiologists, 1996). In trauma, CRYO is commonly transfused after high volumes of crystalloids, RBC, plasma and platelets had been infused, and when dilution and continued blood loss are present. Furthermore, acidosis, hypothermia and consumption of coagulation contribute to coagulopathy in trauma. We hypothesize that current recommended dose of CRYO transfusion is inadequate in the context of dilution and ongoing blood loss, and would result in a plasma fibrinogen increment below $0.5-1.0 \mathrm{~g} / \mathrm{L}$ per standard CRYO dose (8 - 10 units of CRYO per dose) in trauma patients.

\section{Method}

\subsection{Setting}


SHSC is a large academic hospital fully affiliated with the University of Toronto where the vast majority of CRYO is used for major hemorrhage in cardiac surgery and trauma. SHSC is an urban level 1 trauma centre in Toronto, Canada. Approximately 1100 injured patients (80\% blunt traumas; 70 - 80\% males) are treated by the trauma team at SHSC annually, and these patients have an average Injury Severity Score (ISS) of 20. ISS is an anatomic trauma scoring system which takes into account the squared values of the three mostly injured body areas based on the Abbreviated Injury Scale (AIS) and correlates strongly with mortality (Baker et al., 1976; Baker et al.,1974; Linn, 1995; Copes, 1988; Senkowski, 1999). It varies from minor traumas with practically no significant injuries (score point=1) to unsalvageable injuries (score point=75). Mortality increases significantly for scores of 15 or higher. Score values of 25 or above are representative of severe trauma with high mortality rates (Baker et al., 1976; Baker et al.,1974; Linn, 1995; Copes, 1988; Senkowski, 1999).

Of 1100 patients seen at SHSC annually, approximately 35 to 40 patients receive massive transfusions ( $\geq 10$ units of RBC) within the first $24 \mathrm{~h}$ of admission. In our institution, similar to recent published data, $80 \%$ of all blood transfusions to severely injured patients occur within the first 6 hours of hospitalization. This group of massively transfused patients has a mean ISS of $42( \pm 15)$ and has an in-hospital mortality rate of $45 \%$.

In the trauma room at our institution, patients are assessed and treated by the trauma team, led by a trauma team leader who can be a trauma surgeon, emergency physician or anesthesiologist. Acutely, care may also be provided by attending staff from Critical Care Medicine and/or Anesthesia. For massively bleeding trauma patients, transfusion medicine specialists are also automatically contacted, and they are available for assistance with transfusion decisions. Our emergency blood stock consists of 16 units of O+ RBCs , and 8 units of O- RBCs ( reserved for women less than 45 years of age). Our emergency stock is immediately available, with half stored in the trauma room and half in the blood bank. 
Currently, thawed plasma is not available due to our low utilization of this product (1500 units per year or approximately 4 units per day) and potential for wastage. FP is thawed by water bath method which usually takes about 30 minutes for its completion. Based on our current transfusion policy, our blood bank technologists proactively thaw $4-8$ units of FP when they anticipate a patient will use a large amount of blood. In emergency situations, when the patient's blood type in unknown, AB plasma is used until type-specific plasma can be provided. The study proposal was reviewed and approved by SHSC Research Ethics Board.

\subsection{Study Design}

This is a retrospective cohort review of all consecutive cases of CRYO use in various specialties during a period of 10 years (from January 1998 until June 2008) at SHSC.

\subsection{Data Acquisition}

The Hospital Blood Blank generated a report on all cases of CRYO transfusions during the study period and transfusion data were obtained from the blood bank databases (Hemocare, Mediware Information Systems, Inc. Revision 6.1.1, USA and Sunquest, Information Systems, Inc. version 6.2, USA). Clinical and laboratory data were retrieved from the hospital chart and electronic patient records.

\subsection{Study Variables}

Data collected include age, gender, reasons for hemorrhage (type of trauma in injured patients). For trauma patients, ISS and presence of head injury (Head Abbreviated Injury Severity Score - Head AIS) were also determined. Transfusion variables analyzed include indications for CRYO transfusion, time of blood product issue, number of blood products transfused before CRYO transfusion (RBC, platelets and FP) and dosing. Laboratory results 
included initial pH, INR, PTT, platelet count and fibrinogen. For the analysis of fibrinogen response to CRYO transfusion, plasma fibrinogen levels recorded within 2 hours before and after transfusion were utilized.

\subsection{Definitions}

\section{Appropriateness of CRYO Transfusion}

CRYO transfusion was considered appropriate if the fibrinogen levels were $<1.0 \mathrm{~g} / \mathrm{L} 2$ hour before and/or $\leq 1.5 \mathrm{~g} / \mathrm{L}$ within 2 hour after CRYO transfusion. It was classified as outside guidelines if fibrinogen levels were above these thresholds or no fibrinogen levels performed before and after CRYO transfusion.

A more lenient definition of appropriateness, using 6 hour before and after CRYO transfusion, for the same levels of fibrinogen $(<1.0 \mathrm{~g} / \mathrm{L} 6$ hour before and/or $\leq 1.5 \mathrm{~g} / \mathrm{L}$ within 6 hour after CRYO) was also applied. Using the 2 hour cut-off definition (strict definition), patients were categorized according to the appropriateness of their transfusion events into appropriate and outside guideline groups. Demographics, baseline characteristics and transfusion data were analyzed for both groups.

\section{Severe Head Injury}

The Head AIS was used to classify patients with severe head injury. In this injury scoring system, the severity of injury is rated from minor (AIS=1) to unsalvageable (AIS=6) (Table 2).

Table 2. The Abbreviated Injury Scale (AIS) Rating System 
Score

Severity of Injury

$\mathrm{AIS}=1$

AIS $=2$

AIS $=3$

AIS $=4$

AIS $=5$

AIS $=6$
Minor

Moderate

Serious but not life threatening

Severe, life threatening, survival probable

Critical, survival uncertain

Unsurvivable

Based on this rating system, severe head injury is considered to be Head AIS >3 (Baker et al., 1976; Baker et al.,1974; Linn, 1995; Copes, 1988; Senkowski, 1999).

The AIS is the most widely used anatomic injury severity rating system in the world (Garthe et al., 1999). It was developed in 1971 by the American Medical Association Committee on Medical Aspects of Automotive Safety to provide researchers with an accurate method for rating and comparing injuries from automotive crashes, as well as to establish a 
common language when describing injuries (Committee on Medical Aspects of Automotive Safety, 1971, 1972). A subsequent number of revisions followed its original version: (1) 1980, several nonanatomic components were included (Committee on Injury Scaling, 1980); (2) 1985, the scale body regions were expanded from five to nine and expanded sections on thoracic, abdominal and pelvic regions were added. New entries for penetrating, vascular and skin injuries were incorporated (Committee on Injury Scaling, 1985); (3) 1990, more descriptors of penetrating injuries, specific codes for pediatric trauma and a different classification for the body regions were included (Association for the Advancement of Automotive Medicine, 1990).

\subsection{Sunnybrook Hospital Transfusion Protocol}

\section{(Appendix 1)}

During the study period, the hospital transfusion guidelines recommended 1 unit of CRYO/10 kg of body weight (i.e. 8 to 12 units per dose) if plasma fibrinogen level was $<1.0$ $\mathrm{g} / \mathrm{L}$ in the context of massive or microvascular bleeding and regardless of the number of RBC, FP or

PLT transfused. During our massive transfusion protocol, coagulation testing, including fibrinogen levels are performed in an expedited fashion and results are usually delivered within 30 to 60 minutes of sample arrival. Our transfusion guidelines recommend hourly fibrinogen levels during massive transfusion, which is overseen by a transfusion medicine specialist who is automatically contacted for any request of large amounts of blood. In our hospital transfusion guidelines, RBC transfusions are administered to maintain euvolemia, and to maintain hemoglobin levels between $70 \mathrm{~g} / \mathrm{L}$ and $100 \mathrm{~g} / \mathrm{L}$. FP is transfused in 3-4 unit aliquots, for INR >1.8. Platelets are transfused one pool at a time (4 units/ pool of Buffy coat platelets or 
one single donor apheresis; before the buffy coat platelets, each pool of platelets corresponded

to 5 units) to maintain the platelet count above $50 \times 10^{9} / \mathrm{L}\left(>100 \times 10^{9} / \mathrm{L}\right.$ with co-existing brain injury). FP is thawed in the standard warm water bath fashion. If blood group is unknown at the activation of our massive transfusion protocol, AB plasma is thawed in anticipation and issued in an expedited fashion in order to assure constant availability of plasma. Antifibrinolytic drugs were not routinely recommended during the study period.

\subsection{Sunnybrook Blood Bank}

The blood bank is staffed by at least 2 technologists during nights and $10-12$ during days. The blood bank technologist routinely checks the fibrinogen levels at any request for CRYO transfusion and often prompts testing when not requested. CRYO is also prepared in anticipation based on testing independently of medical request as per our massive transfusion guidelines. Blood bank is notified by an automatic alarm of a potential massively transfused trauma patient, if the blood fridge in the trauma room is accessed for emergency stock RBC.

\subsection{Fibrinogen Measurement}

\section{Sample Collection}

Venous or arterial punctures in a clean and fast (in order to minimize blood stasis) fashion were performed for whole blood acquisition for fibrinogen testing. Blood samples for fibrinogen measurement were collected using tubes containing 3.2\% trisodium citrate. During 
sample collection, tubes were filled up to achieve the $9 \mathrm{vol}$ of blood to $1 \mathrm{vol}$ of $0.105 \mathrm{~mol} / \mathrm{L}$ (3.2\%) trisodium citrate standard recommendation (World Health Organization, 1999). After collection, samples were transferred to the Coagulation Laboratory area for processing.

\section{Handling and Processing of Coagulation Specimens}

Our coagulation laboratory has a flowchart for handling coagulation samples that takes into account the acuity of the area the samples are originated from for processing (Appendix 2). Samples coming from areas treating patients with high acuity such as emergency room, operating rooms and intensive care units require STAT handling and processing. Samples are initially checked for possible clots by removing the tube caps. If the presence of clotted sample is detected, laboratory personnel notify the clinical staff and the sample is rejected. Samples with no evidence of clotting are then centrifuged. At our institution, STAT coagulation specimens are prioritized over routine samples; and rapid turnaround times are achieved mainly by shortening labeling and spinning times (barcode pre-labeled tubes are used and placed in STAT spinner with tops off at $7200 \mathrm{rpm}$ for only 2 minutes, instead of at $3500 \mathrm{rpm}$ for 10 minutes used for routine samples) (Appendix 1). After centrifugation, the sample plasma is assessed for evidence of hemolysis. If the presence of hemolysis is confirmed, clinical staff is informed and sample is rejected.

\section{Fibrinogen Assay}

The assay was performed at $37^{0} \mathrm{C}$ on ACL TOP analyzer (Instrumentation Laboratory, IL), which has its endpoint based on the optical density of formed clot.

Plasma fibrinogen levels were determined using the Clauss method for the entire duration of the study. A standardized high concentration of thrombin is added to diluted test 
plasma and the clotting time is recorded (Clauss, 1957). The test result is derived by comparison with calibration curves generated by clotting a series of dilutions of a reference plasma sample of known clottable fibrinogen concentration and expressed in g/L (SI units).

In our laboratory, 100U/mL of thrombin solution (Fibrinogen-C, HemosIl, Instrumentation Laboratory) is added to the citrated diluted plasma. The recommended (1:10) dilution is initially used. Test samples are re-diluted if they are outside the linear range of the assay. Dilutions of 1:5 and 1:20 are used for very low and high levels of fibrinogen, respectively. Our laboratory has four different reference range calibration curves. The range of detectable fibrinogen is from $0.08 \mathrm{~g} / \mathrm{L}$ to $10.0 \mathrm{~g} / \mathrm{L}$. Therefore, fibrinogen levels as low as $0.08 \mathrm{~g} / \mathrm{L}$ can be detected.

Quality control samples for normal and low fibrinogen levels are performed every time the Hemostasis analyzer is utilized for fibrinogen determination.

The Clauss assay uses a high concentration of thrombin, which has the tendency of sticking to foreign surfaces and may contaminate subsequent samples. In order to avoid carryover, appropriate cleaning is employed on the reagent delivery system of the analyzer between tests.

\section{Reporting of Results}

In order to minimize turnaround time for laboratory results in emergency situations, our hospital policy requires the coagulation technologist to initially report fibrinogen results direct to the clinical area by telephone and subsequently to enter results into the patient's electronic laboratory record system. Fibrinogen levels are reported in g/L (SI units).

\section{Study Outcomes}

\section{Main Study Outcome - Part A}


It analyzes the frequency of appropriate and outside guideline CRYO transfusion in the setting of trauma using both definitions discussed above (2 and 6 hour cut-off criteria).

\section{Main Study Outcome - Part B}

To determine the fibrinogen response to CRYO transfusion in trauma patients (the increase in plasma fibrinogen level following CRYO transfusion in g/L and percentage increase will be determined). For this second outcome, CRYO transfusion events with fibrinogen levels measured 1hr before and after; and with no transfusions of plasma and/or platelets within $2 \mathrm{hr}$ prior to the start of CRYO, were included in this analysis so as to avoid confounding by plasma or platelet transfusion as a source of fibrinogen.

\section{Secondary Study Outcomes - Part A}

SOA1 - Total CRYO use according to clinical setting during study period (in percentage, units of CRYO, transfusion events, number of patients and units/patients);

SOA2 - Dosage of CRYO in different clinical settings (in units of CRYO and number of doses);

SOA3 - Percentage of single dose, two doses or more than three doses per clinical setting;

SOA4 - Total CRYO use (in number of units \& percentages) by year in different clinical settings;

SOA5 - Number of CRYO transfusion events and patients in cardio-vascular surgery over study period

SOA6 - Number of CRYO transfusion events and patients in trauma over study period; SOA7 - Hourly rates of fibrinogen measurement before and after CRYO transfusion in trauma; 
SOA8 - Hourly fibrinogen levels $<1.0 \mathrm{~g} / \mathrm{L}$ within 6 hours before CRYO transfusion in trauma;

SOA9 - Hourly fibrinogen levels $\leq 1.5 \mathrm{~g} / \mathrm{L}$ within 6 hours after CRYO transfusion in trauma;

SOA10 - Rates of appropriateness of CRYO transfusion in trauma by year;

SOA11 - Comparison of demographics, baseline characteristics and transfusion of RBC, FP and platelets before CRYO transfusion in appropriate and outside guideline groups;

SOA12 - Comparison of demographics, baseline characteristics and transfusion of RBC, FP and platelets before CRYO transfusion in appropriate and outside guideline (without fibrinogen levels) groups;

SOA13 - Comparison of demographics, baseline characteristics and transfusion of RBC, FP and platelets before CRYO transfusion between events with and without fibrinogen measured within 1 hour.

\section{Secondary Study Outcomes - Part B}

SOB1 - Plasma fibrinogen response (in g/L and percentage increase) in events with fibrinogen level < $1.0 \mathrm{~g} / \mathrm{L}$ before CRYO;

SOB2 - Plasma fibrinogen response (in g/L and percentage increase) in events with fibrinogen level $\geq 1.0 \mathrm{~g} / \mathrm{L}$ before CRYO;

SOB3 - Comparison of demographics, baseline characteristics and transfusion of RBC, FP and Platelets before CRYO transfusion between patients with fibrinogen $<1.0 \mathrm{~g} / \mathrm{L}$ and fibrinogen $\geq 1.0 \mathrm{~g} / \mathrm{L}$ within 1 hour before CRYO.

\section{Statistical Analysis}


Summary data for continuous variables were presented as means and standard deviations or medians and interquartile ranges depending on the distribution. The discrete variables were summarized as frequency and percentages.

Comparisons between appropriate and outside guideline groups were performed using Student's $t$ Test for continuous variables and $\chi^{2}$ analysis for categorical data. The analysis of fibrinogen response was conducted using Student's $t$ Test. Two-tailed tests were applied and statistical significance was defined at $\mathrm{p}<0.05$. All analyses were performed with SPSS 15.0 (Chicago, IL).

\section{Results}

\section{Results - Part A}

During the 10-year period between January 1998 and June 2008, 10,540 units of CRYO were transfused in 1,339 transfusion events in a total of 1,004 patients at SHSC (Figure 2). Hemorrhage in patients with low plasma fibrinogen levels due to cardiac surgery and trauma were the most common indications for CRYO use, corresponding to 405 (40\%) and 288 (29\%) of all patients, respectively (Table 3). Other less frequent indications included: cancer surgery, 59 (6\%); cancer-related hemorrhage, 48 (5\%); vascular surgery, 48 (5\%); general surgery, 34(3\%); orthopedics, 27 (2.7\%); gastro-intestinal bleeding, 26 (2.6\%); sepsis, 15 (1.5\%); neurosurgery, 15 (1.5\%); urology,12 (1.2\%); burns, 8 (0.8\%); cardiology, 8 (0.8\%), obstetric, 5 (0.5\%); neurology, 4 (0.4\%) and von Willebrand's Disease, 2 (0.2\%) (Table 3). Overall, a mean CRYO dose of $7.9( \pm 1.8)$ units was given after transfusion of $10.5( \pm 9.4)$ units of RBC, $6.5( \pm 5.4)$ units of plasma and $9.4( \pm 8)$ units of platelets. Units of CRYO per patient, dose administered and number of patients receiving single dose by diagnostic category are displayed in Table 4. The highest individual dose was on average 8.4 units, and similarly seen 
in trauma, general surgery and sepsis. The lowest individual dose, $6.7( \pm 2.3)$ units, was used for vWD. The percentage of single dose by clinical setting ranged from $50 \%$ in vWD to $100 \%$ in Cardiology, which was the only setting requiring a single dose. Relatively, sepsis and obstetrics had the highest proportions of three or more doses, $26 \%$ and $20 \%$, respectively (Table 4). Despite accounting for the largest proportion of CRYO transfusion for the entire study period, cardiac surgery utilization decreased over the study period and was surpassed by trauma between 2003 and 2004 (Figure 3). In cardio-vascular surgery, both the absolute numbers of transfusion events and patients requiring CRYO declined continuously throughout the study period (Figure 4). In contrast, the number of CRYO transfusion events and patients receiving transfusions continued to rise gradually from 1998 until 2005, dropped in 2006, increased again in 2007, and finally dropped again in 2008 (Figure 5). 
Fig 2. Study Flow Diagram - Part A

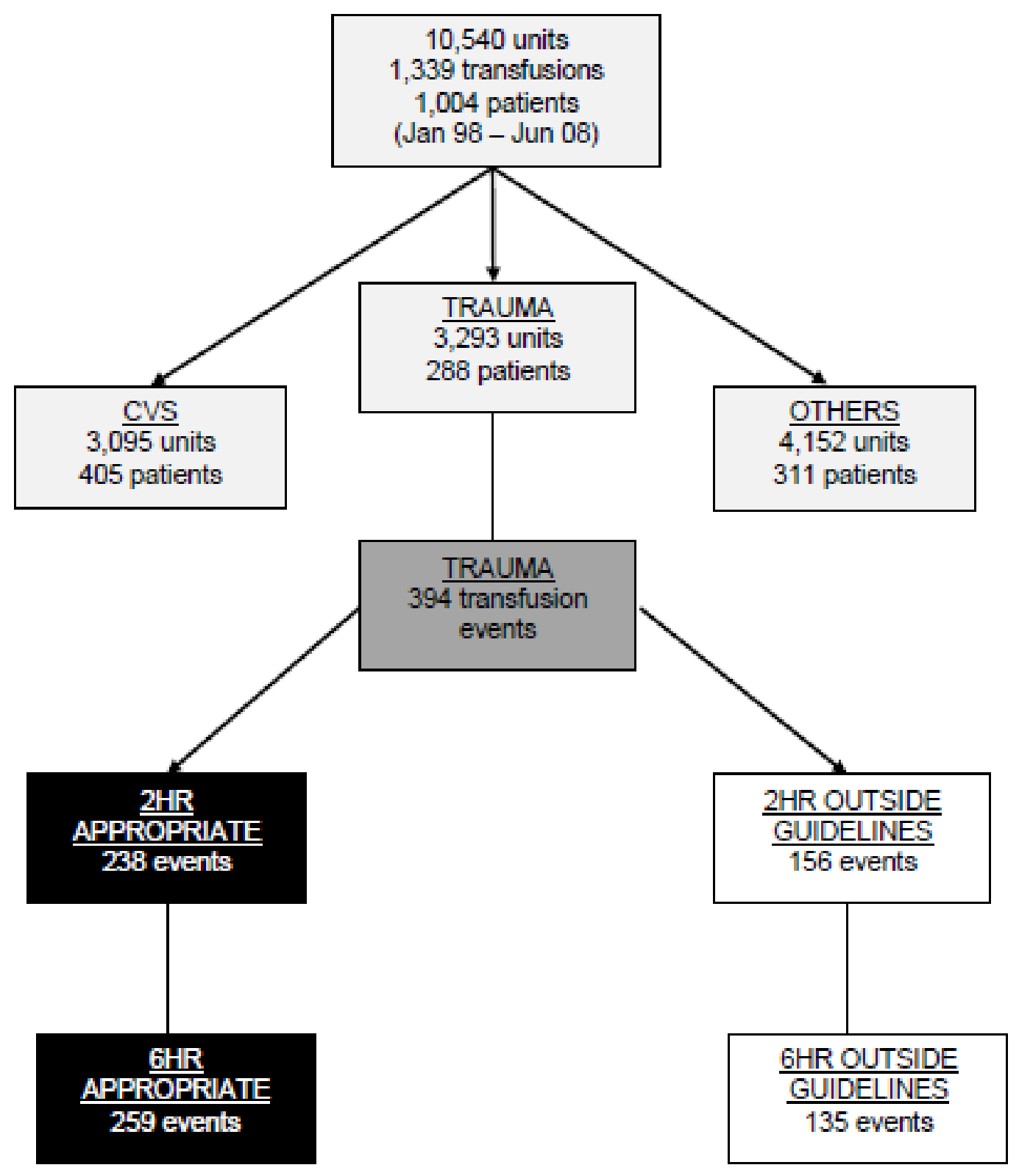

CVS, cardio-vascular surgery 
Table 3. Cryoprecipitate Transfusion at Sunnybrook (1998-2008)

\begin{tabular}{|c|c|c|c|c|}
\hline Clinical Settings & $\begin{array}{c}\text { Units of } \\
\text { CRYO (\%) }\end{array}$ & $\begin{array}{c}\text { Transfusion } \\
\text { Events }\end{array}$ & Patients & Units/Patients \\
\hline All settings & $10,540(100 \%)$ & 1339 & 1004 & 10.5 \\
\hline Cardio-vascular surgery & 3095 (37\%) & 523 & 405 & 9.6 \\
\hline Trauma & $3293(31 \%)$ & 396 & 288 & 11.4 \\
\hline Oncologic surgery & $634(6 \%)$ & 77 & 59 & 10.7 \\
\hline Cancer related-bleeding & 607 (5.8\%) & 78 & 48 & 12.6 \\
\hline Vascular surgery & $533(5 \%)$ & 66 & 48 & 11 \\
\hline General surgery & $363(3.4 \%)$ & 43 & 34 & 10.7 \\
\hline Orthopedic surgery & $209(2 \%)$ & 31 & 27 & 7.7 \\
\hline Gl bleeding & $240(2.3 \%)$ & 31 & 26 & 9.2 \\
\hline Sepsis & $202(1.9 \%)$ & 24 & 15 & 13.5 \\
\hline Neurosurgery & $141(1.3 \%)$ & 18 & 15 & 9.4 \\
\hline Urology & $106( \pm 1)$ & 13 & 12 & 8.8 \\
\hline Burn & $99(0.9 \%)$ & 12 & 8 & 12.4 \\
\hline Cardiology & $66(0.6 \%)$ & 8 & 8 & 8.2 \\
\hline Obstetrics & $78(0.7 \%)$ & 10 & 5 & 15.6 \\
\hline Neurology & $44(0.4 \%)$ & 6 & 4 & 11 \\
\hline von Willebrand's Disease & $20(0.2 \%)$ & 3 & 2 & 10 \\
\hline
\end{tabular}


Table 4. Dose of Cryoprecipitate at Sunnybrook (1998-2008)

\begin{tabular}{|c|c|c|c|c|}
\hline Clinical Settings & $\begin{array}{c}\text { Dose per } \\
\text { patient } \\
\text { (units) }\end{array}$ & $\begin{array}{c}\text { Single dose } \\
\text { (\%) }\end{array}$ & $\begin{array}{c}\text { Two doses } \\
\text { (\%) }\end{array}$ & $\begin{array}{c}\text { Three or more } \\
\text { doses (\%) }\end{array}$ \\
\hline All settings & $7.9( \pm 1.8)$ & $780(78 \%)$ & $150(15 \%)$ & $74(7 \%)$ \\
\hline Cardio-vascular surgery & $7.5( \pm 1.6)$ & $319(78 \%)$ & $61(15 \%)$ & $25(7 \%)$ \\
\hline Trauma & $8.4( \pm 1.8)$ & $218(75 \%)$ & $50(17 \%)$ & $20(8 \%)$ \\
\hline Oncologic surgery & $8.2( \pm 1.9)$ & $51(86 \%)$ & $6(10 \%)$ & $2(4 \%)$ \\
\hline Cancer related-bleeding & $7.8( \pm 2.1)$ & $35(73 \%)$ & $6(12 \%)$ & $7(15 \%)$ \\
\hline Vascular surgery & $7.8( \pm 1.3)$ & $35(73 \%)$ & $7(15 \%)$ & $6(12 \%)$ \\
\hline General surgery & $8.4( \pm 2.6)$ & $26(76 \%)$ & $4(12 \%)$ & $4(12 \%)$ \\
\hline Orthopedic surgery & $6.7( \pm 1.8)$ & $23(85 \%)$ & $4(15 \%)$ & 0 \\
\hline Gl bleeding & $7.7( \pm 2.2)$ & $23(88 \%)$ & $1(4 \%)$ & $2(8 \%)$ \\
\hline Sepsis & $8.4( \pm 2.6)$ & $10(67 \%)$ & $1(7 \%)$ & $4(26 \%)$ \\
\hline Neurosurgery & $7.8( \pm 1.1)$ & $12(80 \%)$ & $3(20 \%)$ & 0 \\
\hline Urology & $8.1( \pm 0.5)$ & $11(92 \%)$ & $1(8 \%)$ & 0 \\
\hline Burn & $8.2( \pm 2.2)$ & $5(62 \%)$ & $2(25 \%)$ & $1(13 \%)$ \\
\hline Cardiology & $8.2( \pm 0.7)$ & $8(100 \%)$ & 0 & 0 \\
\hline Obstetrics & $7.8( \pm 1.5)$ & $3(60 \%)$ & $1(20 \%)$ & $1(20 \%)$ \\
\hline Neurology & $7.3( \pm 1.6)$ & $2(50 \%)$ & $2(50 \%)$ & 0 \\
\hline von Willebrand's & $6.7( \pm 2.3)$ & $1(50 \%)$ & $1(50 \%)$ & 0 \\
\hline Disease & & & & \\
\hline
\end{tabular}

Data presented as number, percentage or mean ( \pm standard deviation) when appropriate.

CRYO, cryoprecipitate 
Fig 3. Cryoprecipitate Use according to Clinical Settings over Study Period

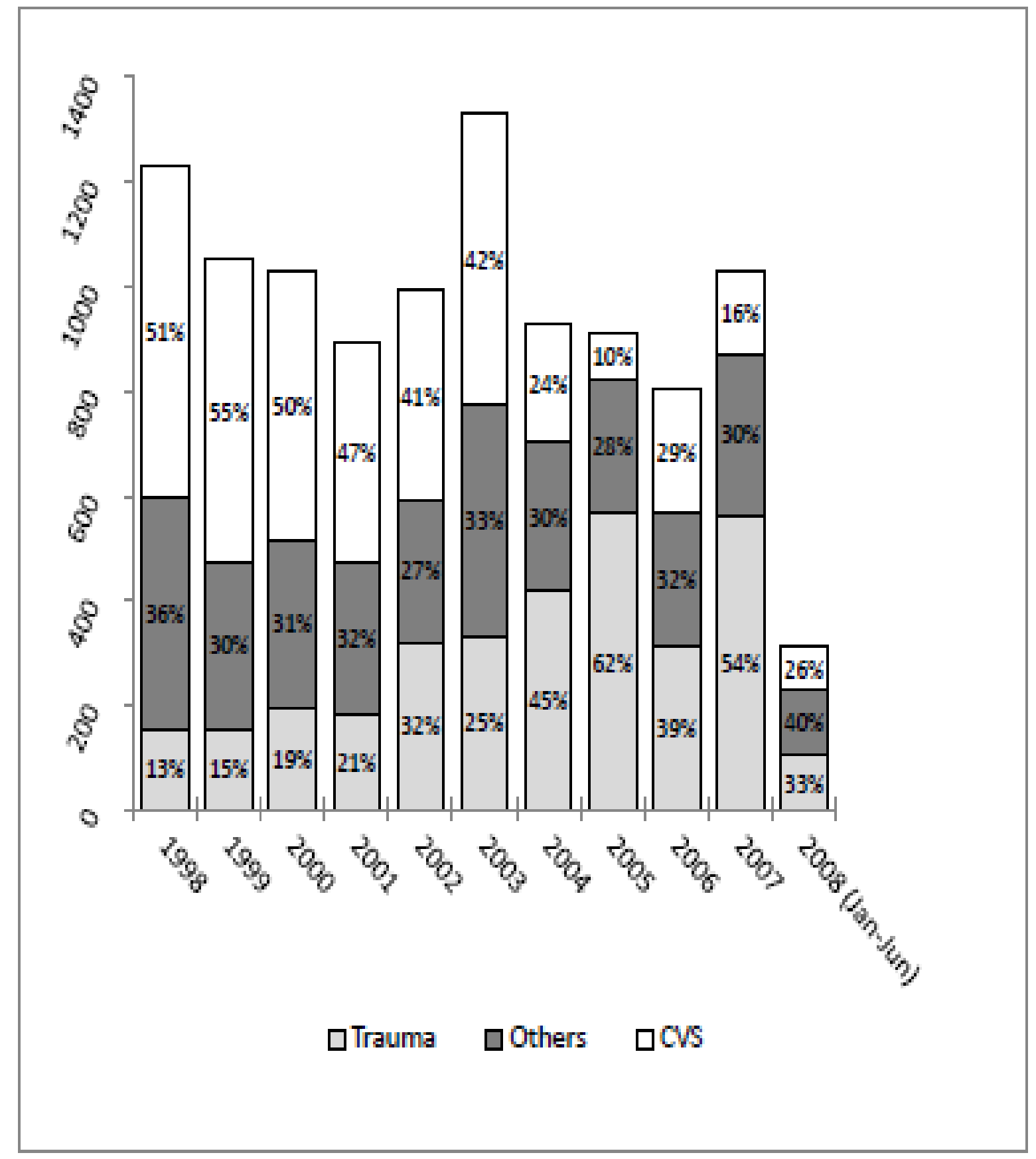

Data presented as absolute numbers and percentage by year of study. CRYO, cryoprecipitate 
Fig 4. Number of Cryoprecipitate Transfusion Events and Patients Receiving Cryoprecipitate in Cardio-vascular Surgery over Study Period

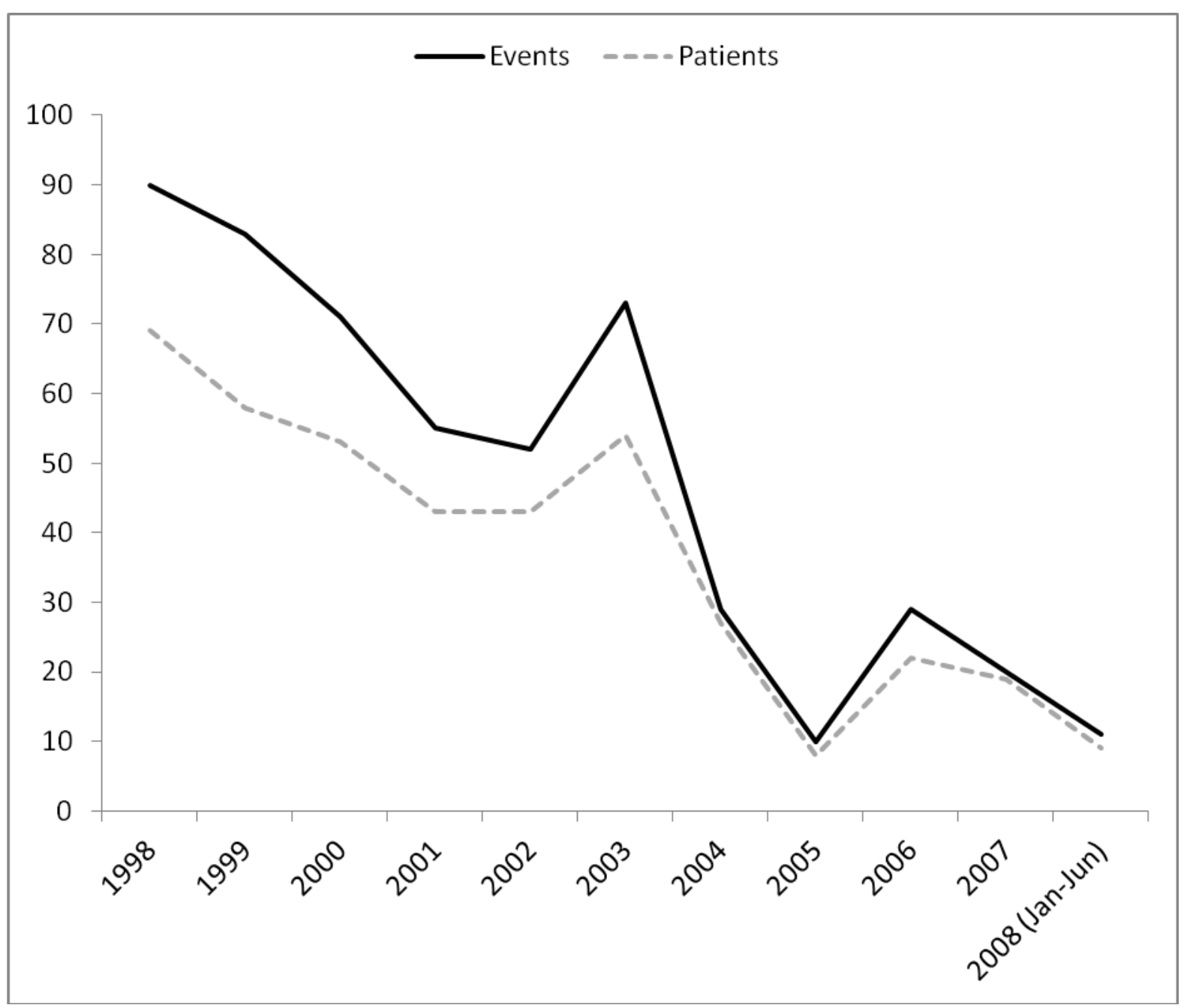


Fig 5. Number of Cryoprecipitate Transfusion Events and Patients Receiving Cryoprecipitate in Trauma over Study Period

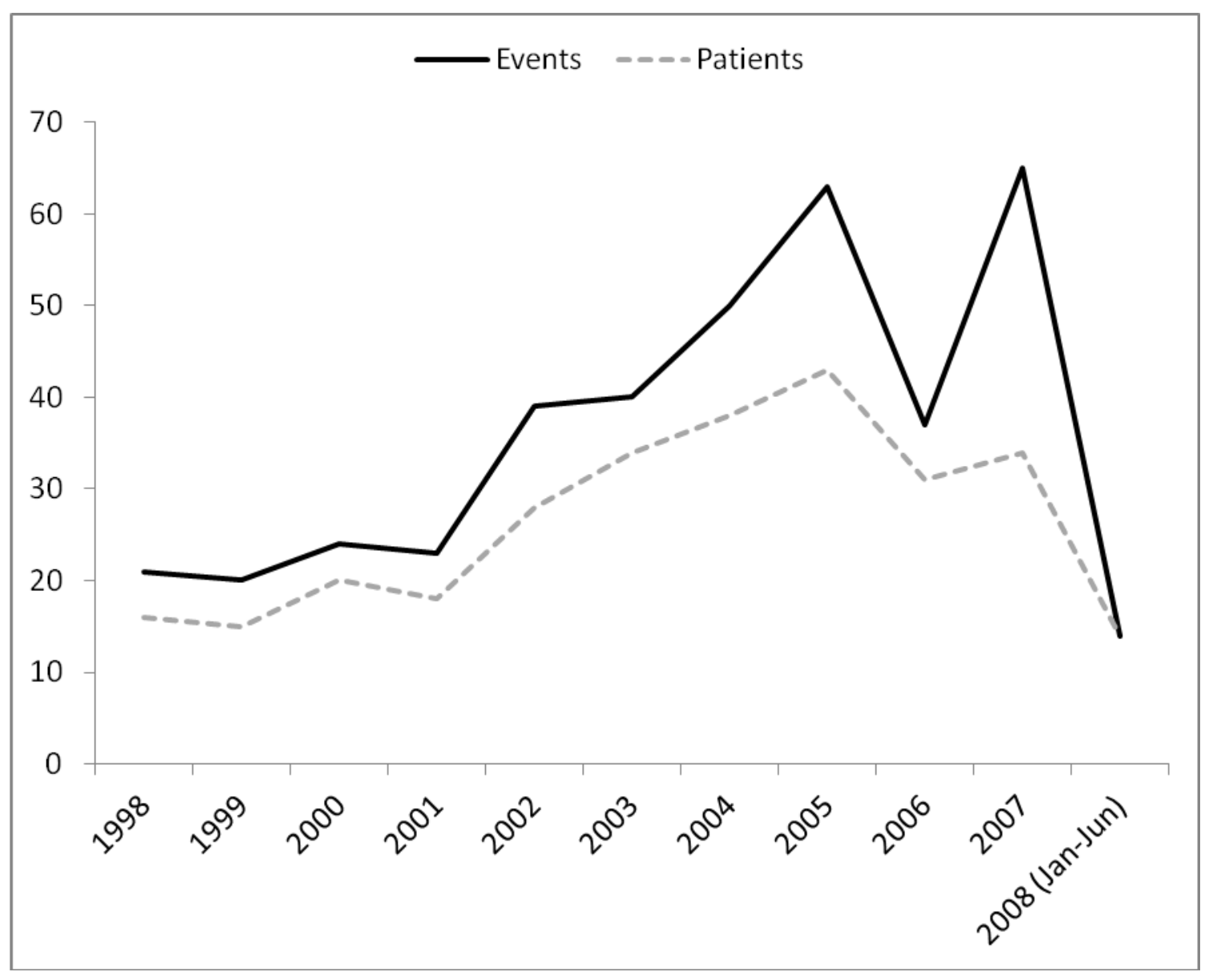


In trauma patients, 3293 units of CRYO were given in 394 transfusion events, involving 288 patients (Figure 6). The mean number of units per dose of CRYO given was $8.4( \pm 1.8)$, at a median of 4.5 hour $(2.9,7.5)$ from hospital admission. Out of 394 transfusion events, 82 (21\%) had no fibrinogen measurement within 2 hour before and/or after CRYO transfusion and 49 (12\%) had no fibrinogen levels measured at any time. The appropriateness rates by both 2 hour and 6 hour cut-off criteria for 394 CRYO transfusion events were 60\% and 66\%, respectively (Figure 7). The rates for fibrinogen measurement before and after increased gradually to the highest levels within 1 hour of the transfusion event (Figure 8). The proportions of events with $<1.0 \mathrm{~g} / \mathrm{L}$ were higher within 2 hour prior to the CRYO transfusion (Figure 9). Hourly fibrinogen measurements after CRYO transfusion showed that rates of failure to raise fibrinogen levels to $>1.5 \mathrm{~g} / \mathrm{L}$ ranged from $35 \%$ at 3 hour to $59 \%$ at 1 hour within 6 hours following the event (Figure 10). Apart from an isolated drop in 2001, rates of appropriateness of CRYO transfusion in trauma increased steadily over the study period, improving from $38.1 \%$ in the beginning to $78.6 \%$ by the end of the study period (Figure 11 ).

The comparison between patients who had appropriate and outside guideline CRYO transfusions revealed they were similar with respect to age, gender, type of trauma, ISS, presence of severe TBI, standard coagulation tests and degree of acidosis (Table 5). However, the appropriate group had less RBC and plasma transfusions before CRYO than the outside guideline group (Table 6).

Subgroup analysis comparing patients with appropriate events to patients with no fibrinogen levels revealed no significant differences in demographics, severity of injury, coagulation parameters, acidosis and transfusion of blood and blood products between groups (Tables 7 \& 8). 
Fig 6. Study Flow Diagram - Part B

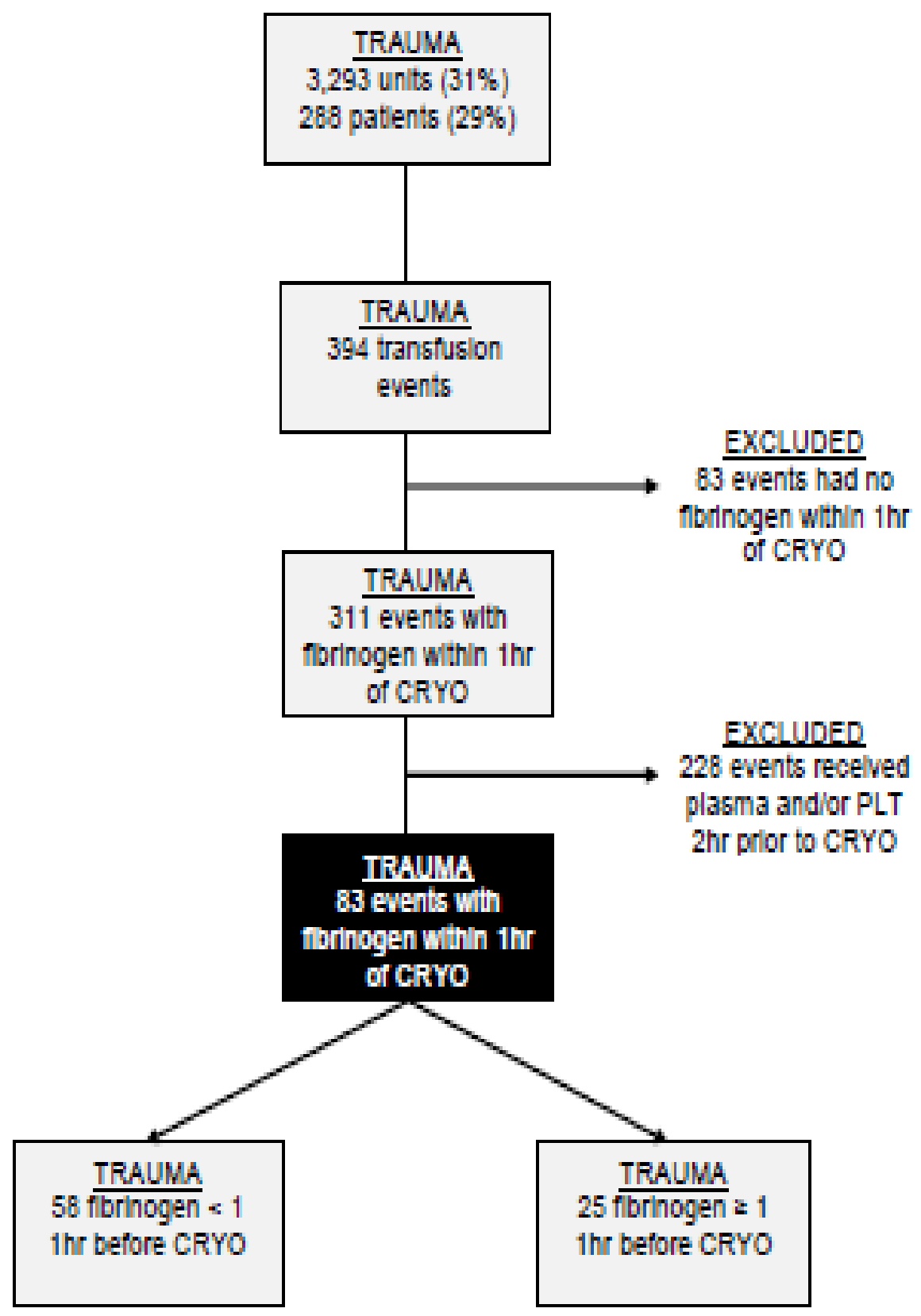

CRYO, cryopreclpitate; PLT, platelets 
Fig 7. Sunnybrook Rates of Appropriateness for Cryoprecipitate Transfusions in Trauma Using Strict ( $2 \mathrm{hr}$ cutoff) and Lenient (6hr cutoff) Criteria

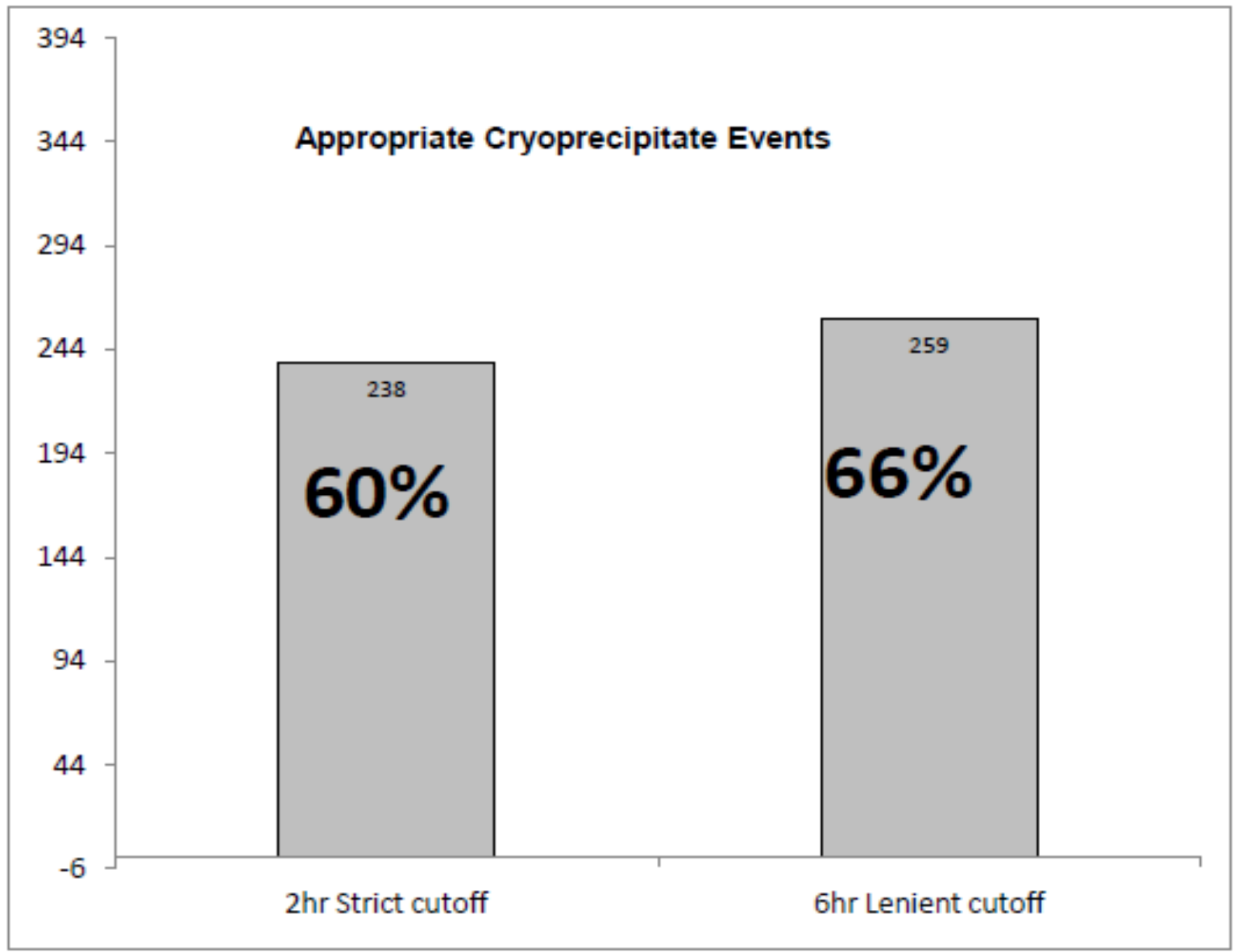

Cryoprecipitate transfusion was considered appropriate if fibrinogen levels were < $1.0 \mathrm{~g} / \mathrm{L}$ before and/or $1.5 \mathrm{~g} / \mathrm{L}$ within 2 hours (strict criteria) or 6 hours (lenient criteria). Data presented as percentage. 
Fig 8. Hourly Rates of Fibrinogen Measurement before and after Cryoprecipitate Transfusion

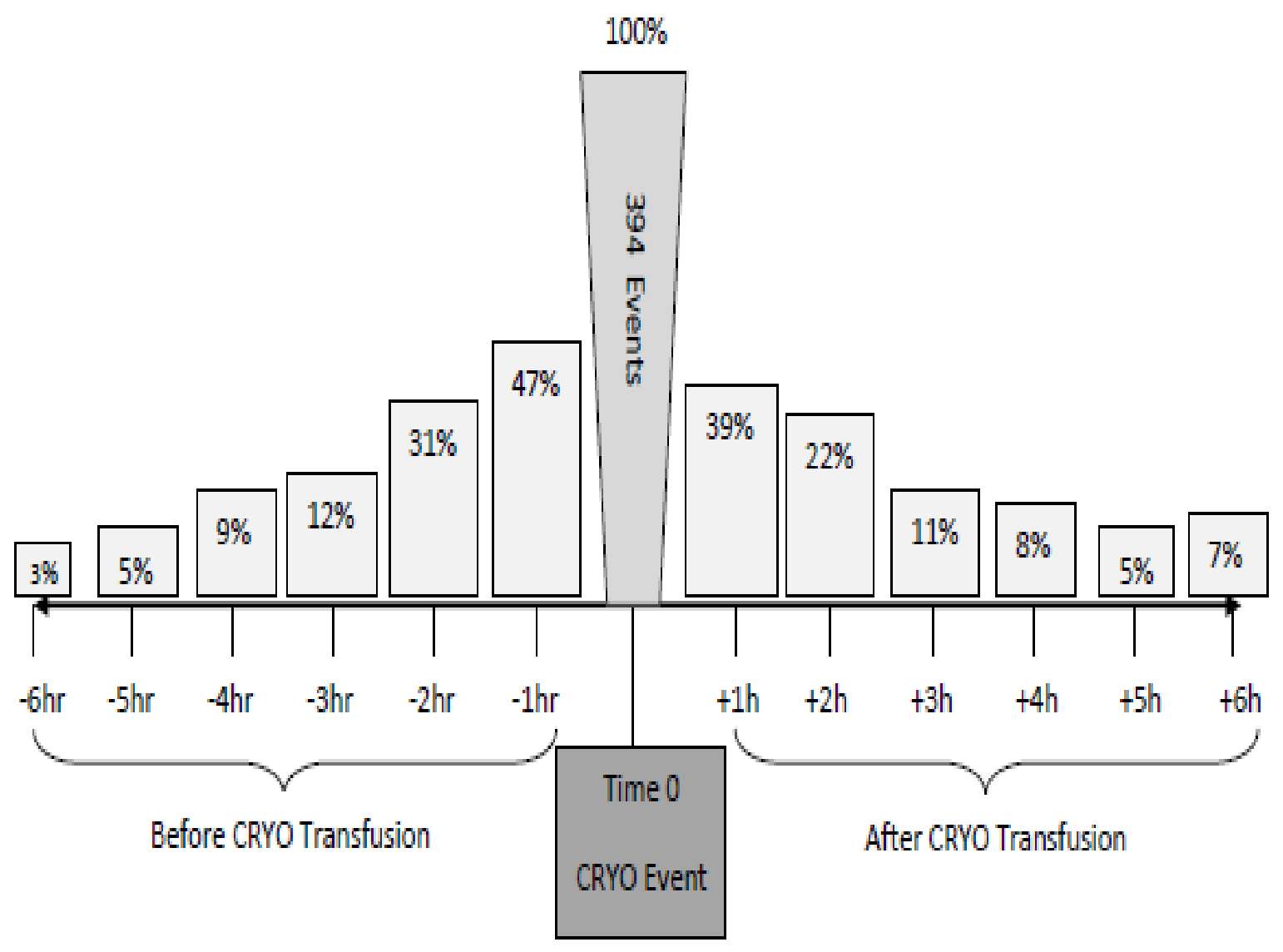

Data presented as percentages. CRYO, cryoprecipitate. 
Fig 9. Hourly Fibrinogen Measurements and Fibrinogen Levels $<1.0 \mathrm{~g} / \mathrm{L}$ within 6 hours before Cryoprecipitate Transfusion for 394 Transfusion Events in Trauma

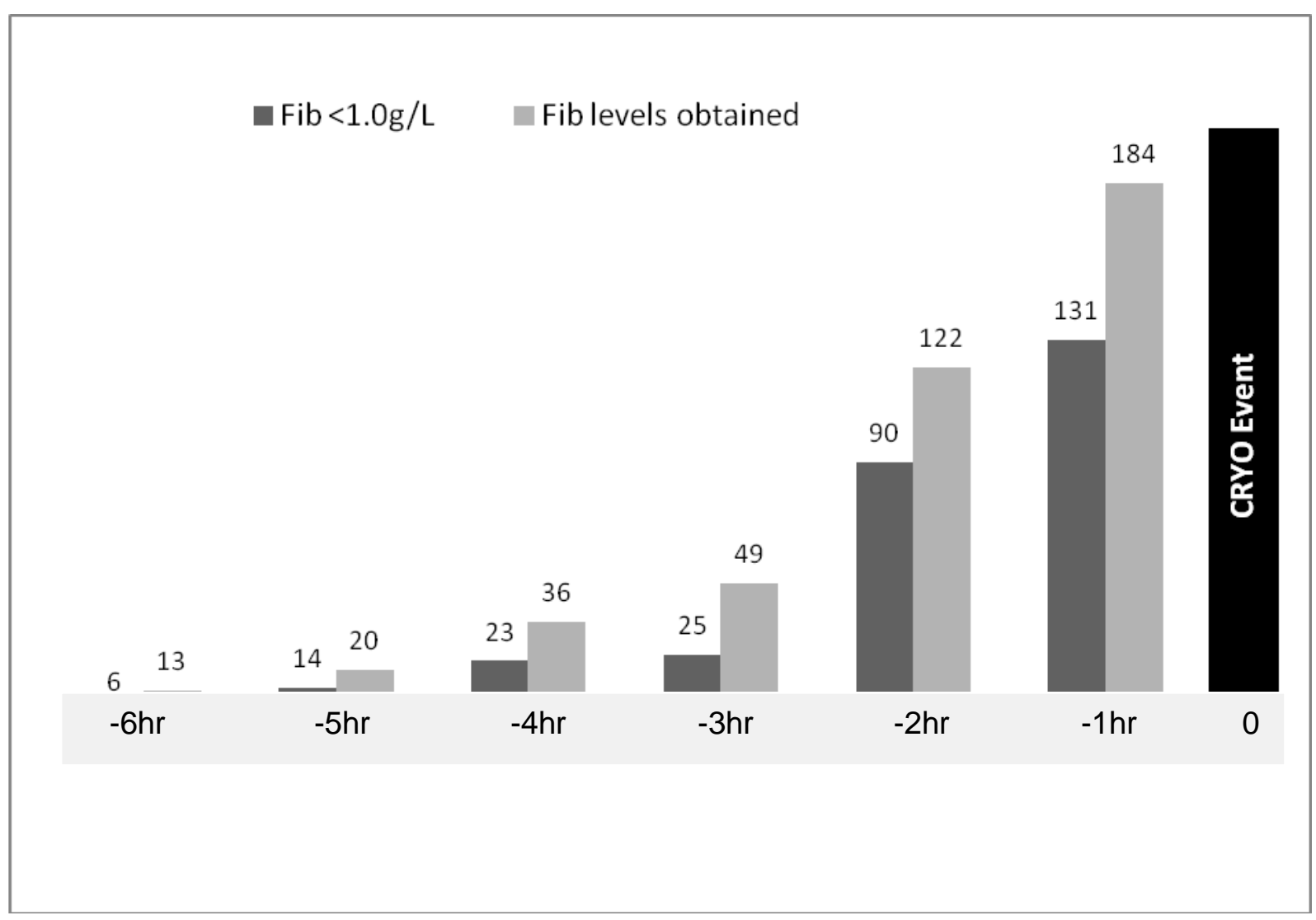

Fib, fibrinogen; CRYO, cryoprecipitate. 
Fig 10. Hourly Fibrinogen Measurements and Fibrinogen Levels $\leq 1.5 \mathrm{~g} / \mathrm{L}$ within 6 hours after Cryoprecipitate Transfusion for 394 Transfusion Events in Trauma

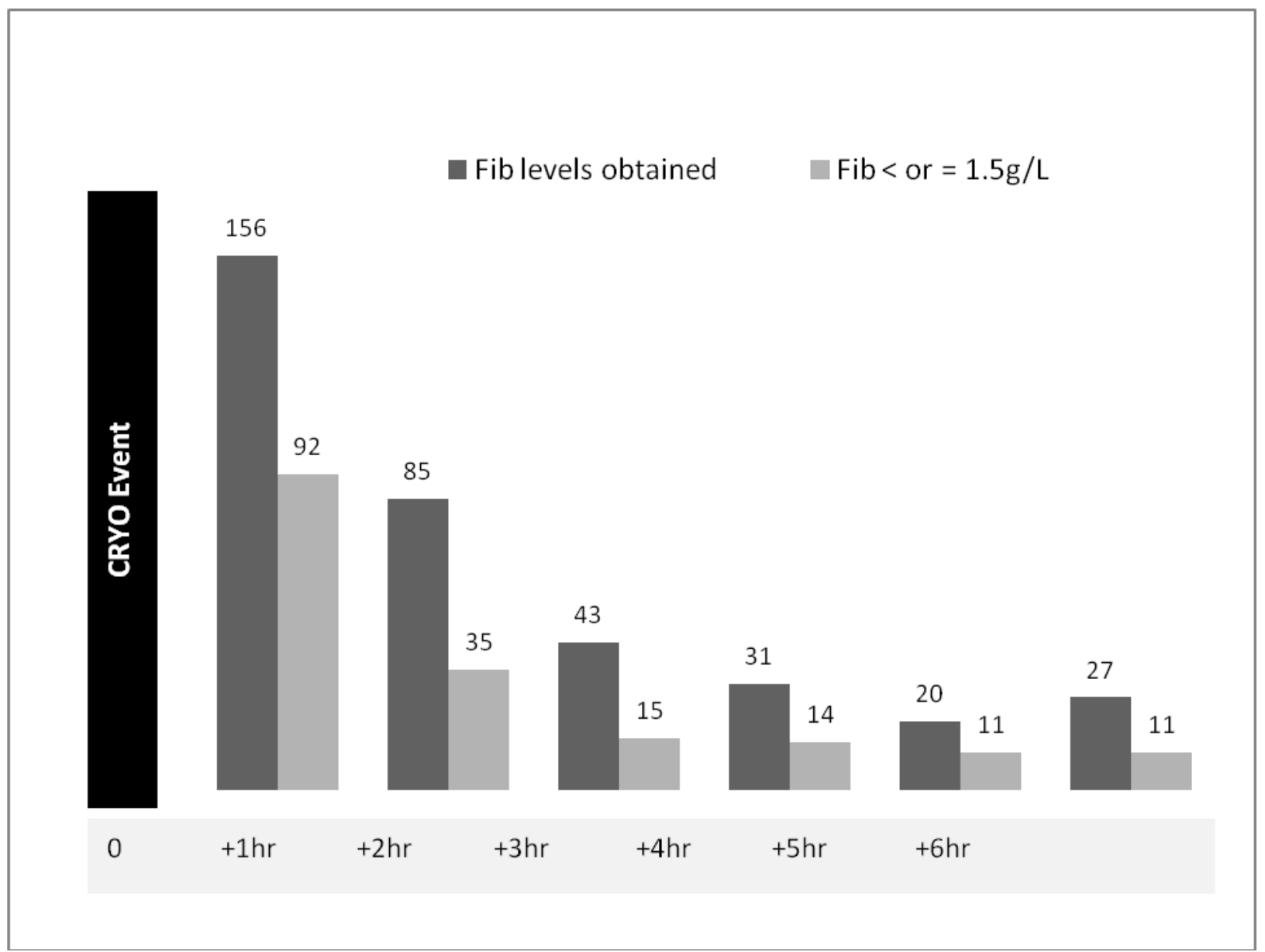

Fib, fibrinogen; CRYO, cryoprecipitate. 
Fig 11. Appropriate Cryoprecipitate Transfusions in Trauma over Study Period

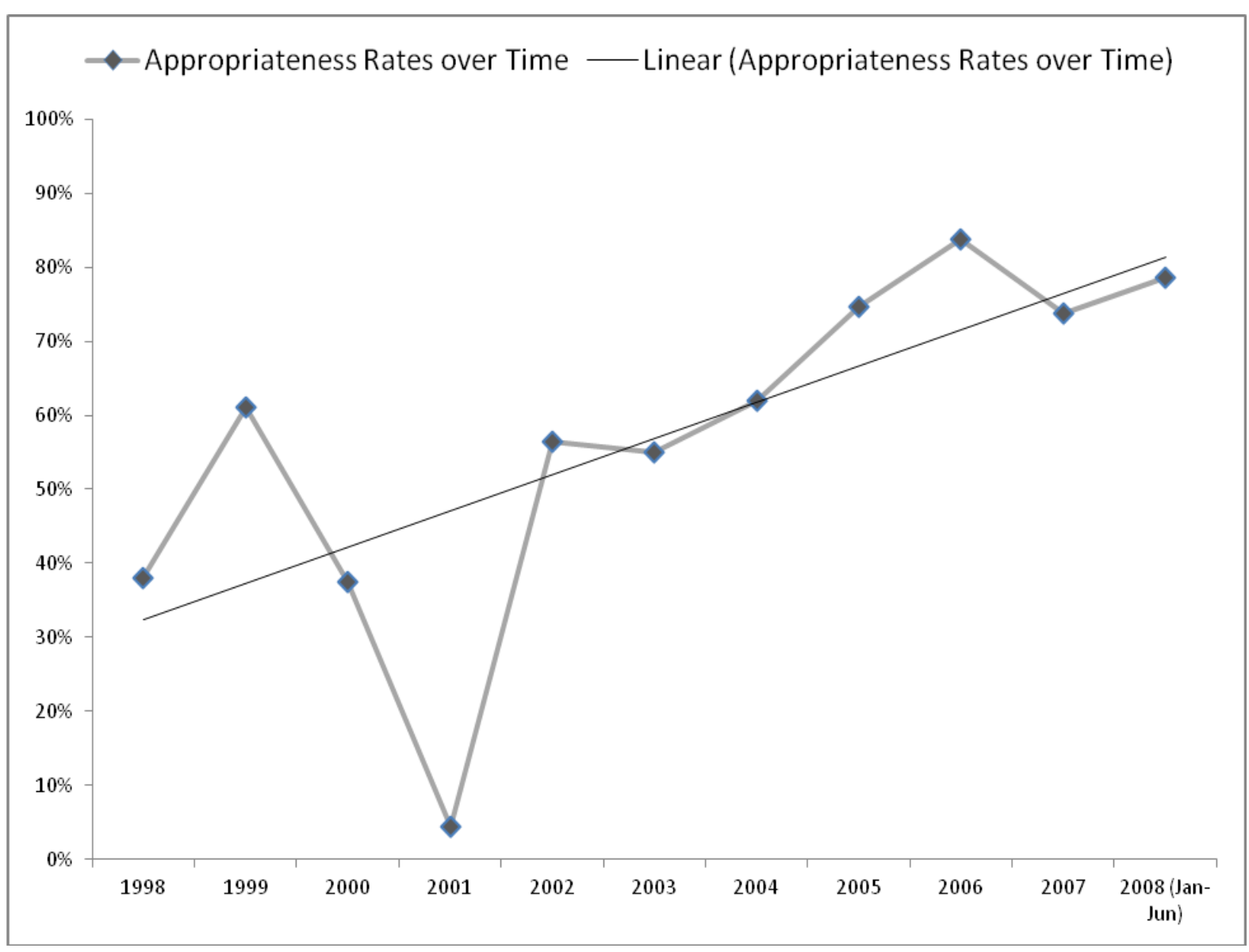

Data presented as percentages by year of study. 
Table 5. Comparison of Baseline Characteristics for Patients with Appropriate and Outside Guidelines Cryoprecipitate Transfusion Events in Trauma Patients

\begin{tabular}{lcccc}
\hline Variables & $\begin{array}{c}\text { Total Cohort } \\
(\mathbf{n}=\mathbf{2 8 8})\end{array}$ & $\begin{array}{c}\text { Appropriate } \\
(\mathbf{n}=\mathbf{1 5 6})\end{array}$ & $\begin{array}{c}\text { Outside } \\
\text { guidelines } \\
(\mathbf{n}=132)\end{array}$ & $\mathbf{P}$ \\
\hline Age (years) & $39( \pm 19)$ & $39( \pm 20)$ & $38( \pm 18)$ & 0.86 \\
Male & $210(73 \%)$ & $96(73 \%)$ & $114(74 \%)$ & 0.9 \\
Penetrating & $61(21 \%)$ & $36(23 \%)$ & $25(19 \%)$ & 0.47 \\
ISS & $40( \pm 15)$ & $41( \pm 15)$ & $40( \pm 14)$ & 0.48 \\
Severe TBI & $109(38 \%)$ & $54(41 \%)$ & $55(35 \%)$ & 0.47 \\
INR & $1.82(1.5,2.4)$ & $1.8(1.5,2.7)$ & $1.8(1.5,2.3)$ & 0.19 \\
PTT (s) & $60(45,109)$ & $64(45,113)$ & $62(46,101)$ & 0.69 \\
Platelets $(\times 10 \%$ L $)$ & $66(40,106)$ & $62(36,96)$ & $69(45,113)$ & 0.77 \\
pH & $7.19( \pm 0.17)$ & $7.19( \pm 0.16)$ & $7.18( \pm 0.17)$ & 0.5 \\
\hline
\end{tabular}

Data presented as number, percentage and median (interquartile ranges) or mean $( \pm S D)$ when appropriate; $p$ values generated by Student's $t$ and Wilcoxon Tests or $x^{2}$ Analysis, as appropriate. Two-sided test performed. CRYO, cryoprecipitate; ISS, injury severity score; Severe TBI (traumatic brain injury) = Head AIS > 3; INR, international normalized ratio; PTT, partial thromboplastin time. Laboratory values at admission. 
Table 6. Comparison of Transfusion Data for Patients with Appropriate and Outside Guidelines Cryoprecipitate Transfusion Events

\begin{tabular}{|c|c|c|c|c|}
\hline Variables & $\begin{array}{c}\text { Total } \\
\text { Cohort } \\
(n=288)\end{array}$ & $\begin{array}{c}\text { Appropriate } \\
(n=156)\end{array}$ & $\begin{array}{c}\text { Outside } \\
\text { guidelines } \\
(n=132)\end{array}$ & $\mathbf{P}$ \\
\hline RBC before CRYO (units) & $13( \pm 8)$ & $14.7( \pm 9)$ & $12.2( \pm 7.8)$ & 0.01 \\
\hline FP before CRYO (units) & $7( \pm 4)$ & $7.8( \pm 5)$ & $6.3( \pm 3.6)$ & $<0.01$ \\
\hline PLT before CRYO (units) & $5(5,10)$ & $5(5,11)$ & $5(5,10)$ & 0.12 \\
\hline
\end{tabular}

Data presented as median (interquartile ranges) or mean ( $\pm S D$ ); $p$ values generated by Student's $t$ and Wilcoxon Tests or $x^{2}$ Analysis, as appropriate. Two-sided test performed and $p<0.05$ considered significant. CRYO, cryoprecipitate; RBC, red blood cells; FP, frozen plasma; PLT, platelets. 
Table 7. Subgroup Comparison of Demographics and Baseline Characteristics for Patients with Appropriate and Outside guidelines (without Fibrinogen Levels) Cryoprecipitate Transfusion Events

\begin{tabular}{lccc}
\hline Variables & Appropriate $(\mathbf{n}=\mathbf{1 5 6})$ & $\begin{array}{c}\text { No Fibrinogen Levels } \\
(\mathbf{n}=\mathbf{3 8})\end{array}$ & $\mathbf{P}$ \\
\hline Age (years) & $39( \pm 20)$ & $35( \pm 17)$ & 0.36 \\
Male & $96(73 \%)$ & $30(79 \%)$ & 0.53 \\
Penetrating & $36(23 \%)$ & $7(18 \%)$ & 0.66 \\
ISS & $41( \pm 15)$ & $39( \pm 15)$ & 0.7 \\
Severe TBI & $54(41 \%)$ & $12(32 \%)$ & 0.7 \\
INR & $1.8(1.5,2.7)$ & $1.75(1.4,2.2)$ & 0.08 \\
PTT (s) & $64(45,113)$ & $53(43,101)$ & 0.56 \\
Platelets $\left(\times 10^{9} / \mathrm{L}\right)$ & $62(36,96)$ & $74(51,181)$ & 0.004 \\
pH & $7.19( \pm 0.16)$ & $7.2( \pm 0.15)$ & 0.5 \\
\hline
\end{tabular}

Data presented as number, percentage and median (interquartile ranges) or mean ( $\pm S D$ ) when appropriate; $p$ values generated by Student's $t$ and Wilcoxon Tests or $x^{2}$ Analysis, as appropriate. Two-sided test performed and $p<0.05$ considered significant. ISS, injury severity score; Severe TBI (traumatic brain injury) = Head AIS > 3; INR, international normalized ratio; PTT, partial thromboplastin time. Laboratory values at admission. 
Table 8. Subgroup Comparison of Transfusion Data for Patients with Appropriate and Outside guidelines (without Fibrinogen Levels) Cryoprecipitate Transfusion Events

\begin{tabular}{lccc}
\hline Variables & Appropriate $(\mathbf{n = 1 5 6 )}$ & $\begin{array}{c}\text { No Fibrinogen } \\
\text { Levels }(\mathbf{n = 3 8})\end{array}$ & $\mathbf{P}$ \\
\hline RBC before CRYO (units) & $14.7( \pm 9)$ & $15.4( \pm 9.8)$ & 0.06 \\
FP before CRYO (units) & $7.8( \pm 5)$ & $7.6( \pm 4)$ & 0.07 \\
PLT before CRYO (units) & $5(5,11)$ & $8.5(5,14)$ & 1.0 \\
\hline
\end{tabular}

Data presented as median (interquartile ranges) or mean $( \pm S D) ; p$ values generated by Student's $t$ and Wilcoxon Tests or $x^{2}$ Analysis, as appropriate. Two-sided test performed and $p<0.05$ considered significant. CRYO, cryoprecipitate; RBC, red blood cells; FP, frozen plasma; PLT, platelets. 
In 2001, 22 patients received 23 CRYO transfusions, of which, 22 were classified as outside guidelines (95.6\%). Comparing 2001 patients versus non-2001 patients, no differences in baseline characteristics were found except for lower platelet count in the outside guideline group (Tables 9 \& 10).

Interestingly, a subgroup analysis evaluating only events which fibrinogen levels were obtained 1 hour before CRYO against events without fibrinogen, demonstrated more severe TBI, worse coagulation status and acidosis related to events where fibrinogen measurements were performed (Table 11). No transfusion differences were observed between groups (Table 12).

There was no difference in hospital mortality rates when appropriate and outside guideline groups were compared (48\% versus $48 \%, \mathrm{p}=0.9$ ).

\section{Results - Part B}

For the fibrinogen response analysis, we first selected all transfusion events that had fibrinogen levels measured 1hour before and after CRYO transfusion (311 events) (Figure 6). In order to avoid confounding (transfusion of plasma and platelets as a source of fibrinogen), we then excluded 228 events of 311 events which were associated with any FP and/or platelet transfusion within 2 hour prior to the start of CRYO transfusion. Overall, 83 of the total 394 CRYO transfusions in trauma were included in the final analysis to determine the plasma fibrinogen response. Out of 83 CRYO events, 58 had fibrinogen $<1.0 \mathrm{~g} / \mathrm{L}$ and 25 had fibrinogen $\geq 1.0 \mathrm{~g} / \mathrm{L}$ before the CRYO transfusion occurred.

The overall increase in plasma fibrinogen levels after transfusion of an average of 8.7 $( \pm 1.7)$ units of CRYO in trauma was $0.55 \mathrm{~g} / \mathrm{L}( \pm 0.24)$, or $0.06 \mathrm{~g} / \mathrm{L}$ per unit of CRYO (Table 13$)$. Out of 83 CRYO transfusions, 59 (71\%), 38 (46\%) and 13 (16\%) resulted in plasma fibrinogen levels $\geq 1.0 \mathrm{~g} / \mathrm{L}, \geq 1.5 \mathrm{~g} / \mathrm{L}$ and $\geq 2.0 \mathrm{~g} / \mathrm{L}$, respectively. In 58 events where fibrinogen was < 
1.0g/L before CRYO, 8.4 units $( \pm 1.5)$ of CRYO caused an increase in plasma fibrinogen of $0.69( \pm 0.4)$ (Table 14). However, when fibrinogen levels were $\geq 1.0 \mathrm{~g} / \mathrm{L}$ before CRYO, despite

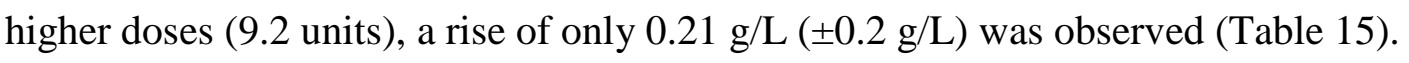
Comparison between patients associated with either events where fibrinogen were $<1.0 \mathrm{~g} / \mathrm{L}$ or fibrinogen were $\geq 1.0$ before CRYO, revealed the groups were similar with respect to age, gender, type of trauma, severity of injury, coagulation tests, degree of acidosis and number of units of RBC, FP and platelet transfused prior to the CRYO event (Table 16 \& 17). 
Table 9. Subgroup Comparison of Demographics and Baseline

Characteristics for 2001 (year) patients and non-2001 patients with Outside Guidelines Cryoprecipitate Transfusion Events

\begin{tabular}{lccc}
\hline Variables & $\begin{array}{c}\text { Non-2001 outside } \\
\text { guidelines }(\mathbf{n}=\mathbf{1 3 1})\end{array}$ & $\begin{array}{c}\text { 2001 outside } \\
\text { guidelines }(\mathbf{n}=\mathbf{2 2})\end{array}$ & $\mathbf{P}$ \\
\hline Age (years) & $38( \pm 18)$ & $40( \pm 23)$ & 0.6 \\
Male & $93(71 \%)$ & $19(86 \%)$ & 0.19 \\
Penetrating & $25(19 \%)$ & $6(27 \%)$ & 0.39 \\
ISS & $42( \pm 15)$ & $39( \pm 17)$ & 0.37 \\
Severe TBI & $50(38 \%)$ & $8(36 \%)$ & 1.0 \\
INR & $1.78(1.5,2.7)$ & $1.96(1.8,2.5)$ & 0.24 \\
PTT $(\mathrm{s})$ & $59(43,109)$ & $66(52,150)$ & 0.15 \\
Platelets $\left(\mathrm{x} 10^{9} / \mathrm{L}\right)$ & $69(33,124)$ & $42(28,62)$ & 0.01 \\
pH & $7.19( \pm 0.16)$ & $7.2( \pm 0.1)$ & 0.7 \\
\hline
\end{tabular}

Data presented as percentage and median (interquartile ranges) or mean $( \pm S D)$ when appropriate; $p$ values generated by Student's $t$ and Wilcoxon Tests or $x^{2}$ Analysis, as appropriate. Two-sided test performed and $\mathrm{p}<0.05$ considered significant. ISS, injury severity score; Severe TBI (traumatic brain injury) = Head AIS > 3; INR, international normalized ratio; PTT, partial thromboplastin time. Laboratory values at admission. 
Table 10. Subgroup Comparison of Transfusion Data for 2001 (year)

patients and non-2001 patients with Outside Guidelines Cryoprecipitate

Transfusion Events

\begin{tabular}{lccc}
\hline Variables & $\begin{array}{c}\text { Non-2001 outside } \\
\text { guidelines }(\mathbf{n = 1 3 1})\end{array}$ & $\begin{array}{c}\text { 2001 outside } \\
\text { guidelines }(\mathbf{n}=\mathbf{2 2})\end{array}$ & $\mathbf{P}$ \\
\hline RBC before CRYO (units) & $15.9( \pm 10)$ & $20.4( \pm 13)$ & 0.08 \\
FP before CRYO (units) & $8.6( \pm 5.9)$ & $9.8( \pm 5.9)$ & 0.39 \\
PLT before CRYO (units) & $9.7( \pm 8.9)$ & $12.8( \pm 8.4)$ & 0.13 \\
\hline
\end{tabular}

Data presented as median (interquartile ranges) or mean ( $\pm S D$ ); $p$ values generated by Student's $t$ and Wilcoxon Tests or $x^{2}$ Analysis, as appropriate. Two-sided test performed and $p<0.05$ considered significant. CRYO, cryoprecipitate; RBC, red blood cells; FP, frozen plasma; PLT, platelets. 
Table 11. Subgroup Comparison of Demographics and Baseline

Characteristics for CRYO events with and without fibrinogen measured within $1 \mathrm{hr}$ before Cryoprecipitate Transfusion

\begin{tabular}{lccc}
\hline Variables & $\begin{array}{c}\text { Events with } \\
\text { fibrinogen 1hr before } \\
\text { CRYO }(\mathbf{n}=83)\end{array}$ & $\begin{array}{c}\text { Events without } \\
\text { fibrinogen 1hr before } \\
\text { CRYO }(\mathbf{n = 3 1 1})\end{array}$ & $\mathbf{P}$ \\
\hline Age (years) & $39( \pm 18)$ & $38( \pm 23)$ & 0.79 \\
Male & $59(72 \%)$ & $232(74 \%)$ & 0.57 \\
Penetrating & $22(26 \%)$ & $69(22 \%)$ & 0.46 \\
ISS & $38( \pm 14)$ & $41( \pm 15)$ & 0.05 \\
Severe TBI & $28(34 \%)$ & $152(49 \%)$ & 0.02 \\
INR & $2.06(1.6,4.4)$ & $1.9(1.5,2.8)$ & 0.06 \\
PTT $(\mathrm{s})$ & $88(53,150)$ & $66(45,124)$ & 0.02 \\
Platelets $\left(\times 10^{9} / \mathrm{L}\right)$ & $58(30,93)$ & $64(32,100)$ & 0.03 \\
pH & $7.14( \pm 0.18)$ & $7.19( \pm 0.16)$ & 0.03 \\
\hline
\end{tabular}

Data presented as number, percentage and median (interquartile ranges) or mean $( \pm S D)$ when appropriate; $p$ values generated by Student's $t$ and Wilcoxon Tests or $x^{2}$ Analysis, as appropriate. Two-sided test performed and $p<0.05$ considered significant. ISS, injury severity score; Severe TBI (traumatic brain injury) = Head AIS > 3; INR, international normalized ratio; PTT, partial thromboplastin time. Laboratory values at admission. 
Table 12. Subgroup Comparison of Transfusion Data for CRYO events with and without fibrinogen measured within $1 \mathrm{hr}$ before Cryoprecipitate transfusion.

\begin{tabular}{lccc}
\hline Variables & $\begin{array}{c}\text { Events with } \\
\text { fibrinogen } 1 \mathrm{hr} \\
\text { before CRYO }(\mathbf{n}=\mathbf{8 3})\end{array}$ & $\begin{array}{c}\text { Events without } \\
\text { fibrinogen 1hr } \\
\text { before CRYO } \\
(\mathbf{n}=\mathbf{3 1 1})\end{array}$ & $\mathbf{P}$ \\
\hline RBC before CRYO (units) & $15( \pm 10)$ & $16.7( \pm 11)$ & 0.25 \\
FP before CRYO (units) & $8.2( \pm 6)$ & $8.9( \pm 6.2)$ & 0.34 \\
PLT before CRYO (units) & $10(5,15)$ & $10(5,15)$ & 0.52 \\
\hline
\end{tabular}

Data presented as median (interquartile ranges) or mean ( $\pm S D$ ); $p$ values generated by Student's $t$ and Wilcoxon Tests or $x^{2}$ Analysis, as appropriate. Two-sided test performed and $\mathrm{p}<0.05$ considered significant. CRYO, cryoprecipitate; RBC, red blood cells; FP, frozen plasma; PLT, platelets. 
Table 13. Plasma Fibrinogen Response to Cryoprecipitate Transfusion during Massive Transfusion in Trauma

\begin{tabular}{ccccc}
\hline $\mathbf{N}$ & $\begin{array}{c}\text { Pre-CRYO } \\
\text { fibrinogen (g/L) }\end{array}$ & $\begin{array}{c}\text { Post-CRYO } \\
\text { fibrinogen (g/L) }\end{array}$ & $\begin{array}{c}\Delta \\
\text { (Post - Pre) }\end{array}$ & $\begin{array}{c}\text { Increase } \\
\text { (\%) }\end{array}$ \\
\hline 83 & $0.83( \pm 0.35)$ & $1.38( \pm 0.59)$ & $0.55( \pm 0.24)$ & $66 \%$ \\
\hline
\end{tabular}

Data presented as mean ( $\pm S D)$ and percentages.

Table 14. Plasma Fibrinogen Response to Cryoprecipitate Transfusion for Events with Fibrinogen $<1.0 \mathrm{~g} / \mathrm{L}$ before Administration of Cryoprecipitate during Massive Transfusion in Trauma

\begin{tabular}{ccccc}
\hline $\mathbf{N}$ & $\begin{array}{c}\text { Pre-CRYO } \\
\text { fibrinogen (g/L) }\end{array}$ & $\begin{array}{c}\text { Post-CRYO } \\
\text { fibrinogen (g/L) }\end{array}$ & $\begin{array}{c}\Delta \\
\text { (Post - Pre) }\end{array}$ & $\begin{array}{l}\text { Increase } \\
\mathbf{( \% )}\end{array}$ \\
\hline 58 & $0.65( \pm 0.2)$ & $1.35( \pm 0.6)$ & $0.69( \pm 0.4)$ & $106 \%$ \\
\hline
\end{tabular}

Data presented as mean ( $\pm \mathrm{SD})$ and percentages. 
Table 15. Plasma Fibrinogen Response to Cryoprecipitate

Transfusion for Events with Fibrinogen $\geq 1.0 \mathrm{~g} / \mathrm{L}$ before

Administration of Cryoprecipitate during Massive Transfusion in Trauma

\begin{tabular}{ccccc}
\hline $\mathbf{N}$ & $\begin{array}{c}\text { Pre-CRYO } \\
\text { fibrinogen (g/L) }\end{array}$ & $\begin{array}{c}\text { Post-CRYO } \\
\text { fibrinogen (g/L) }\end{array}$ & $\begin{array}{c}\Delta \\
\text { (Post - Pre) }\end{array}$ & $\begin{array}{l}\text { Increase } \\
\text { (\%) }\end{array}$ \\
\hline 25 & $1.2( \pm 0.3)$ & $1.45( \pm 0.5)$ & $0.21( \pm 0.2)$ & $17 \%$ \\
\hline
\end{tabular}

Data presented as mean ( $\pm S D)$ and percentages. 
Table 16. Subgroup Comparison of Demographics and Baseline Characteristics for patients with fibrinogen $<1.0 \mathrm{~g} / \mathrm{L}$ and with fibrinogen $\geq$ 1.0g/L within $1 \mathrm{hr}$ before Cryoprecipitate transfusion.

\begin{tabular}{lccc}
\hline Variables & Fibrinogen $<\mathbf{1}(\mathbf{n}=\mathbf{5 8})$ & Fibrinogen $\geq \mathbf{1}(\mathbf{n}=\mathbf{2 5})$ & $\mathbf{P}$ \\
\hline Age (years) & $39.8( \pm 18)$ & $37( \pm 21)$ & 0.62 \\
Male & $34(65 \%)$ & $19(79 \%)$ & 0.29 \\
Penetrating & $13(25 \%)$ & $5(21 \%)$ & 0.78 \\
ISS & $39( \pm 14)$ & $39( \pm 15)$ & 0.98 \\
Severe TBI & $15(29 \%)$ & $8(33 \%)$ & 0.79 \\
INR & $2(1.6,3.3)$ & $1.9(1.7,4.1)$ & 0.69 \\
PTT (s) & $83(48,150)$ & $78(60,115)$ & 0.8 \\
Platelets $\left(x 10^{9} / \mathrm{L}\right)$ & $58(34,100)$ & $61(32,82)$ & 0.55 \\
pH & $7.12( \pm 0.2)$ & $7.18( \pm 0.15)$ & 0.18 \\
\hline
\end{tabular}

Data presented as percentage and median (interquartile ranges) or mean ( $\pm S D$ ) when appropriate; $p$ values generated by Student's $t$ and Wilcoxon Tests or $x^{2}$ Analysis, as appropriate. Two-sided test performed and $\mathrm{p}<0.05$ considered significant. ISS, injury severity score; Severe TBI (traumatic brain injury) = Head AIS > 3; INR, international normalized ratio; PTT, partial thromboplastin time. Laboratory values at admission. 


\section{Discussion}

\section{Discussion - Part A}

Compared to previous audits, our review found high rates of appropriateness for CRYO use (60\% and $66 \%$ based on fibrinogen levels of $<1.0 \mathrm{~g} / \mathrm{L}$ before and $/$ or $\leq 1.5 \mathrm{~g} / \mathrm{L}$ after $\mathrm{CRYO}$ transfusion, measured at 2 or 6 hour cut-off points, respectively) in the context of massively transfused trauma patients, with notable improvement during the study period. Of note, in the final year of the study $78.6 \%$ were appropriate.

During massive transfusion, the definition of appropriateness can be challenging. CRYO preparation involves thawing, reconstitution and pooling which requires about 30 min. The turnaround time for laboratory results of fibrinogen levels usually requires up to $30-60$ minutes. In addition, the emergent nature of massive blood loss might preclude performing and/or waiting for laboratory results before transfusing blood and/or blood products. In our cohort of trauma patients, CRYO was administered at a median of $4.5 \mathrm{hr}$ from hospital admission. Also, the subgroup analysis comparing patients who had appropriate and outside guideline events, showed that both groups had the same severity of injury, degree of acidosis and coagulopathy, but had different amounts of RBC and plasma transfused prior to CRYO. Patients in the outside guideline group received more RBC and plasma than the appropriate group, implying a possible difference in bleeding rates, possibly more urgency for CRYO transfusion, and more unstable clinical setting. Unlike a previous audit that used fibrinogen levels taken $6 \mathrm{hr}$ before/after transfusion to categorize appropriateness (Alport et al., 2008), we adopted a narrower time window of $2 \mathrm{hr}$, as we believed this to be more appropriate for the clinical setting of actively bleeding patients.

Alport et al. conducted an audit involving 25 Canadian hospitals and reported an overall 24\% of appropriateness for CRYO use in different clinical settings (Alport et al., 2008). The 
single most common indication for CRYO use was cardiac surgery (45.4\% of events), followed by noncardiac surgery (16.9\%) and trauma, which corresponded to only $12.3 \%$ of the events. The authors categorized CRYO transfusions as likely appropriate if a fibrinogen level, taken within $6 \mathrm{hr}$ before or after transfusion was not more than 1.0g/L. However, the authors did not report on individual appropriateness rates for the different clinical settings. In 2003, an Australian study reported that only 38\% of CRYO transfusions were considered appropriate when the same fibrinogen level criteria were applied (Schofield et al., 2003). However, the time to fibrinogen measurement in this report was not stated. Finally, an audit from the United States also published in 2003, applying different criteria for appropriateness, reported that 76\% of CRYO transfusions were appropriate in 51 patients (Pantanowitz et al., 2003). In that report, CRYO transfusion was considered appropriate for a fibrinogen level less than $1.0 \mathrm{~g} / \mathrm{L}$ when bleeding, and in addition, for tissue plasminogen activator-related hemorrhage, transfusion of 10 or more PRBC units irrespective of fibrinogen level, uremic bleeding and von Willebrand's disease. The two latter indications are considered inappropriate by others due to the availability of desmopressin, virally inactivated human-derived factor VIII/von Willebrand factor concentrates and fibrin (Janson et al., 1980; Maierhoter et al., 1981; Triulzi et al., 1990; Weigert et al., 1998; Mannucci, 2004).

We believe that there are several local hospital/medical factors associated with the high rates of appropriateness seen in our review as discussed below.

First, there is a high compliance rates among trauma team, surgeons, anesthesiologists and intensivists with the hospital massive transfusion guidelines, which were officially introduced as hospital policy in 2003. However, it was in place as transfusion medicine recommendations since the onset of this review. Our transfusion guidelines recommend hourly fibrinogen levels during massive transfusion, which is overseen by a transfusion medicine specialist and blood bank technologists. During our massive transfusion protocol, coagulation 
testing, including fibrinogen levels are performed in an expedited fashion and results are usually delivered within 30 to 60 minutes of sample arrival. Furthermore, in our institution, the blood bank technologist routinely checks the fibrinogen levels at any request for CRYO transfusion and often prompts testing when the test has not been requested on the most recent coagulation sample.

Our transfusion medicine service has a policy of prospectively auditing all transfusion requests outside our transfusion guidelines. The medical laboratory technologist prompts review by the medical director of transfusion medicine who follows-up these cases on a "caseby-case” basis. The medical director or his/her delegate, first, reviews the transfusion request and patient's clinical data pertinent to transfusion medicine. Then, the reason for the deviation is discussed in a "real time fashion” with the ordering physician who has to justify their order. This model allows the opportunity for education if lack of knowledge is a factor. Finally, agreement is reached and the request might be: (i) disregarded and documentation for the inappropriateness is performed on the request form by the medical director; (ii) withheld until further clinical/laboratorial information is available and case reassessed; medical director documented reason for withholding on request form and follows-up on the case until final decision is made and/or no additional transfusion medicine input is required; (iii) the transfusion request is approved and executed but justification for the guidelines deviation documented on request form by medical director. A recent systematic review of behavioral interventions, including guidelines, prospective audits, retrospective audits, and reminders, or a combination of them, concluded that such interventions appear to be effective in changing physician transfusion practice and reducing inappropriate blood utilization (Tinmouth et al., 2005).

Finally, CRYO is also prepared in anticipation based on laboratory results independent of the medical request as per our massive transfusion guidelines. The medical team is made 
aware of the product availability and responsible for the ultimate decision regarding utilization. Of these non-clinician driven CRYO transfusion events, 100\% would be appropriate according to our hospital transfusion policies.

\section{Discussion - Part B}

This study also suggests that the response to CRYO transfusion $(0.55 \mathrm{~g} / \mathrm{L}$ increase in plasma levels of fibrinogen) in trauma is at the lower limit of the expected range, when standard CRYO dosing is applied, according to expert opinions. The transfusion of 8.7 units of CRYO resulted in plasma fibrinogen levels of $1.5 \mathrm{~g} / \mathrm{L}$ or greater in only $47 \%$ of the cases. The same dose produced fibrinogen levels of $2.0 \mathrm{~g} / \mathrm{L}$ or greater in only $16 \%$ of the events.

CRYO is exclusively used for the replenishment of fibrinogen at our institution. A standard CRYO dose of 8 units contains at least $2 \mathrm{~g}$ of fibrinogen. The American Society of Anesthesiology, in their guidelines for blood component therapy, states that an average dose of 1 unit of CRYO per 10kg of body weight raises plasma fibrinogen by approximately $0.5 \mathrm{~g} / \mathrm{L}$ in the absence of continued consumption or massive bleeding (American Society of Anesthesiologists, 1996). In 2002, the American Association of Blood Banks guide to blood transfusion therapy stated that 1 unit of CRYO increases the fibrinogen by $0.05-0.1 \mathrm{~g} / \mathrm{L}$ in average sized adult (American Association of Blood Banks, 2002). In 2006, Rossaint et al. suggested that 1 unit of CRYO per 7 - 10kg of body weight increases plasma fibrinogen level by 0.5g/L (Rossaint et al., 2006). Recently, the British guidelines on the management of Disseminated Intravascular Coagulation (DIC) stated that a dose of 3g of fibrinogen would be expected to raise plasma fibrinogen by around $1 \mathrm{~g} / \mathrm{L}$ (Levi et al., 2009). Interestingly, those statements are not supported by clinical evidence and these statements reflect expert opinion only. To the best of our knowledge, our study, which analyzes the fibrinogen response of 83 CRYO transfusions in a population of massively transfused trauma patients, represents the 
largest series addressing the issue in this setting to date. Of note, our fibrinogen response is likely similar to other settings where fibrinogen is used, such as in massive surgical or obstetric hemorrhage.

In the context of significant bleeding in elective surgical patients, a drop in fibrinogen level is the first coagulation defect observed (Hiippala et al., 1995). The cleavage of fibrinogen by thrombin results in the formation of fibrin polymers, which by binding FXIII, produces a strong fibrin network (Velik-Salchner et al., 2007). Fibrinogen also plays an important role in inducing platelet activation and aggregation. It is also a positive acute-phase reactant protein (Lowe et al., 2004), which might be also elevated in a wide spectrum of physiological, pathological and lifestyle conditions, such as increasing age and female sex (Lowe et al., 1997); colder season (Van der Bom et al., 1997); pregnancy and oral contraception (Kluft and Lansink, 1997); menopause (Lowe et al., 1997); smoking (Humphries et al., 1999; Woodward et al.,1997); acute exercise (Humphries et al., 1999); genetic conditions (Humphries et al., 1999); and acute-phase reactions (Hemostasis \& Thrombosis, 1994; Humphries et al., 1999). Of note, plasma fibrinogen is expected to increase to levels of approximately $7 \mathrm{~g} / \mathrm{L}$ by postoperative day 5 after trauma and surgery, even without intra-operative administration (Thompson et al., 2007; Wei et al., 1995). Our study performed fibrinogen measurements during resuscitation with a narrow window (1 hour before and after CRYO), which we believe might reflect more exogenous replacement than physiologic response. Of note, our study used the Clauss method for fibrinogen determination during the entire duration of the study. It determines the functional plasma fibrinogen levels, and remains the routine assay of choice for the diagnosis of hypofrinogenemia in the context of bleeding (Mackie et al., 2003). No colloids are used for trauma resuscitation in our trauma system, which may potentially alter fibrinogen measurements in the Clauss method. 
In trauma, a recent retrospective review of 252 combat-related trauma patients requiring massive transfusion, demonstrated an association between increased fibrinogen (mainly from plasma and CRYO transfusion) to RBC ratios and improved survival (Stinger et al., 2008). The role of fibrinogen for the management of coagulopathy in massive transfusion has been increasingly recognized and alternatives to CRYO use, such as fibrinogen concentrate, also intensively investigated (Sorensen et al., 2010; Fries et al., 2010; Tisherman, 2010).

\section{Limitations}

Our study has several limitations as follows:

(i) The retrospective nature of our study did not allow us to further explore the reasons for inappropriate CRYO transfusion at the physician level. In the context of massive bleeding, the characterization of inappropriateness can be extremely challenging. Commonly, the decision to transfuse unstable bleeding trauma patients in based solely on clinical grounds. High rates of bleeding coupled with long turnaround times for fibrinogen level testing precludes waiting for blood test results in some patients. However, we tried to address the issue by analyzing the data using both strict and lenient criteria for appropriateness;

(ii) Our retrospective cohort study design included patients who received CRYO transfusion only, thus did not address the issue of under treatment (trauma patients with fibrinogen level $<1.0 \mathrm{~g} / \mathrm{L}$ but no CRYO given), which may be regarded as inappropriate practice;

(iii) We were unable to account for the contribution of other blood products in raising fibrinogen levels, the dilutional effects of crystalloid resuscitation between fibrinogen levels and ongoing consumption. In an attempt to avoid this confounding, we analyzed only patients who did not receive any blood product containing fibrinogen $2 \mathrm{hr}$ before CRYO transfusion. Furthermore, we utilized a narrow window for fibrinogen measurements (1 hour 
before and after CRYO) in the fibrinogen response analysis, likely limiting potential confounding from physiologic elevation of fibrinogen following trauma and ongoing consumption;

(iv) The lack of control group is another important limitation. The ideal control group would be patients with low fibrinogen levels and no active hemorrhage.

(v) Finally, potential variations in fibrinogen response to CRYO transfusion due to differences in patients' weights and in CRYO doses were not accounted for.

\section{Future Directions}

This study also enabled us to identify several areas that deserve further investigations:

(i) The impact of behavioral interventions on physician transfusion practices and patient's outcomes.

Our study demonstrated that it is possible to achieve high rates of appropriateness for CRYO transfusion in trauma when behavioral interventions are in place and constantly reinforced in an organized transfusion and trauma programs. However, further improvement might still be possible, which should be investigated in a prospective research design in order to address appropriateness at the physician level. Moreover, it remains unknown whether or not such interventions would improve patient's outcomes. Therefore, the impact of such interventions on patient's outcomes should be investigated;

(ii) The dosage of cryoprecipitate necessary to adequately replete hypofibrinogenemia.

Our review suggested that, in the context of trauma and bleeding, current recommended dosage for CRYO causes only a modest increase in plasma levels of fibrinogen; and a bleeding trauma patient requires double the dose used in our patients to more consistently achieve a 
fibrinogen $>1.5 \mathrm{~g} / \mathrm{L}$. Further investigation on dose response should be conducted to elucidate the appropriate dosage of CRYO in the setting of active bleeding;

(iii) The role of fibrinogen concentrates.

Alternatives to CRYO for fibrinogen replacement is warranted due to the potential complications of CRYO transfusion, variability in fibrinogen content and time required for thawing, pooling and issuing;

(iv) The role of other cryoprecipitate contents.

The role of fibronectin and platelet microparticles in infection and hemostasis should be further investigated;

(v) The role of cryoprecipitate in formula-driven transfusion strategy.

A growing body of literature suggests a potential role of increased ratios of clotting factors, including fibrinogen, to RBC in trauma resuscitation. The role of FFP, platelets and CRYO in transfusion protocol with fixed ratios of products should be investigated in a prospective fashion;

(vi) The incidence of adverse events associated with cryoprecipitate transfusion.

The consequences of increased exposure of trauma patients to plasma products remain unclear. It would be important to establish a compulsory national reporting system to record adverse events of CRYO.

\section{Conclusions}

In our institution, CRYO is commonly used in cardiac surgery and trauma for low fibrinogen levels in the context of bleeding. Our study demonstrated that, in an organized system, where massive transfusion protocols are in place and overseen by blood bank technologists and transfusion medicine specialists, it is possible to achieve high rates of 
appropriateness for CRYO transfusion in trauma. The role of behavioral interventions in appropriateness of CRYO transfusion and their impact on patient's outcomes should be further explored.

The current recommended dose of CRYO in the context of massive transfusion causes a modest increase in plasma fibrinogen levels $(0.55 \mathrm{~g} / \mathrm{L})$. Further studies are needed to further define when and how much fibrinogen is needed as well as the best way to provide it in the setting of severe traumatic hemorrhage.

\section{Disclaimer}

Bartolomeu Nascimento is the 2010-11 National Blood Foundation Grant Recipient for the conduct of research related to coagulopathy in trauma.

\section{Conflict of Interest}

Sandro Rizoli received honorarium and speaker’s fees (as a member of the Scientific Advisory Board) from NovoNordisk S/A, manufacturer of NovoSeven (recombinant factor VII). The other authors have no conflict of interest relevant to the subject matter of this publication.

\section{Appendices}




\section{Appendix 1. Sunnybrook Massive Transfusion Guidelines - Trauma}

S - SURGERY for surgical bleeding required?

M - MASSIVE TRANSFUSION risk? (SBP $\leq 90 \mathrm{mmHg}$ or base deficit $>5$ and bleeding)

A - ACTIVATION of massive transfusion pack needed? (call blood bank \# 4051)

R - RESTRICTION of crystalloids considered? (maximum 3 litres before blood)

T - TEMPERATURE controlled? (keep $>36^{\circ} \mathrm{C}$ )

\begin{tabular}{|lll|}
\hline Product & Goal & Dose \\
\hline RBCs & $70-100 \mathrm{~g} / \mathrm{L}$ & As per rate of blood loss \& risk factors \\
\hline Platelets & $>50 / \mu \mathrm{L}$, or $>100 / \mu \mathrm{L}$ if CNS injury & 1 pool \\
& 2 pools if count $<30+$ ongoing massive bleeding) \\
\hline Plasma & INR $\leq 1.8$ & $3-4$ units \\
\hline Cryoprecipitate & fibrinogen $>1.0 \mathrm{~g} / \mathrm{L}$ & $8-12$ units \\
\hline
\end{tabular}

- $\quad$ Q1h CBC, INR, aPTT, fibrinogen;

- $\quad$ Q4h ABG, lytes, creatinine, ionized $\mathrm{Ca}, \mathrm{Mg}$, Lactate

- If expected transfusion $>4$ RBCs before lab results + evidence of massive bleeding:

- Order massive transfusion pack: 4 RBCs; 4 FFP; 1 Platelet pool (infuse based on laboratory values where possible)

\begin{tabular}{|c|c|}
\hline \multicolumn{2}{|c|}{ Appropriate Interventions } \\
\hline $\bar{\checkmark}$ & $\begin{array}{l}2 \geq 16 \text {-gauge IVs; initial resuscitation - NS or RL; permissive hypotension (SBP no }>90 \mathrm{mmHg} \text { ) considered in } \\
\text { penetrating torso trauma only }\end{array}$ \\
\hline$\checkmark$ & Crystalloid, RBCs \& FFP via warmer \\
\hline $\bar{\checkmark}$ & Rewarming for $<36^{\circ} \mathrm{C}$; room at $28^{\circ} \mathrm{C}$; forced air blanks; extra-corporeal; \\
\hline$\sqrt{ }$ & Notify relevant services (Surgery, Interventional Radiology, ICU, Anesthesia); consider cell-saver in OR \\
\hline$\checkmark$ & Reassess bleeding \& lab between transfusions \\
\hline$\checkmark$ & $1 \mathrm{~g} \mathrm{CaCl} \mathrm{IV} \mathrm{if} \mathrm{ionized} \mathrm{calcium}<1.15 \mathrm{mmol} / \mathrm{L}$ \\
\hline$\checkmark$ & Tranexamic acid $1 \mathrm{~g}$ bolus followed by $1 \mathrm{~g}$ infusion over $8 \mathrm{~h}$ \\
\hline
\end{tabular}

\begin{tabular}{|cl|}
\hline Policy & \\
\hline$\checkmark$ & Massive Blood Loss - > 1 blood volume/24h = 5L or 10 RBCs; half of blood vol. within 3h; bleeding rate \\
& $>150 \mathrm{ml} /$ min or 4 RBCs within 1h \\
\hline$\checkmark$ & Initiation - physician informs Blood Bank - One ordering MD communicating with a single BB tech \\
\hline$\checkmark$ & Unknown ABO $\rightarrow$ O RBCs \& AB plasma until ABO confirmed \\
\hline$\checkmark$ & Rh-neg $\rightarrow$ Rh - neg. RBC \& Platelets issued; Blood Bank may switch to Rh + if inventory short \\
\hline$\checkmark$ & Unknown Rh $\rightarrow$ Rh - neg. only for females < 45y or anti-D antibody history \\
\hline$\checkmark$ & RBC, Platelets, FFP, Cryoprecipitate infused with filter (170 - 260 micron) \& only with 0.9\% NS \\
\hline$\checkmark$ & Change blood tubing q6 h or as per manufacturer; PTL via fresh tubing \\
\hline$\checkmark$ & $\begin{array}{l}\text { Documentation - careful attention to patient identification; If no identifiers } \rightarrow \text { request ER unique anonymous } \\
\text { ID; document start time for all blood products; end-time not required in massive transfusion }\end{array}$ \\
\hline$\checkmark$ & Bleeding in hereditary coagulopathy or on anti-coagulation $\rightarrow$ transfusion medicine consult (ext.:4051) \\
\hline \hline
\end{tabular}

\begin{tabular}{|c|c|c|}
\hline Anticoagulant & Antidote & Dose \\
\hline Unfractionated heparin (UFH) & Protamine & $\begin{array}{l}1 \mathrm{mg} / 100 \mathrm{IU} \text { of UFH given within past } 4 \text { hours; } \\
\text { repeat } 50 \mathrm{mg} \text { dose if aPTT rebounds }\end{array}$ \\
\hline Low molecular weight heparin (LMWH) - Dalteparin & Protamine & $\begin{array}{l}1 \mathrm{mg} \text { per } 1 \mathrm{mg} \text { LMWH administered within past } 4 \\
\text { hours }\end{array}$ \\
\hline Vitamin $\mathrm{K}$ antagonists (Coumadin) & $\begin{array}{l}\text { Vitamin K } \\
\text { PCC }\end{array}$ & $\begin{array}{l}10 \mathrm{mg} \text { IV } \\
1000 \mathrm{IU} \text { if INR }<4 \text { or } 2000 \text { IU if INR }>4\end{array}$ \\
\hline
\end{tabular}

No evidence to support the routine use of rFVIIa in trauma (Consider in consultation with Blood Bank MD) Adapted with permission: Sunnybrook Hospital Transfusion Medicine Committee.

\section{Appendix 2. Handling and Processing of Coagulation Specimens at the}

\section{Sunnybrook Campus Flowchart}




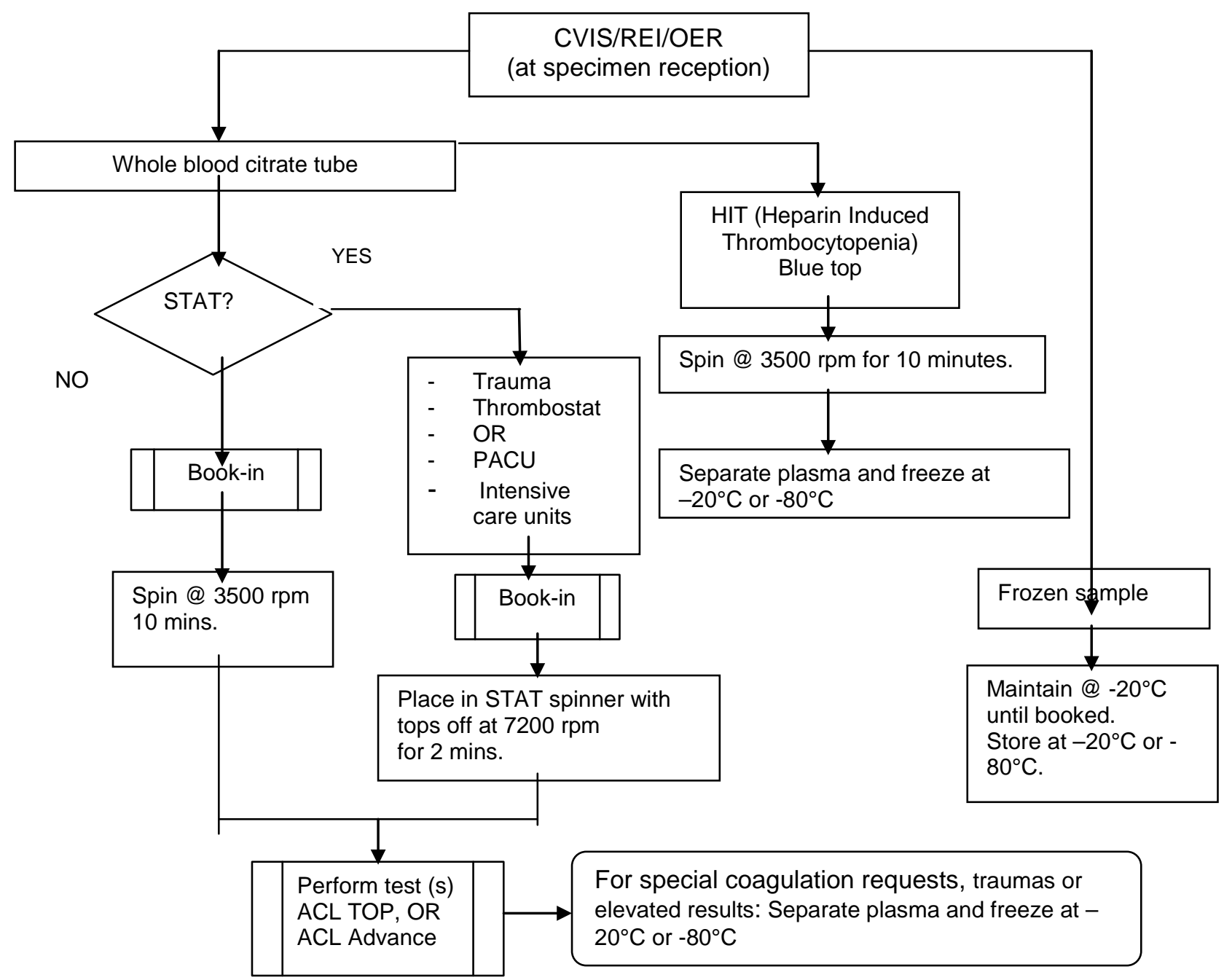

Adapted with permission: Integrated and Core Laboratories - Coagulation, Department of Clinical Pathology, Sunnybrook Health Sciences Center. CVIS, indicates samples that had the tests ordered by the floors and clinics and already have a barcode label on the tube; REI, indicates samples that had the tests ordered by the floors and clinics but still need the barcode; OER, indicates sample received with a requisition and the laboratory has to enter all the patient identification information into the lab computer system and order the tests in order to generate the barcode labels for the tubes; OR, operating room; PACU, post-anesthesia care unit; ACL TOP OR ACL Advance, ACL Hemostasis Analyzer, Instrumentation Laboratory, Beckman Coulter.

\section{Reference List}


1. (1971) Rating the severity of tissue damage. I. The abbreviated scale. JAMA, 215, 277280.

2. (1972) Rating the severity of tissue damage. II. The comprehensive scale. JAMA, 220, 717-720.

3. (1994) Practice parameter for the use of fresh-frozen plasma, cryoprecipitate, and platelets. Fresh-Frozen Plasma, Cryoprecipitate, and Platelets Administration Practice Guidelines Development Task Force of the College of American Pathologists. JAMA, 271, 777-781.

4. (2006) Practice guidelines for perioperative blood transfusion and adjuvant therapies: an updated report by the American Society of Anesthesiologists Task Force on Perioperative Blood Transfusion and Adjuvant Therapies. Anesthesiology, 105, 198-208.

5. Acosta,J.A., Yang,J.C., Winchell,R.J., Simons,R.K., Fortlage,D.A., HollingsworthFridlund,P., \& Hoyt,D.B. (1998) Lethal injuries and time to death in a level I trauma center. J.Am.Coll.Surg., 186, 528-533.

6. Allain,J.P. (1984) Non Factor VIII related constituents in concentrates. Scand.J.Haematol.Suppl, 41, 173-180.

7. Alport,E.C., Callum,J.L., Nahirniak,S., Eurich,B., \& Hume,H.A. (2008) Cryoprecipitate use in 25 Canadian hospitals: commonly used outside of the published guidelines. Transfusion, 48, 2122-2127.

8. American Association of Blood Banks. (2002) Blood Transfusion Therapy: A Physician's Handbook ( $7^{\text {th }}$ edn). Bethesda (Md), American Red Cross.

9. American Association of Blood Banks. (2008) Standards for Blood Banks and Transfusion Services (25 ${ }^{\text {th }}$ edn). Bethesda (Md), American Association of Blood Banks.

10. Ardoin,S.P., Shanahan,J.C., \& Pisetsky,D.S. (2007) The role of microparticles in inflammation and thrombosis. Scand.J.Immunol., 66, 159-165.

11. Association for the Advancement of Automotive Medicine.(1990) Abbreviated Injury Scale. Revision. Des Plaines, IL, United States.

12. Aygoren-Pursun,E., Martinez,S., I, Rusicke,E., Louwen,F., Geka,F., Ivaskevicius, V., Oldenburg,J., Klingebiel,T., \& Kreuz,W. (2007) Retrochorionic hematoma in congenital afibrinogenemia: resolution with fibrinogen concentrate infusions. Am.J.Hematol., 82, 317-320.

13. Baker,S.P. \& O'Neill,B. (1976) The injury severity score: an update. J.Trauma, 16, 882885. 
14. Baker,S.P., O'Neill,B., Haddon,W., Jr., \& Long,W.B. (1974) The injury severity score: a method for describing patients with multiple injuries and evaluating emergency care. J.Trauma, 14, 187-196.

15. Barrett,K.E., Israels,M.C., \& Burn,A.M. (1967) The effect of cryoprecipitate concentrate in patients with classical haemophilia. Lancet, 1, 191-192.

16. Beekley,A.C. (2008) Damage control resuscitation: a sensible approach to the exsanguinating surgical patient. Crit Care Med., 36, S267-S274.

17. Bennett,E. \& Dormandy,K. (1966) Pool's cryoprecipitate and exhausted plasma in the treatment of von Willebrand's disease and factor-XI deficiency. Lancet, 2, 731-732.

18. Blombäck,B. \& Blombäck, M. (1956) Preparation of human fibrinogen fraction 1 - 2. Arkiv Kemi, 10, 415 - 443.

19. Blome,M., Isgro,F., Kiessling,A.H., Skuras,J., Haubelt,H., Hellstern,P., \& Saggau,W. (2005) Relationship between factor XIII activity, fibrinogen, haemostasis screening tests and postoperative bleeding in cardiopulmonary bypass surgery. Thromb.Haemost., 93, 1101-1107.

20. Board,P.G., Losowsky,M.S., \& Miloszewski,K.J. (1993) Factor XIII: inherited and acquired deficiency. Blood Rev., 7, 229-242.

21. Brecher,M.E. (2005) American Association of Blood Banks Technical Manual. (15 ${ }^{\text {th }}$ edn). Bethesda (Md), American Association of Blood Banks.

22. Brenni,M., Worn,M., Bruesch,M., Spahn,D.R., \& Ganter,M.T. (2010) Successful rotational thromboelastometry-guided treatment of traumatic haemorrhage, hyperfibrinolysis and coagulopathy. Acta Anaesthesiol.Scand., 54, 111-117.

23. Brohi,K., Cohen,M.J., \& Davenport,R.A. (2007a) Acute coagulopathy of trauma: mechanism, identification and effect. Curr.Opin.Crit Care, 13, 680-685.

24. Brohi,K., Cohen,M.J., Ganter,M.T., Matthay,M.A., Mackersie,R.C., \& Pittet,J.F. (2007b) Acute traumatic coagulopathy: initiated by hypoperfusion: modulated through the protein C pathway? Ann.Surg., 245, 812-818.

25. Brohi,K., Singh,J., Heron,M., \& Coats,T. (2003) Acute traumatic coagulopathy. J.Trauma, 54, 1127-1130.

26. Brook,R.H. (2009) Assessing the appropriateness of care--its time has come. JAMA, 302, 997-998.

27. Brook,R.H., Chassin,M.R., Fink,A., Solomon,D.H., Kosecoff, J., \& Park, R.E. (1986) A method for the detailed assessment of the appropriateness of medical technologies. Int $J$ Technol Assess Health Care., 2 (1), 53 - 63. 
28. Bundesaertzekammer/ German Medical Association. (2009) Cross-sectional Guidelines for Therapy with Blood Components and Plasma Derivates ( $4^{\text {th }}$ edn). German Medical Association. URL http:www.bundesaertzekammer.de/page.asp?his=0.6.3288.6716 (Accessed on 30/11/10).

29. Burman,D., Hodson,A.K., Wood,C.B., \& Brueton,N.F. (1973) Acute anaphylaxis, pulmonary oedema, and intravascular haemolysis due to cryoprecipitate. Arch.Dis.Child, 48, 483-485.

30. Callum,J.L. \& Pinkerton,P.H. (2005) Bood Easy 2: A Guide to Transfusion Medicine. (2 ${ }^{\text {nd }}$ edn). Helen Stevenson Savattuq Inc. Toronto, Canada.

31. Callum,J.L., Karkouti,K., \& Lin,Y. (2009) Cryoprecipitate: the current state of knowledge. Transfus.Med.Rev., 23, 177-188.

32. Callum,J.L., Lin, Y., \& Pinkerton,P.H. (2011) Bood Easy 3: A Guide to Transfusion Medicine. ( ${ }^{\text {rd }}$ edn). Orbcon, Ontario, Canada.

33. Canadian Blood Services. (2005) Circular of Information for the use of human blood and blood components. Canadian Blood Services, Ottawa, Canada.

34. Canadian Blood Services. (2006) In:Clinical Guide to Transfusion (4 ${ }^{\text {th }}$ edn). Canadian Blood Services, Ottawa, Canada.

35. Canadian Society for Transfusion Medicine. (2007) Canadian Standards for Transfusion Medicine (version 2). Canadian Society for Transfusion Medicine, Otawa, Canada.

36. Canadian Standards Association. (2004) CSA Z902: Blood and Blood Components. Canadian Standards Association, Mississauga, Ontatio, Canada.

37. Cardigan,R., Philpot,K., Cookson,P., \& Luddington,R. (2009) Thrombin generation and clot formation in methylene blue-treated plasma and cryoprecipitate. Transfusion, 49, 696-703.

38. Cesarman-Maus,G. \& Hajjar,K.A. (2005) Molecular mechanisms of fibrinolysis. Br.J.Haematol., 129, 307-321.

39. Chandler,W.L. (1996) The human fibrinolytic system. Crit Rev.Oncol.Hematol., 24, 2745.

40. Chandler, W.L., Ferrell, C., Trimble, S. \& Moody S. Development of a rapid emergency hemorrhage panel. (2010) Transfusion. 50, 2547-2552.

41. Chantarangkul,V., Tripodi,A., \& Mannucci,P.M. (1987) Evaluation of a fully automated centrifugal analyzer for performance of hemostasis tests. Clin.Chem., 33, 1888-1890.

42. Chantarangkul,V., Tripodi,A., \& Mannucci,P.M. (1994) Results of a collaborative study for fibrinogen measurement. Evidence that the use of a common calibrator improves interlaboratory agreement. Blood Coagul.Fibrinolysis, 5, 761-766. 
43. Charbit,B., Mandelbrot,L., Samain,E., Baron,G., Haddaoui,B., Keita,H., Sibony,O., Mahieu-Caputo,D., Hurtaud-Roux,M.F., Huisse,M.G., Denninger,M.H., \& de,P.D. (2007) The decrease of fibrinogen is an early predictor of the severity of postpartum hemorrhage. J.Thromb.Haemost., 5, 266-273.

44. Chitolie,A., Mackie,I.J., \& Machin,S.,J. (1998) The type of thromboplastin reagent has important effects on PT-derived fibrinogen potency. Lab Hematol, 4, 149 - 155.

45. Chitolie,A., Mackie,I.J., Grant,D., Hamilton,J.L., \& Machin,S.M. (1994) Inaccuracy of the 'derived' fibrinogen measurement. Blood Coagul.Fibrinolysis, 5, 955-957.

46. Chowdhury,P., Saayman,A.G., Paulus,U., Findlay,G.P., \& Collins,P.W. (2004) Efficacy of standard dose and $30 \mathrm{ml} / \mathrm{kg}$ fresh frozen plasma in correcting laboratory parameters of haemostasis in critically ill patients. Br.J.Haematol., 125, 69-73.

47. Ciavarella,D., Reed,R.L., Counts,R.B., Baron,L., Pavlin,E., Heimbach,D.M., \& Carrico,C.J. (1987) Clotting factor levels and the risk of diffuse microvascular bleeding in the massively transfused patient. Br.J.Haematol., 67, 365-368.

48. Clauss,A. (1957) [Rapid physiological coagulation method in determination of fibrinogen]. Acta Haematol. , 17, 237-246.

49. Colman, R.W., Clowes, A.W., George, J.N., Goldhaber, S.Z., \& Marder V.J. (2006) Overview of Hemostasis. In: Colman RW, Marder VJ, Clowes AW, George, JN, Goldhaber, SZ. Hemostasis and Thrombosis: Basic Principles and Clinical Practice. $\left(5^{\text {th }}\right.$ edn). Philadelphia: JB Lippincott Co, 1, 3-16.

50. Committee on Injury Scaling. (1985) Abbreviated Injury Scale. Revision. American Association for Automotive Medicine, Arlington Heights, IL, United States.

51. Copes,W.S., Champion,H.R., Sacco,W.J., Lawnick,M.M., Keast,S.L., \& Bain,L.W. (1988) The Injury Severity Score revisited. J.Trauma, 28, 69-77.

52. Cotton,B.A., Guy,J.S., Morris,J.A., Jr., \& Abumrad,N.N. (2006) The cellular, metabolic, and systemic consequences of aggressive fluid resuscitation strategies. Shock, 26, 115121.

53. Council of Europe. (2006) Guide to preparation, use an quality assurance of blood components. $\left(12^{\text {th }}\right.$ edn). Council of Europe Publishing, Strasbourg, France.

54. Cunningham,M.T., Brandt,J.T., Laposata,M., \& Olson,J.D. (2002) Laboratory diagnosis of dysfibrinogenemia. Arch.Pathol.Lab Med., 126, 499-505.

55. Danes,A.F., Cuenca,L.G., Bueno,S.R., Mendarte,B.L., \& Ronsano,J.B. (2008) Efficacy and tolerability of human fibrinogen concentrate administration to patients with acquired fibrinogen deficiency and active or in high-risk severe bleeding. Vox Sang., 94, 221-226. 
56. Danesh,J., Collins,R., Appleby,P., \& Peto,R. (1998) Association of fibrinogen, C-reactive protein, albumin, or leukocyte count with coronary heart disease: meta-analyses of prospective studies. JAMA, 279, 1477-1482.

57. Danesh,J., Collins,R., Peto,R., \& Lowe,G.D. (2000) Haematocrit, viscosity, erythrocyte sedimentation rate: meta-analyses of prospective studies of coronary heart disease. Eur.Heart J., 21, 515-520.

58. Dara,S.I., Rana,R., Afessa,B., Moore,S.B., \& Gajic,O. (2005) Fresh frozen plasma transfusion in critically ill medical patients with coagulopathy. Crit Care Med., 33, 26672671.

59. De,C.R. \& Landolfi,R. (1998) Measurement of plasma fibrinogen concentration by the prothrombin-time-derived method: applicability and limitations. Blood Coagul.Fibrinolysis, 9, 251-259.

60. de,M.M. \& van Wersch,J.W. (1987) Use of a centrifugal analyzer for a chromogenic prothrombin time, a chromogenic activated partial thromboplastin time and a kinetic fibrinogen assay in a routine hospital laboratory. Haemostasis, 17, 254-259.

61. Droubatchevskaia,N., Wong,M.P., Chipperfield,K.M., Wadsworth, L.D. \& Ferguson, D.J. (2007) Guidelines for cryoprecipitate transfusion. BC Medical Journal, 49, 441-445.

62. Fakhry, S.M. \&Sheldon, G.F. (1994) Massive transfusion in the surgical patient. In: Massive Transfusion (ed. By L.C. Jeffries \& M.E. Brecher) American Assciation of Blood Banks, Bethesda.

63. Faringer,P.D., Mullins,R.J., Johnson,R.L., \& Trunkey,D.D. (1993) Blood component supplementation during massive transfusion of AS-1 red cells in trauma patients. J. Trauma, 34, 481-485.

64. Fenger-Eriksen,C., Ingerslev,J., \& Sorensen,B. (2009a) Fibrinogen concentrate--a potential universal hemostatic agent. Expert.Opin.Biol.Ther., 9, 1325-1333.

65. Fenger-Eriksen,C., Jensen,T.M., Kristensen,B.S., Jensen,K.M., Tonnesen,E., Ingerslev,J., \& Sorensen,B. (2009b) Fibrinogen substitution improves whole blood clot firmness after dilution with hydroxyethyl starch in bleeding patients undergoing radical cystectomy: a randomized, placebo-controlled clinical trial. J.Thromb.Haemost., 7, 795802.

66. Fenger-Eriksen,C., Lindberg-Larsen,M., Christensen,A.Q., Ingerslev,J., \& Sorensen,B. (2008) Fibrinogen concentrate substitution therapy in patients with massive haemorrhage and low plasma fibrinogen concentrations. Br.J.Anaesth., 101, 769-773.

67. Fink,A., Kosecoff,J., Chassin,M., \& Brook,R.H. (1984) Consensus methods: characteristics and guidelines for use. Am.J.Public Health, 74, 979-983. 
68. Freyssinet,J.M. (2003) Cellular microparticles: what are they bad or good for? J.Thromb. Haemost., 1, 1655-1662.

69. Friedman,M.T. \& Ebrahim,A. (2006) Adequacy of physician documentation of red blood cell transfusion and correlation with assessment of transfusion appropriateness. Arch.Pathol.Lab Med., 130, 474-479.

70. Fries,D. \& Martini,W.Z. (2010) Role of fibrinogen in trauma-induced coagulopathy. Br.J.Anaesth., 105, 116-121.

71. Fries,D., Haas,T., Klingler,A., Streif,W., Klima,G., Martini,J., Wagner-Berger,H., \& Innerhofer,P. (2006) Efficacy of fibrinogen and prothrombin complex concentrate used to reverse dilutional coagulopathy--a porcine model. Br.J.Anaesth., 97, 460-467.

72. Fries,D., Krismer,A., Klingler,A., Streif,W., Klima,G., Wenzel,V., Haas,T., \& Innerhofer,P. (2005) Effect of fibrinogen on reversal of dilutional coagulopathy: a porcine model. Br.J.Anaesth., 95, 172-177.

73. Gaffney,P.J. \& Wong,M.Y. (1992) Collaborative study of a proposed international standard for plasma fibrinogen measurement. Thromb.Haemost. , 68, 428-432.

74. Gando,S. (2006) Tissue factor in trauma and organ dysfunction. Semin. Thromb.Hemost., 32, 48-53.

75. Gando,S. (2009) Acute coagulopathy of trauma shock and coagulopathy of trauma: a rebuttal. You are now going down the wrong path. J.Trauma, 67, 381-383.

76. Gando,S., Nanzaki,S., \& Kemmotsu,O. (1999) Coagulofibrinolytic changes after isolated head injury are not different from those in trauma patients without head injury. J.Trauma, 46, 1070-1076.

77. Gando,S., Sawamura,A., \& Hayakawa,M. (2011) Trauma, shock, and disseminated intravascular coagulation: lessons from the classical literature. Ann.Surg., 254, 10-19.

78. Garthe,E., States,J.D., \& Mango,N.K. (1999) Abbreviated injury scale unification: the case for a unified injury system for global use. J.Trauma, 47, 309-323.

79. Gentilello,L.M., Jurkovich,G.J., Stark,M.S., Hassantash,S.A., \& O'Keefe,G.E. (1997) Is hypothermia in the victim of major trauma protective or harmful? A randomized, prospective study. Ann.Surg., 226, 439-447.

80. George,J.N., Pickett,E.B., \& Heinz,R. (1986) Platelet membrane microparticles in blood bank fresh frozen plasma and cryoprecipitate. Blood, 68, 307-309.

81. Groner,A. (2008) Reply. Pereira A. Cryoprecipitate versus commercial fibrinogen concentrate in patients who occasionally require a therapeutic supply of fibrinogen: risk comparison in the case of an emerging transfusion-transmitted infection. Haematologica 2007;92:846-9. Haematologica, 93, e24-e26. 
82. Grottke,O., Braunschweig,T., Henzler,D., Coburn,M., Tolba,R., \& Rossaint,R. (2010) Effects of different fibrinogen concentrations on blood loss and coagulation parameters in a pig model of coagulopathy with blunt liver injury. Crit Care, 14, R62.

83. Guyatt,G., Gutterman,D., Baumann,M.H., Addrizzo-Harris,D., Hylek,E.M., Phillips,B., Raskob,G., Lewis,S.Z., \& Schunemann,H. (2006) Grading strength of recommendations and quality of evidence in clinical guidelines: report from an american college of chest physicians task force. Chest, 129, 174-181.

84. Haas,T., Fries,D., Velik-Salchner,C., Oswald,E., \& Innerhofer,P. (2008) Fibrinogen in craniosynostosis surgery. Anesth.Analg., 106, 725-31, table.

85. Hantgan, R.R. \& Lord, S.T. (2006) Fibrinogen Structure and Physiology. In: Colman RW, Marder VJ, Clowes AW, George, JN, Goldhaber, SZ. Hemostasis and Thrombosis: Basic Principles and Clinical Practice. (5 ${ }^{\text {th }}$ edn). Philadelphia: JB Lippincott Co, 16, $285-316$.

86. Hedges,S.J., Dehoney,S.B., Hooper,J.S., Amanzadeh,J., \& Busti,A.J. (2007) Evidencebased treatment recommendations for uremic bleeding. Nat.Clin.Pract.Nephrol., 3, 138153.

87. Heindl,B., Delorenzo,C., \& Spannagl,M. (2005) [High dose fibrinogen administration for acute therapy of coagulopathy during massive perioperative transfusion]. Anaesthesist, 54, 787-790.

88. Henry,D.A., Carless,P.A., Moxey,A.J., O'Connell,D., Stokes,B.J., McClelland,B., Laupacis,A., \& Fergusson,D. (2007) Anti-fibrinolytic use for minimising perioperative allogeneic blood transfusion. Cochrane.Database.Syst.Rev., CD001886.

89. Hess,J.R., Brohi,K., Dutton,R.P., Hauser,C.J., Holcomb,J.B., Kluger,Y., MackwayJones,K., Parr,M.J., Rizoli,S.B., Yukioka,T., Hoyt,D.B., \& Bouillon,B. (2008) The coagulopathy of trauma: a review of mechanisms. J.Trauma, 65, 748-754.

90. Hiippala,S.T. (1995) Dextran and hydroxyethyl starch interfere with fibrinogen assays. Blood Coagul.Fibrinolysis, 6, 743-746.

91. Hiippala,S.T., Myllyla,G.J., \& Vahtera,E.M. (1995) Hemostatic factors and replacement of major blood loss with plasma-poor red cell concentrates. Anesth.Analg., 81, 360-365.

92. Hoffmann,J.J. \& Verhappen,M.A. (1988) Automated nephelometry of fibrinogen: analytical performance and observations during thrombolytic therapy. Clin.Chem., 34, 2135-2140.

93. Holcomb JB. Traditional transfusion practices are changing (2010). Critical Care. 14(3), 162. Epub 2010 Jun 1.

94. Holcomb,J.B., Jenkins,D., Rhee,P., Johannigman,J., Mahoney,P., Mehta,S., Cox,E.D., Gehrke,M.J., Beilman,G.J., Schreiber,M., Flaherty,S.F., Grathwohl,K.W., Spinella,P.C., Perkins,J.G., Beekley,A.C., McMullin,N.R., Park,M.S., Gonzalez,E.A., Wade,C.E., 
Dubick,M.A., Schwab,C.W., Moore,F.A., Champion,H.R., Hoyt,D.B., \& Hess,J.R. (2007) Damage control resuscitation: directly addressing the early coagulopathy of trauma. J.Trauma, 62, 307-310.

95. Horstman,L.L. \& Ahn,Y.S. (1999) Platelet microparticles: a wide-angle perspective. Crit Rev.Oncol.Hematol., 30, 111-142.

96. Huber-Wagner,S., Qvick,M., Mussack,T., Euler,E., Kay,M.V., Mutschler,W., \& Kanz,K.G. (2007) Massive blood transfusion and outcome in 1062 polytrauma patients: a prospective study based on the Trauma Registry of the German Trauma Society. Vox Sang., 92, 69-78.

97. Hulka,F., Mullins,R.J., \& Frank,E.H. (1996) Blunt brain injury activates the coagulation process. Arch.Surg., 131, 923-927.

98. Humphries,S.E., Henry,J.A., \& Montgomery,H.E. (1999) Gene-environment interaction in the determination of levels of haemostatic variables involved in thrombosis and fibrinolysis. Blood Coagul.Fibrinolysis, 10 Suppl 1, S17-S21.

99. Hupe,K., Blazycek,U., Gent,H.J., Kunz,G., Roth,B., \& Schwarte,B. (1971) [Clinical and animal experiment studies on the therapy of fat embolism]. Bruns.Beitr.Klin.Chir, 219, 56-65.

100. Jacobsson,K. (1955) I. Studies on the determination of fibrinogen in human blood plasma. II. Studies on the trypsin and plasmin inhibitors in human blood serum. Scand.J.Clin.Lab Invest, 7, 3-102.

101. Janson,P.A., Jubelirer,S.J., Weinstein,M.J., \& Deykin,D. (1980) Treatment of the bleeding tendency in uremia with cryoprecipitate. N.Engl.J.Med., 303, 1318-1322.

102. Karlsson,M., Ternstrom,L., Hyllner,M., Baghaei,F., Flinck,A., Skrtic,S., \& Jeppsson,A. (2009) Prophylactic fibrinogen infusion reduces bleeding after coronary artery bypass surgery. A prospective randomised pilot study. Thromb. Haemost., 102, 137-144.

103. Karlsson,M., Ternstrom,L., Hyllner,M., Baghaei,F., Nilsson,S., \& Jeppsson,A. (2008) Plasma fibrinogen level, bleeding, and transfusion after on-pump coronary artery bypass grafting surgery: a prospective observational study. Transfusion, 48, 2152-2158.

104. Kashuk,J.L., Moore,E.E., Johnson,J.L., Haenel,J., Wilson,M., Moore,J.B., Cothren,C.C., Biffl,W.L., Banerjee,A., \& Sauaia,A. (2008) Postinjury life threatening coagulopathy: is $1: 1$ fresh frozen plasma:packed red blood cells the answer? J.Trauma, 65, 261-270.

105. Kasper,C.K., Myhre,B.A., McDonald,J.D., Nakasako,Y., \& Feinstein,D.I. (1975) Determinants of factor VIII recovery in cryoprecipitate. Transfusion, 15, 312-322.

106. Kauvar,D.S., Lefering,R., \& Wade,C.E. (2006) Impact of hemorrhage on trauma outcome: an overview of epidemiology, clinical presentations, and therapeutic considerations. J.Trauma, 60, S3-11. 
107. Ketchum,L., Hess,J.R., \& Hiippala,S. (2006) Indications for early fresh frozen plasma, cryoprecipitate, and platelet transfusion in trauma. J.Trauma, 60, S51-S58.

108. Kitchen,S., Jennings,I., \& Preston,P.,E. (1995) Comparisons of fibrinogen determinations using a Clauss assay and two prothrombin time derived methods. Thromb Haemost, 73, $1245-1248$.

109. Klein,H.G., Anstee D.J. (2005) Mollison's Blood Transfusion in Clinical Medicine (Ed 11). Malden, Massachusetts, Wiley-Blackwell.

110. Kluft,C. \& Lansink,M. (1997) Effect of oral contraceptives on haemostasis variables. Thromb. Haemost., 78, 315-326.

111. Kreuz,W., Meili,E., Peter-Salonen,K., Dobrkovska,A., Devay,J., Haertel,S., Krzensk,U., \& Egbring,R. (2005a) Pharmacokinetic properties of a pasteurised fibrinogen concentrate. Transfus.Apher.Sci. , 32, 239-246.

112. Kreuz,W., Meili,E., Peter-Salonen,K., Haertel,S., Devay,J., Krzensk,U., \& Egbring,R. (2005b) Efficacy and tolerability of a pasteurised human fibrinogen concentrate in patients with congenital fibrinogen deficiency. Transfus.Apher.Sci., 32, 247-253.

113. Kushimoto,S., Shibata,Y., \& Yamamoto,Y. (2003) Implications of fibrinogenolysis in patients with closed head injury. J.Neurotrauma, 20, 357-363.

114. Lawrie,A.S., McDonald,S.J., Purdy,G., Mackie,I.J., \& Machin,S.J. (1998) Prothrombin time derived fibrinogen determination on Sysmex CA-6000. J.Clin.Pathol., 51, 462-466.

115. Levi,M., Fries,D., Gombotz,H., van der Linden,P., Nascimento,B., Callum,J.L., Belisle,S., Rizoli,S., Hardy,J.F., Johansson,P.I., Samama,C.M., Grottke,O., Rossaint,R., Henny,C.P., Goslings,J.C., Theusinger,O.M., Spahn,D.R., Ganter,M.T., Hess,J.R., Dutton,R.P., Scalea,T.M., Levy,J.H., Spinella,P.C., Panzer,S., \& Reesink,H.W. (2011) Prevention and treatment of coagulopathy in patients receiving massive transfusions. Vox Sang., 101, 154-174.

116. Levi,M., ten,C.H., van der Poll,T., \& van Deventer,S.J. (1993) Pathogenesis of disseminated intravascular coagulation in sepsis. JAMA, 270, 975-979.

117. Levi,M., Toh,C.H., Thachil,J., \& Watson,H.G. (2009) Guidelines for the diagnosis and management of disseminated intravascular coagulation. British Committee for Standards in Haematology. Br.J.Haematol., 145, 24-33.

118. Lovejoy,A.E., Reynolds,T.C., Visich,J.E., Butine,M.D., Young,G., Belvedere,M.A., Blain,R.C., Pederson,S.M., Ishak,L.M., \& Nugent,D.J. (2006) Safety and pharmacokinetics of recombinant factor XIII-A2 administration in patients with congenital factor XIII deficiency. Blood, 108, 57-62.

119. Lowe,G.D. \& Rumley,A. (1999) Use of fibrinogen and fibrin D-dimer in prediction of arterial thrombotic events. Thromb. Haemost., 82, 667-672. 
120. Lowe,G.D. (1987) Blood rheology in vitro and in vivo. Baillieres Clin.Haematol., 1, 597636.

121. Lowe,G.D., Rumley,A., \& Mackie,I.J. (2004) Plasma fibrinogen. Ann.Clin.Biochem., 41, 430-440.

122. Lowe,G.D., Rumley,A., Woodward,M., Morrison,C.E., Philippou,H., Lane,D.A., \& Tunstall-Pedoe,H. (1997) Epidemiology of coagulation factors, inhibitors and activation markers: the Third Glasgow MONICA Survey. I. Illustrative reference ranges by age, sex and hormone use. Br.J.Haematol., 97, 775-784.

123. Lucena,S., Arocha Pinango,C.L., \& Guerrero,B. (2007) [Fibronectin. Structure and functions associated to hemostasis. Review]. Invest Clin., 48, 249-262.

124. Luk,C., Eckert,K.M., Barr,R.M., \& Chin-Yee,I.H. (2002) Prospective audit of the use of fresh-frozen plasma, based on Canadian Medical Association transfusion guidelines. CMAJ., 166, 1539-1540.

125. Mack,M., Kleinschmidt,A., Bruhl,H., Klier,C., Nelson,P.J., Cihak,J., Plachy,J., Stangassinger,M., Erfle,V., \& Schlondorff,D. (2000) Transfer of the chemokine receptor CCR5 between cells by membrane-derived microparticles: a mechanism for cellular human immunodeficiency virus 1 infection. Nat.Med., 6, 769-775.

126. Mackie,I.J., Kitchen,S., Machin,S.J., \& Lowe,G.D. (2003) Guidelines on fibrinogen assays. Br.J.Haematol., 121, 396-404.

127. Mackie,J., Lawrie,A.S., Kitchen,S., Gaffney,P.J., Howarth,D., Lowe,G.D., Martin,J., Purdy,G., Rigsby,P., \& Rumley,A. (2002) A performance evaluation of commercial fibrinogen reference preparations and assays for Clauss and PT-derived fibrinogen. Thromb. Haemost., 87, 997-1005.

128. MacLeod,J.B., Lynn,M., McKenney,M.G., Cohn,S.M., \& Murtha,M. (2003) Early coagulopathy predicts mortality in trauma. J.Trauma, 55, 39-44.

129. Maierhoter,W., Adams,M.B., Kleinman,J.G., \& Roth,D.A. (1981) Treatment of the bleeding tendency in uremia with cryoprecipitate. N.Engl.J.Med., 305, 645.

130. Malone,D.L., Hess,J.R., \& Fingerhut,A. (2006) Massive transfusion practices around the globe and a suggestion for a common massive transfusion protocol. J.Trauma, 60, S91S96.

131. Mannucci,P.M. (2004) Treatment of von Willebrand's Disease. N.Engl.J.Med., 351, 683694.

132. Marbet,G.,A., \& Duckert,F. (1992) Fibrinogen. In: Jespersen J,Bertina RM, Haverkate F, eds. ECAT Assays Procedures: a Manual of Laboratory Techniques, $47-56$. Dordrecht, Kluwer, Holland. 
133. Mardel,S.N., Saunders,F.M., Allen,H., Menezes,G., Edwards,C.M., Ollerenshaw,L., Baddeley,D., Kennedy,A., \& Ibbotson,R.M. (1998) Reduced quality of clot formation with gelatin-based plasma substitutes. Br.J.Anaesth., 80, 204-207.

134. Martini,W.Z. \& Holcomb,J.B. (2007) Acidosis and coagulopathy: the differential effects on fibrinogen synthesis and breakdown in pigs. Ann.Surg., 246, 831-835.

135. Martini,W.Z., Chinkes,D.L., Pusateri,A.E., Holcomb,J.B., Yu,Y.M., Zhang,X.J., \& Wolfe,R.R. (2005) Acute changes in fibrinogen metabolism and coagulation after hemorrhage in pigs. Am.J.Physiol Endocrinol.Metab, 289, E930-E934.

136. Martini,W.Z., Chinkes,D.L., Sondeen,J., \& Dubick,M.A. (2006) Effects of hemorrhage and lactated Ringer's resuscitation on coagulation and fibrinogen metabolism in swine. Shock, 26, 396-401.

137. McVerry,B.A. \& Machin,S.J. (1979) Incidence of allo-immunization and allergic reactions to cryoprecipitate in haemophilia. Vox Sang., 36, 77-80.

138. Medcalf,R.L. (2007) Fibrinolysis, inflammation, and regulation of the plasminogen activating system. J.Thromb. Haemost., 5 Suppl 1, 132-142.

139. Medical Devices Agency. (2000) Medical Devices Agency Evaluation Report: Fibrinogen Assay Reagents and Methods. (MDA 2000/01). Her Majesty's Stationery Office, Norwich, England.

140. Mellor,A. \& Soni,N. (2001) Fat embolism. Anaesthesia, 56, 145-154.

141. Meng,Z.H., Wolberg,A.S., Monroe,D.M., III, \& Hoffman,M. (2003) The effect of temperature and $\mathrm{pH}$ on the activity of factor VIla: implications for the efficacy of highdose factor VIla in hypothermic and acidotic patients. J.Trauma, 55, 886-891.

142. Meyer,M.A., Ostrowski,S.R., Windelov,N.A., \& Johansson,P.I. (2011) Fibrinogen concentrates for bleeding trauma patients: what is the evidence? Vox Sang. .

143. Mitrovic,S., Mitrovic,D., \& Todorovic,V. (1995) [Fibronectin--a multifunctional glycoprotein]. Srp.Arh.Celok.Lek., 123, 198-201.

144. Mittermayr,M., Streif,W., Haas,T., Fries,D., Velik-Salchner,C., Klingler,A., Oswald,E., Bach,C., Schnapka-Koepf,M., \& Innerhofer,P. (2007) Hemostatic changes after crystalloid or colloid fluid administration during major orthopedic surgery: the role of fibrinogen administration. Anesth.Analg., 105, 905-17, table.

145. Mollisson, P.L., Engelfreit, C.P. \& Contreras, M. (1997) Transfusion in Oligaemia. Blood Transfusion in Clinical Practice, p.47. Blackwell Science, Oxford.

146. Moore,F.A., Nelson,T., McKinley,B.A., Moore,E.E., Nathens,A.B., Rhee,P., Puyana,J.C., Beilman,G.J., \& Cohn,S.M. (2008a) Is there a role for aggressive use of fresh frozen plasma in massive transfusion of civilian trauma patients? Am.J.Surg., 196, 948-958. 
147. Moore,F.A., Nelson,T., McKinley,B.A., Moore,E.E., Nathens,A.B., Rhee,P., Puyana,J.C., Beilman,G.J., \& Cohn,S.M. (2008b) Massive transfusion in trauma patients: tissue hemoglobin oxygen saturation predicts poor outcome. J.Trauma, 64, 1010-1023.

148. Mosher,D.F. (1984) Physiology of fibronectin. Annu.Rev.Med., 35, 561-575.

149. Nascimento, B., Callum, J., Rubenfeld, G., Neto, J.B., Lin, Y., \& Rizoli, S. (2010) Clinical review: Fresh frozen plasma in massive bleedings - more questions than answers. Crit Care, 14(1):202.

150. Nieuwenhuizen,W. (1995) Biochemistry and measurement of fibrinogen. Eur. Heart J., 16 Suppl A, 6-10.

151. O'Brien,S.F., Yi,Q.L., Fan,W., Scalia,V., Kleinman,S.H., \& Vamvakas,E.C. (2007) Current incidence and estimated residual risk of transfusion-transmitted infections in donations made to Canadian Blood Services. Transfusion, 47, 316-325.

152. O'Neill,E.M., Rowley,J., Hansson-Wicher,M., McCarter,S., Ragno,G., \& Valeri,C.R. (1999) Effect of 24-hour whole-blood storage on plasma clotting factors. Transfusion, 39, 488-491.

153. O'Shaughnessy,D.F., Atterbury,C., Bolton,M.P., Murphy,M., Thomas,D., Yates,S., \& Williamson,L.M. (2004) Guidelines for the use of fresh-frozen plasma, cryoprecipitate and cryosupernatant. Br.J.Haematol., 126, 11-28.

154. Palareti,G., Maccaferri,M., Manotti,C., Tripodi,A., Chantarangkul,V., Rodeghiero,F., Ruggeri,M., \& Mannucci,P.M. (1991) Fibrinogen assays: a collaborative study of six different methods. C.I.S.M.E.L. Comitato Italiano per la Standardizzazione dei Metodi in Ematologia e Laboratorio. Clin. Chem., 37, 714-719.

155. Pantanowitz,L., Kruskall,M.S., \& Uhl,L. (2003) Cryoprecipitate. Patterns of use. Am.J.Clin.Pathol., 119, 874-881.

156. Park,R.E., Fink,A., Brook,R.H., Chassin,M.R., Kahn,K.L., Merrick,N.J., Kosecoff,J., \& Solomon,D.H. (1986) Physician ratings of appropriate indications for six medical and surgical procedures. Am.J.Public Health, 76, 766-772.

157. Pool,J.G. \& HINK,J.H. (1964) Experiences in the Preparation of AHG Concentrates from Human Plasma. Bibl.Haematol., 19, 146-150.

158. Pool,J.G. (1965) Preparation and testing of antihemophilic globulin (Factor 8 ) sources for transfusion therapy in hemophilia. Description of a new sterile concentrate process for blood banks. Scand.J.Clin.Lab Invest, 17, Suppl-7, 70 -77.

159. Pool,J.G., Gershglod,E.J., \& Pappenhagen,A.R. (1964) High-potency Antihaemophilic Factor Concentrate Prepared from Cryoglobulin Precipitate. Nature, 203, 312. 
160. Poon,M.C. (1993) Cryoprecipitate: uses and alternatives. Transfus.Med.Rev., 7, 180192.

161. Popovsky,M.A. (2006) Pulmonary consequences of transfusion: TRALI and TACO. Transfus.Apher.Sci. 34, 243-244.

162. Practice Guidelines for blood component therapy. (1996) A report by the American Society of Anesthesiologists Task Force on Blood Component Therapy. Anesthesiology, 84, 732-747.

163. Rahe-Meyer,N., Pichlmaier,M., Haverich,A., Solomon,C., Winterhalter,M., Piepenbrock,S., \& Tanaka,K.A. (2009a) Bleeding management with fibrinogen concentrate targeting a high-normal plasma fibrinogen level: a pilot study. Br.J.Anaesth., 102, 785-792.

164. Rahe-Meyer,N., Solomon,C., Winterhalter,M., Piepenbrock,S., Tanaka,K., Haverich,A., \& Pichlmaier,M. (2009b) Thromboelastometry-guided administration of fibrinogen concentrate for the treatment of excessive intraoperative bleeding in thoracoabdominal aortic aneurysm surgery. J.Thorac.Cardiovasc. Surg., 138, 694-702.

165. Rao,M.P., Boralessa,H., Morgan,C., Soni,N., Goldhill,D.R., Brett,S.J., Boralessa,H., \& Contreras,M. (2002) Blood component use in critically ill patients. Anaesthesia, 57, 530534.

166. Ratnoff,O.D. \& Menzie,C. (1951) A new method for the determination of fibrinogen in small samples of plasma. J.Lab Clin.Med., 37, 316-320.

167. Reed,R.L., Bracey,A.W., Jr., Hudson,J.D., Miller,T.A., \& Fischer,R.P. (1990) Hypothermia and blood coagulation: dissociation between enzyme activity and clotting factor levels. Circ.Shock, 32, 141-152.

168. Reilly,J.T., McVerry,B.A., \& Mackie,M.J. (1983) Fibronectin in blood products--an in vitro and in vivo study. J.Clin.Pathol., 36, 1377-1381.

169. Renaudier,P., Rebibo,D., Waller,C., Schlanger,S., Vo Mai,M.P., Ounnoughene,N., Breton,P., Cheze,S., Girard,A., Hauser,L., Legras,J.F., Saillol,A., Willaert,B., \& Caldani,C. (2009) [Pulmonary complications of transfusion (TACO-TRALI)]. Transfus.Clin.Biol., 16, 218-232.

170. Roberts,I., Shakur,H., Afolabi,A., Brohi,K., Coats,T., Dewan,Y., Gando,S., Guyatt,G., Hunt,B.J., Morales,C., Perel,P., Prieto-Merino,D., \& Woolley,T. (2011) The importance of early treatment with tranexamic acid in bleeding trauma patients: an exploratory analysis of the CRASH-2 randomised controlled trial. Lancet, 377, 1096-101, 1101.

171. Rodriguez,R.C., Buchanan,G.R., \& Clanton,M.S. (1988) Prophylactic cryoprecipitate in congenital afibrinogenemia. Clin.Pediatr.(Phila), 27, 543-545. 
172. Rossaint,R., Bouillon,B., Cerny,V., Coats,T.J., Duranteau,J., Fernandez-Mondejar,E., Hunt,B.J., Komadina,R., Nardi,G., Neugebauer,E., Ozier,Y., Riddez,L., Schultz,A., Stahel,P.F., Vincent,J.L., \& Spahn,D.R. (2010) Management of bleeding following major trauma: an updated European guideline. Crit Care, 14, R52.

173. Rossaint,R., Bouillon,B., Cerny,V., Coats,T.J., Duranteau,J., Fernandez-Mondejar,E., Hunt,B.J., Komadina,R., Nardi,G., Neugebauer,E., Ozier,Y., Riddez,L., Schultz,A., Stahel,P.F., Vincent,J.L., \& Spahn,D.R. (2010) Management of bleeding following major trauma: an updated European guideline. Crit Care, 14, R52.

174. Rossaint,R., Cerny,V., Coats,T.J., Duranteau,J., Fernandez-Mondejar,E., Gordini,G., Stahel,P.F., Hunt,B.J., Neugebauer,E., \& Spahn,D.R. (2006) Key issues in advanced bleeding care in trauma. Shock, 26, 322-331.

175. Rossi,E., Mondonico,P., Lombardi,A., \& Preda,L. (1988) Method for the determination of functional (clottable) fibrinogen by the new family of ACL coagulometers. Thromb.Res., 52, 453-468.

176. Rugeri,L., Levrat,A., David,J.S., Delecroix,E., Floccard,B., Gros,A., Allaouchiche,B., \& Negrier,C. (2007) Diagnosis of early coagulation abnormalities in trauma patients by rotation thrombelastography. J.Thromb. Haemost., 5, 289-295.

177. Rutherford,E.J., Morris,J.A., Jr., Reed,G.W., \& Hall,K.S. (1992) Base deficit stratifies mortality and determines therapy. J. Trauma, 33, 417-423.

178. Saba,T.M. \& Jaffe,E. (1980) Plasma fibronectin (opsonic glycoprotein): its synthesis by vascular endothelial cells and role in cardiopulmonary integrity after trauma as related to reticuloendothelial function. Am.J.Med., 68, 577-594.

179. Salter, D., \& Lloyd, A. (2005) EU Blood Directive - Blood Safety and Quality Regulations.Welsh Health Circ. Wales, United Kingdom.

180. Saltzherr,T.P., Wendt,K.W., Nieboer,P., Nijsten,M.W., Valk,J.P., Luitse,J.S., Ponsen,K.J., \& Goslings,J.C. (2010) Preventability of trauma deaths in a Dutch Level-1 trauma centre. Injury.

181. Sanddal,T.L., Esposito,T.J., Whitney,J.R., Hartford,D., Taillac,P.P., Mann,N.C., \& Sanddal,N.D. (2011) Analysis of preventable trauma deaths and opportunities for trauma care improvement in utah. J.Trauma, 70, 970-977.

182. Sauaia,A., Moore,F.A., Moore,E.E., Moser,K.S., Brennan,R., Read,R.A., \& Pons,P.T. (1995) Epidemiology of trauma deaths: a reassessment. J.Trauma, 38, 185-193.

183. Saxena,S., Odono,V., Francis,R.B., Jr., Endahl,G.L., \& Shulman,I.A. (1990) Can storage of thawed cryoprecipitate be extended to more than six hours? Am.J.Clin.Pathol., 94, 203-206. 
184. Schochl,H., Forster,L., Woidke,R., Solomon,C., \& Voelckel,W. (2010a) Use of rotation thromboelastometry (ROTEM) to achieve successful treatment of polytrauma with fibrinogen concentrate and prothrombin complex concentrate. Anaesthesia, 65, 199-203.

185. Schochl,H., Nienaber,U., Hofer,G., Voelckel,W., Jambor,C., Scharbert,G., KozekLangenecker,S., \& Solomon,C. (2010b) Goal-directed coagulation management of major trauma patients using thromboelastometry (ROTEM)-guided administration of fibrinogen concentrate and prothrombin complex concentrate. Crit Care, 14, R55.

186. Schochl,H., Posch,A., Hanke,A., Voelckel,W., \& Solomon,C. (2010c) High-dose fibrinogen concentrate for haemostatic therapy of a major trauma patient with recent clopidogrel and aspirin intake. Scand.J.Clin.Lab Invest, 70, 453-457.

187. Schofield,W.N., Rubin,G.L., \& Dean,M.G. (2003) Appropriateness of platelet, fresh frozen plasma and cryoprecipitate transfusion in New South Wales public hospitals. Med.J.Aust., 178, 117-121.

188. Senkowski,C.K. \& McKenney,M.G. (1999) Trauma scoring systems: a review. J.Am.Coll.Surg., 189, 491-503.

189. Shafi,S., Elliott,A.C., \& Gentilello,L. (2005) Is hypothermia simply a marker of shock and injury severity or an independent risk factor for mortality in trauma patients? Analysis of a large national trauma registry. J.Trauma, 59, 1081-1085.

190. Shakur,H., Roberts,I., Bautista,R., Caballero,J., Coats,T., Dewan,Y., El-Sayed,H., Gogichaishvili,T., Gupta,S., Herrera,J., Hunt,B., Iribhogbe,P., Izurieta,M., Khamis,H., Komolafe,E., Marrero,M.A., Mejia-Mantilla,J., Miranda,J., Morales,C., Olaomi,O., Olldashi,F., Perel,P., Peto,R., Ramana,P.V., Ravi,R.R., \& Yutthakasemsunt,S. (2010) Effects of tranexamic acid on death, vascular occlusive events, and blood transfusion in trauma patients with significant haemorrhage (CRASH-2): a randomised, placebocontrolled trial. Lancet, 376, 23-32.

191. Shander,A., Fink,A., Javidroozi,M., Erhard,J., Farmer,S.L., Corwin,H., Goodnough,L.T., Hofmann,A., Isbister,J., Ozawa,S., \& Spahn,D.R. (2011) Appropriateness of allogeneic red blood cell transfusion: the international consensus conference on transfusion outcomes. Transfus.Med.Rev., 25, 232-246.

192. Siegel,J.H., Rivkind,A.I., Dalal,S., \& Goodarzi,S. (1990) Early physiologic predictors of injury severity and death in blunt multiple trauma. Arch.Surg., 125, 498-508.

193. Simak,J. \& Gelderman,M.P. (2006) Cell membrane microparticles in blood and blood products: potentially pathogenic agents and diagnostic markers. Transfus.Med.Rev., 20, $1-26$.

194. Smith,J.F., Ness,P.M., Moroff,G., \& Luban,N.L. (2000) Retention of coagulation factors in plasma frozen after extended holding at 1-6 degrees C. Vox Sang., 78, 28-30. 
195. Sobas,F., Hanss,M., Ffrench,P., Trzeciak,M.C., Dechavanne,M., \& Negrier,C. (2002) Human plasma fibrinogen measurement derived from activated partial thromboplastin time clot formation. Blood Coagul.Fibrinolysis, 13, 61-68.

196. Sorensen,B. \& Bevan,D. (2010) A critical evaluation of cryoprecipitate for replacement of fibrinogen. Br.J.Haematol., 149, 834-843.

197. Spahn,D.R., Cerny,V., Coats,T.J., Duranteau,J., Fernandez-Mondejar,E., Gordini,G., Stahel,P.F., Hunt,B.J., Komadina,R., Neugebauer,E., Ozier,Y., Riddez,L., Schultz,A., Vincent,J.L., \& Rossaint,R. (2007) Management of bleeding following major trauma: a European guideline. Crit Care, 11, R17.

198. Stainsby,D., MacLennan,S., Thomas,D., Isaac,J., \& Hamilton,P.J. (2006) Guidelines on the management of massive blood loss. Br.J.Haematol., 135, 634-641.

199. Stanworth,S.J. (2007) The evidence-based use of FFP and cryoprecipitate for abnormalities of coagulation tests and clinical coagulopathy. Hematology.Am.Soc.Hematol.Educ.Program., 179-186.

200. Stanworth,S.J., Brunskill,S.J., Hyde,C.J., McClelland,D.B., \& Murphy,M.F. (2004) Is fresh frozen plasma clinically effective? A systematic review of randomized controlled trials. Br.J.Haematol., 126, 139-152.

201. Stanworth,S.J., Grant-Casey,J., Lowe,D., Laffan,M., New,H., Murphy,M.F., \& Allard,S. (2011) The use of fresh-frozen plasma in England: high levels of inappropriate use in adults and children. Transfusion, 51, 62-70.

202. Stein,S.C., Graham,D.I., Chen,X.H., \& Smith,D.H. (2004) Association between intravascular microthrombosis and cerebral ischemia in traumatic brain injury. Neurosurgery, 54, 687-691.

203. Stinger,H.K., Spinella,P.C., Perkins,J.G., Grathwohl,K.W., Salinas,J., Martini,W.Z., Hess,J.R., Dubick,M.A., Simon,C.D., Beekley,A.C., Wolf,S.E., Wade,C.E., \& Holcomb,J.B. (2008) The ratio of fibrinogen to red cells transfused affects survival in casualties receiving massive transfusions at an army combat support hospital. J.Trauma, 64, S79-S85.

204. Swaim,W.R. \& Feders,M.B. (1967) Fibrinogen assay. Clin.Chem., 13, 1026-1028.

205. Sweetnam,P.M., Thomas,H.F., Yarnell,J.W., Beswick,A.D., Baker,I.A., \& Elwood,P.C. (1996) Fibrinogen, viscosity and the 10-year incidence of ischaemic heart disease. Eur.Heart J., 17, 1814-1820.

206. Sweetnam,P.M., Yarnell,J.W., Lowe,G.D., Baker,I.A., O'Brien,J.R., Rumley,A., Etherington,M.D., Whitehead,P.J., \& Elwood,P.C. (1998) The relative power of heatprecipitation nephelometric and clottable (Clauss) fibrinogen in the prediction of ischaemic heart disease: the Caerphilly and Speedwell studies. Br.J.Haematol., 100, 582-588. 
207. Tanaka,K.A., Key,N.S., \& Levy,J.H. (2009a) Blood coagulation: hemostasis and thrombin regulation. Anesth.Analg., 108, 1433-1446.

208. Tanaka,K.A., Key,N.S., \& Levy,J.H. (2009b) Blood coagulation: hemostasis and thrombin regulation. Anesth.Analg., 108, 1433-1446.

209. Teixeira,P.G., Inaba,K., Hadjizacharia,P., Brown,C., Salim,A., Rhee,P., Browder,T., Noguchi,T.T., \& Demetriades,D. (2007) Preventable or potentially preventable mortality at a mature trauma center. J.Trauma, 63, 1338-1346.

210. Thomas,D., Wee,M., Clyburn,P., Walker,I., Brohi,K., Collins,P., Doughty,H., Isaac,J., Mahoney,P.M., \& Shewry,L. (2010) Blood transfusion and the anaesthetist: management of massive haemorrhage. Anaesthesia, 65, 1153-1161.

211. Thompson,G.H., Florentino-Pineda,I., Armstrong,D.G., \& Poe-Kochert,C. (2007) Fibrinogen levels following Amicar in surgery for idiopathic scoliosis. Spine (Phila Pa 1976.), 32, 368-372.

212. Tien,H.C., Acharya,S., \& Redelmeier,D.A. (2010) Preventing deaths in the Canadian military. Am.J.Prev.Med., 38, 331-339.

213. Tien,H.C., Spencer,F., Tremblay,L.N., Rizoli,S.B., \& Brenneman,F.D. (2007) Preventable deaths from hemorrhage at a level I Canadian trauma center. J.Trauma, 62, 142-146.

214. Tieu,B.H., Holcomb,J.B., \& Schreiber,M.A. (2007) Coagulopathy: its pathophysiology and treatment in the injured patient. World J.Surg., 31, 1055-1064.

215. Tinmouth,A., Macdougall,L., Fergusson,D., Amin,M., Graham,I.D., Hebert,P.C., \& Wilson,K. (2005) Reducing the amount of blood transfused: a systematic review of behavioral interventions to change physicians' transfusion practices. Arch.Intern.Med., 165, 845-852.

216. Tisherman,S.A. (2010) Is fibrinogen the answer to coagulopathy after massive transfusions? Crit Care, 14, 154.

217. Triulzi,D.J. \& Blumberg,N. (1990) Variability in response to cryoprecipitate treatment for hemostatic defects in uremia. Yale J.Biol.Med., 63, 1-7.

218. Tsuei,B.J. \& Kearney,P.A. (2004) Hypothermia in the trauma patient. Injury, 35, 7-15.

219. Ucar,H.I., Oc,M., Tok,M., Dogan,O.F., Oc,B., Aydin,A., Farsak,B., Guvener,M., Yorgancioglu,A.C., Dogan,R., Demircin,M., \& Pasaoglu,I. (2007) Preoperative fibrinogen levels as a predictor of postoperative bleeding after open heart surgery. Heart Surg.Forum, 10, E392-E396.

220. UK Blood Tranfusion \& Tissue Transplantation Services. (2004) Transfusion Guidelines Report. UK Blood Transfusion \& Tissue Transplantation Services, United Kingdom. 
221. United States Department of Health and Human Services. Agency for Health Care Policy and Research. (1993) Acute Pain Management: Operative or Medical Procedures and Trauma. AHCPR, 107. Clinical practice guideline No. 1, AHCPR publication No. 920023). Rockville, Maryland, United States

222. US Preventive Services Task Forces. (1989) Guide to Clinical Preventive Services: An Assessment of the Effectiveness of 169 Interventions. Williams and Wilkins, Baltimore, United States.

223. van der Bom,J.G., de Maat,M.P., Bots,M.L., Hofman,A., Kluft,C., \& Grobbee,D.E. (1997) Seasonal variation in fibrinogen in the Rotterdam Study. Thromb. Haemost., 78, 10591062.

224. van,G.C., Sixma,J.J., Borst-Eilers,E., Leautavd,M., Moes,M., van der Plas,P.M., Bouma,B.N., \& Sybesma,J.P. (1973) Preparation and infusion of cryoprecipitate from exercised donors. Br.J.Haematol., 25, 461-466.

225. Velik-Salchner,C., Haas,T., Innerhofer,P., Streif,W., Nussbaumer,W., Klingler,A., Klima,G., Martinowitz,U., \& Fries,D. (2007) The effect of fibrinogen concentrate on thrombocytopenia. J.Thromb.Haemost., 5, 1019-1025.

226. Verhovsek,M., Moffat,K.A., \& Hayward,C.P. (2008) Laboratory testing for fibrinogen abnormalities. Am.J.Hematol., 83, 928-931.

227. Wallis,J.P. \& Dzik,S. (2004) Is fresh frozen plasma overtransfused in the United States? Transfusion, 44, 1674-1675.

228. Wei,K.L., Lin,C.J., \& Lai,K.A. (1995) Changes in coagulatory profile after orthopedic surgery. J.Formos.Med.Assoc., 94, 541-547.

229. Weigert,A.L. \& Schafer,A.I. (1998) Uremic bleeding: pathogenesis and therapy. Am.J.Med.Sci. , 316, 94-104.

230. Weinkove,R. \& Rangarajan,S. (2008) Fibrinogen concentrate for acquired hypofibrinogenaemic states. Transfus. Med., 18, 151-157.

231. Westerman,R.W., Davey,K.L., \& Porter,K. (2008) Assessing the potential for major trauma transfusion guidelines in the UK. Emerg.Med.J., 25, 134-135.

232. Wolberg,A.S., Meng,Z.H., Monroe,D.M., III, \& Hoffman,M. (2004) A systematic evaluation of the effect of temperature on coagulation enzyme activity and platelet function. J.Trauma, 56, 1221-1228.

233. Wolf,P. (1967) The nature and significance of platelet products in human plasma. Br.J.Haematol., 13, 269-288.

234. Woodward,M., Lowe,G.D., Rumley,A., Tunstall-Pedoe,H., Philippou,H., Lane,D.A., \& Morrison,C.E. (1997) Epidemiology of coagulation factors, inhibitors and activation 
markers: The Third Glasgow MONICA Survey. II. Relationships to cardiovascular risk factors and prevalent cardiovascular disease. Br.J.Haematol., 97, 785-797.

235. World Health Organisation Report. (1999). Use of Anticoagulants in Diagnostic Laboratory Investigations. World Health Organisation/DIL/LAB/99. 1 Rev 1.

236. Young,P.P., Cotton,B.A., \& Goodnough,L.T. (2011) Massive Transfusion Protocols for Patients With Substantial Hemorrhage. Transfus.Med.Rev..

237. Zehtabchi,S. \& Liu,T. (2008) Effect of hypoperfusion and the protein C pathway on the early coagulopathy after traumatic brain injury. J.Trauma, 65, 1571-1572. 